\title{
An examination of the relationships between ego development, Dabrowski's theory of positive disintegration, and the behavioral characteristics of gifted adolescents
}

\author{
Carrie Lynn Bailey \\ College of William \& Mary - School of Education
}

Follow this and additional works at: https://scholarworks.wm.edu/etd

Part of the Developmental Psychology Commons, Educational Psychology Commons, Special

Education and Teaching Commons, and the Student Counseling and Personnel Services Commons

\section{Recommended Citation}

Bailey, Carrie Lynn, "An examination of the relationships between ego development, Dabrowski's theory of positive disintegration, and the behavioral characteristics of gifted adolescents" (2009). Dissertations, Theses, and Masters Projects. Paper 1539618436.

https://dx.doi.org/doi:10.25774/w4-n2qk-hf70

This Dissertation is brought to you for free and open access by the Theses, Dissertations, \& Master Projects at W\&M ScholarWorks. It has been accepted for inclusion in Dissertations, Theses, and Masters Projects by an authorized administrator of W\&M ScholarWorks. For more information, please contact scholarworks@wm.edu. 
AN EXAMINATION OF THE RELATIONSHIPS BETWEEN

EGO DEVELOPMENT,

DABROWSKI'S THEORY OF POSITIVE DISINTEGRATION,

AND THE BEHAVIORAL CHARACTERISTICS OF GIFTED ADOLESCENTS

A Dissertation

Presented to

The Faculty of the School of Education

The College of William and Mary in Virginia

In Partial Fulfillment

Of the Requirements for the Degree

Doctor of Philosophy

By

Carrie Lynn Bailey

April 2009 


\section{AN EXAMINATION OF THE RELATIONSHIPS BETWEEN EGO DEVELOPMENT,} DABROWSKI'S THEORY OF POSITIVE DISINTEGRATION, AND THE BEHAVIORAL CHARACTERISTICS OF GIFTED ADOLESCENTS

By

\section{Carrie Lynn Bailey}

Approved April 2009 by

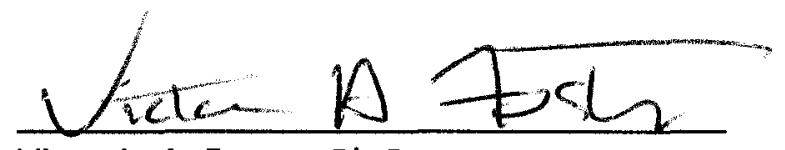

Victoria A. Foster, Ph.D.

Chair of Dissertation Committee

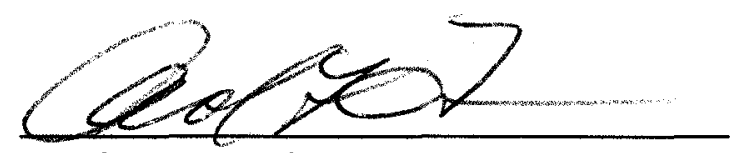

Carol L. Tieso, Ph.D.

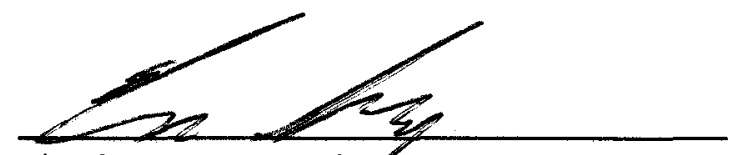

Charles F. Gressard, Ph.D. 


\section{Acknowledgements}

It almost seems as this is the most difficult portion of my dissertation to write, as I know that I will not be able to put into words the depth of appreciation and gratitude that I have for the many who have supported and nurtured me through this journey. I must, of course, start with my parents who have always been there for me, supported me in the various paths I have wandered down, and nurtured my passion for learning. They have modeled a life dedicated to helping and serving others, and I will always be grateful for the endless opportunities they have facilitated for me throughout my life.

To the many students that I have been blessed to work with that provided me a window into their lives... this research and desire to learn more would not have even been imagined had you not shared with me the richness of your struggles and experiences, your vitality for life, and deep need to better understand both yourselves and the world around you.

To my former classmates in high school and college who inspired the specific focus of this work and made me to feel less "different" in my thinking and perspectives... this research is aimed at better understanding that crazy world of gifted education that we lived in and how to reach out to others who are need of someone to realize that as smart as they may be, they are human as well and just as worthy of compassion and acceptance for all that they are and may become.

To Dr. Victoria Foster, my advisor and chair, who reached out to me from the beginning of my time here at William and Mary and helped me realize that I could be both a mother and a counselor educator... your belief in my abilities, encouragement, and support were invaluable. You were able to provide that optimal balance of challenge and support that I needed to grow into my place in the counseling world.

To Dr. Rick Gressard... I don't quite know how to put into words the sense of acceptance that I always felt from you, whether in the classroom, the halls of Jones, or during the many random discussions in various settings these last few years. You modeled a true Rogerian presence for me - authentic, genuine, and committed to recognizing the innate worth of each and every student with whom you work. You challenged me to think beyond my own perspectives and provided the tools for me to integrate these beliefs into my own work.

To Dr. Carol Tieso, who took under her wing a counseling student with little to no knowledge of the world of gifted education and provided me with so much more than I ever could have imagined... Your guidance and wisdom, sense of humor, and commitment have been critical to my research and success. You've given me the language and knowledge to support my intuitions in working with gifted students, as well as to better understand myself, overexcitabilities and all.

To Dr. Brendel... what can I say, other than I don't believe I can count the times that you were my saving grace on a number of different levels. Your consistent support, 
advocacy, and voice of experience have been an invaluable part of my experiences here at William and Mary. I am most appreciative for the guidance and supervision you have given me both in furthering my counseling skills, and in finding my path as a counselor educator. You nurturing voice will always pop into my head when I find myself rambling, and I will smile as I acknowledge that I've gone on a bit too long.

To Dr. McAdams, my very first counseling professor so many years back... I thank you for your continued support and look fondly upon the chance conversations we often had in the halls of Jones.

To Dr. Bryan, who pushed me even when I did not want to be pushed... I am grateful to you for forcing me to grow and develop insight into myself as a counselor and supervisor. Your energy and smile will stay with me as I move forward in my work with future students.

To my amazing fellow students and friends... I certainly would not have made it through without your support, compassion, and understanding. Greg, who was there for me as far back as when we interviewed at 'that other school,' you are like the big brother I always needed growing up - thank you for the empathic ear and words of wisdom. Thanks to my wonderfully supportive cohort - Kristi, Adele, \& Esther - who will always have a special place in my heart. Thanks to my fellow moms and mentors - Jill, Dana, Emilie, Kylie, \& Esther - you all constantly amaze me, I am grateful for your shared wisdom and love. Thanks to my friends Jani \& Max, you not only supported me through entertaining my family when I was holed up studying, you listened and shared - I am grateful for all that you are and all that you have given me and my family.

Finally, to my most wonderful family... Ellie, you've grown into quite the young woman during the past few years - I thank you for your patience and understanding, your unwavering support and belief in your mama, and your delightful insights and guidance. Cooper, its hard to believe that we started this together, though you weren't too fond of class and preferred playing with the toys in the clinic - I thank you for your own brand of understanding and support and for your unwavering ability to bring a smile to my face. And to Neil, my husband, partner, and best friend - your unwavering support, love, and encouragement are what made it possible for me to follow this path. You have been with me every step of the way, believing in me even when I questioned myself. I thank you for the countless hours listening, guiding, and doing so very much. Your faith has helped me to keep perspective, to recognize our many blessings, and to keep my focus in the right place. I am excited for us as we begin the next phase of this life-long journey we share, and will forever appreciate for all that you are and all that you give to us as a family. 


\section{Dedication}

This research is dedicated to my wonderfully gifted and overexcitable children, Cooper \& Ellie.

May you fully embrace life and the opportunities before you,

May you be accepted, appreciated, and embraced for the vital spirits that you are. You are both truly the greatest blessings in my life. 


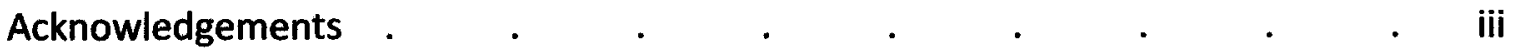

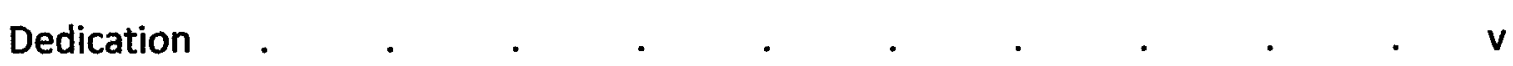

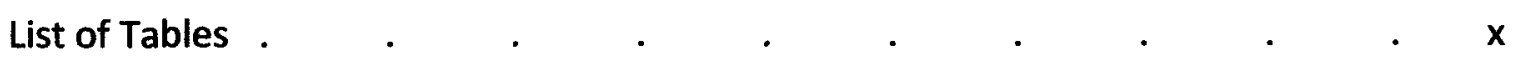

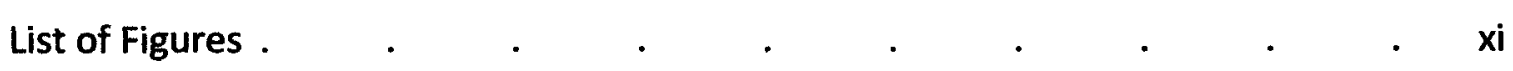

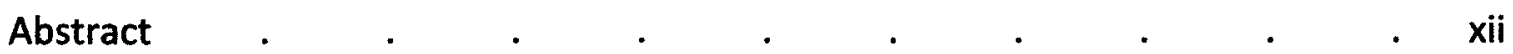

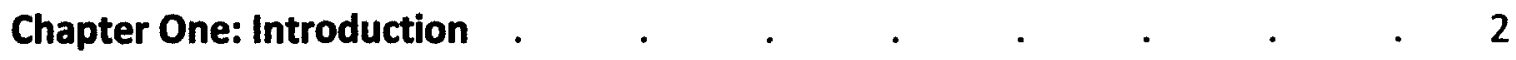

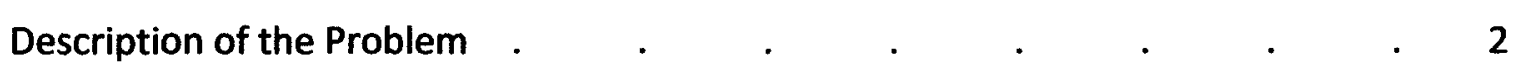

Social and Emotional Characteristics

and Behavioral Traits of Gifted Adolescents . $\quad$ - $\quad$. $\quad$. $\quad$. 4

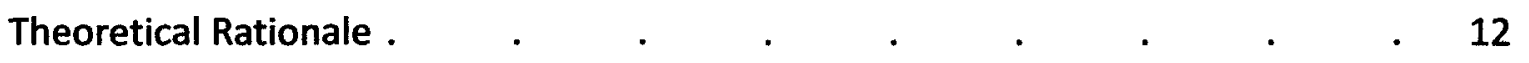

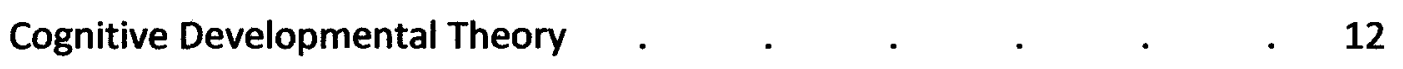

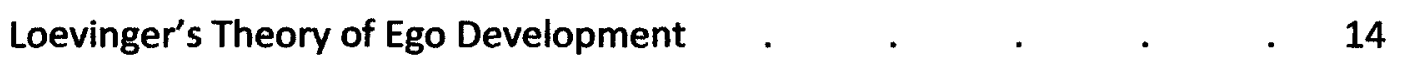

Dabrowski's Theory of Positive Disintegration $\quad . \quad$. $\quad . \quad$. 17

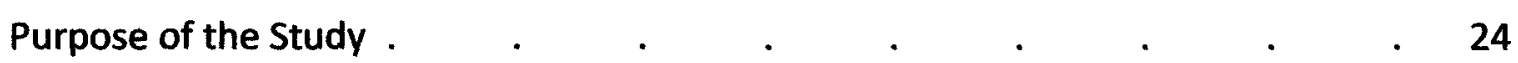

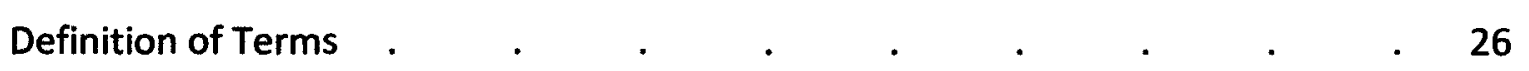

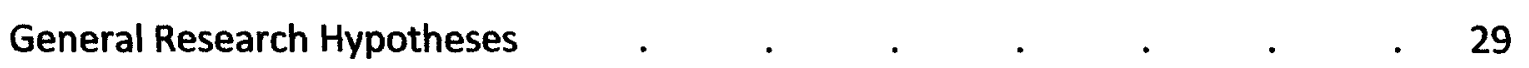

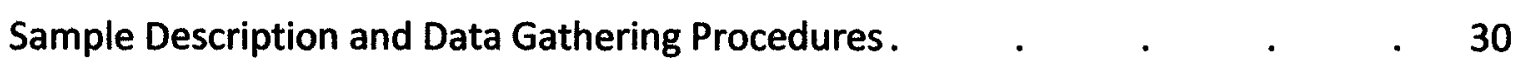

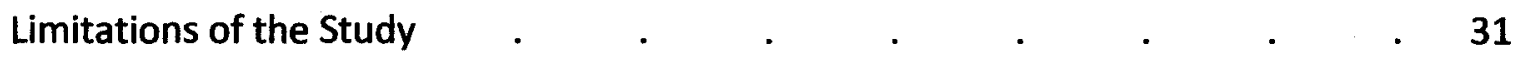

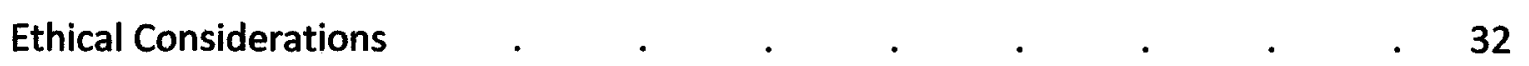

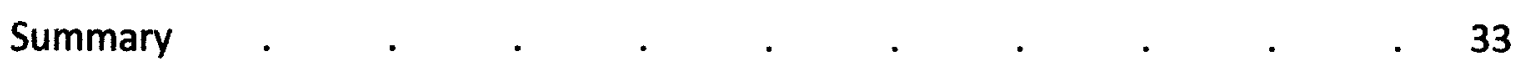

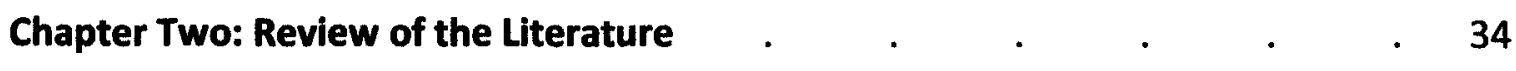

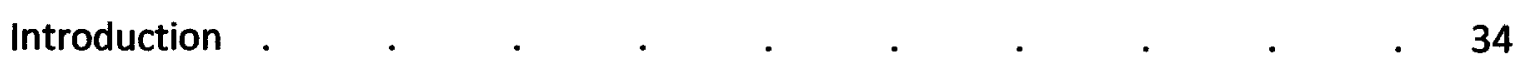

Social and Emotional Characteristics of Gifted Adolescents . $\quad$. $\quad$. $\quad$. $\quad 35$ 


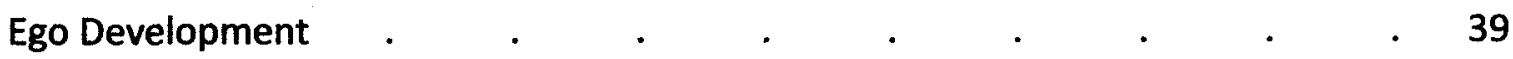

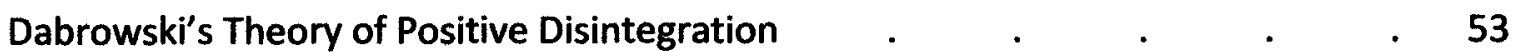

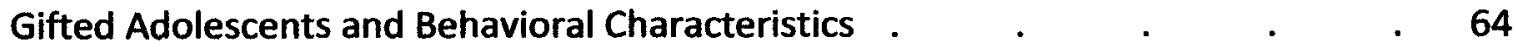

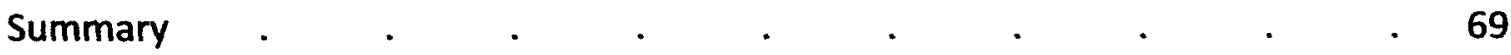

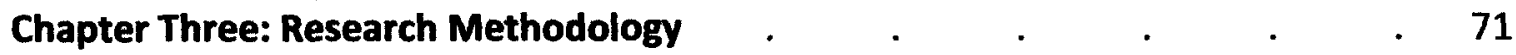

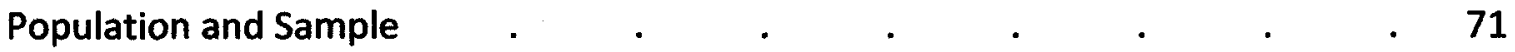

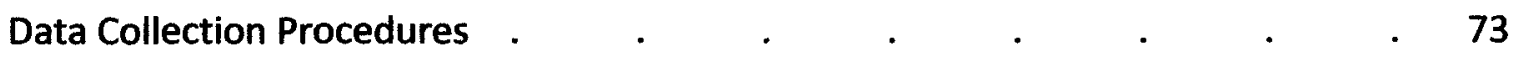

Method . . . . . . . . . 73

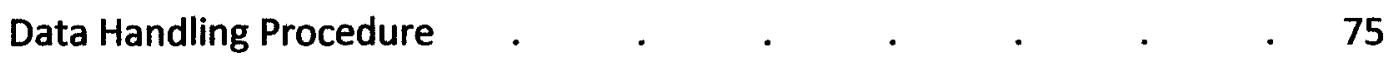

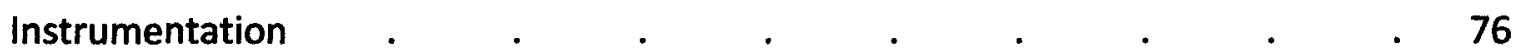

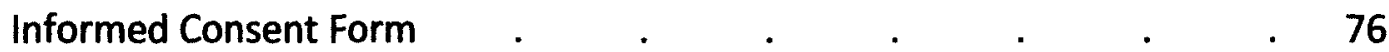

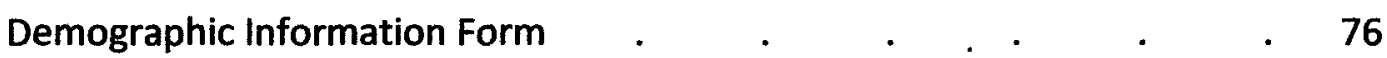

The Washington University Sentence Completion Test $\quad . \quad$. 77

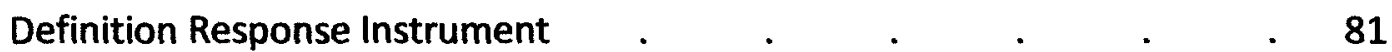

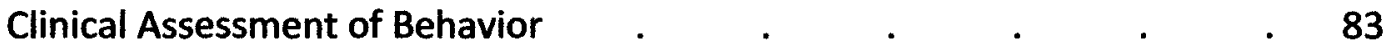

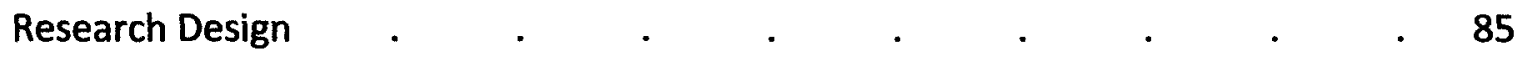

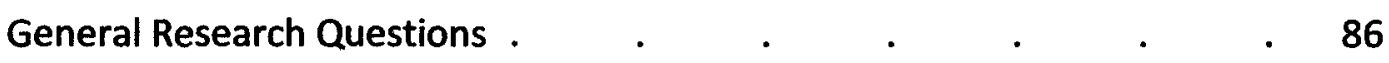

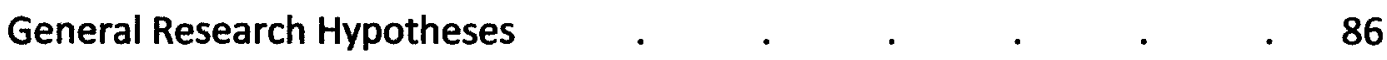

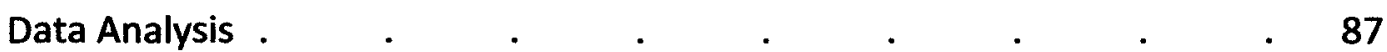

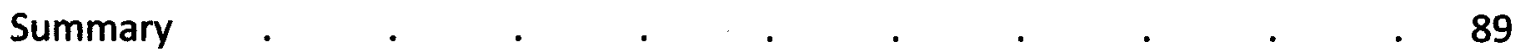

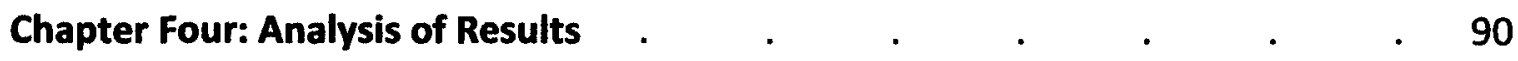

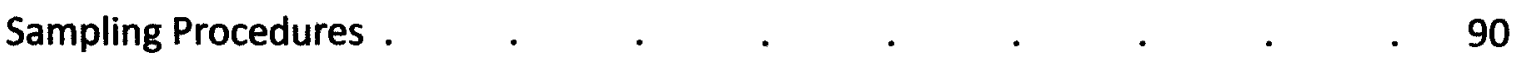

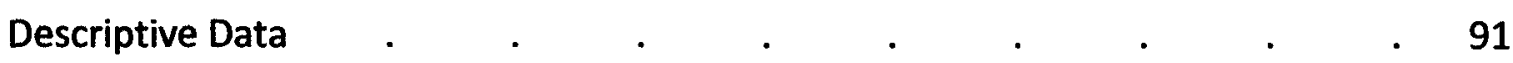

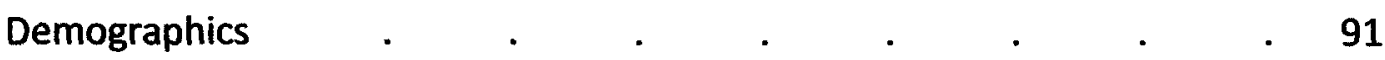

Ego Development - Research Question One . $\quad . \quad$. $\quad . \quad$. $\quad 93$ 
Dabrowskian Developmental Level - Research Question Two . $\quad$. 95

Behavioral Characteristics - Research Question Three $\quad . \quad$. $\quad 98$

Data Analysis Specific to the Research Hypotheses . $\quad . \quad$. $\quad . \quad$. 101

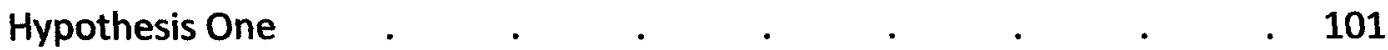

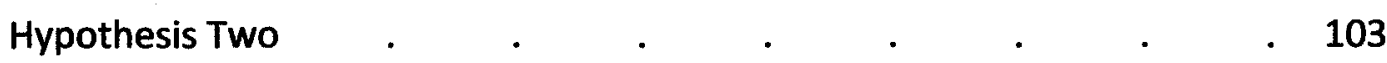

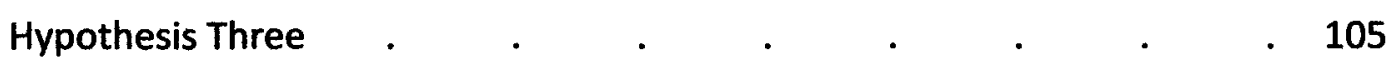

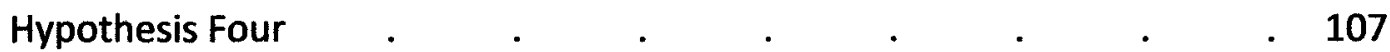

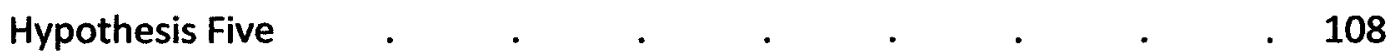

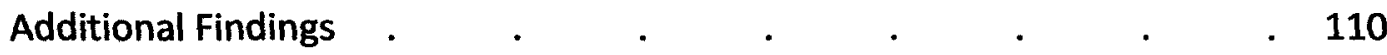

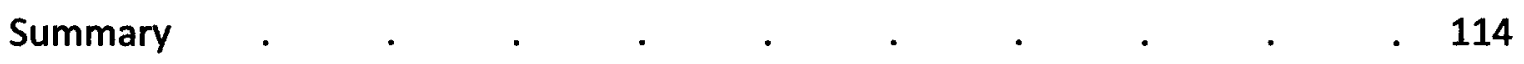

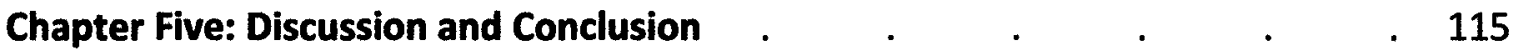

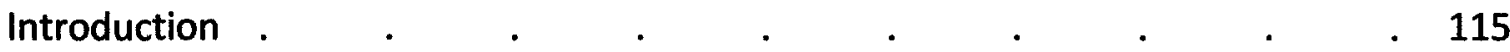

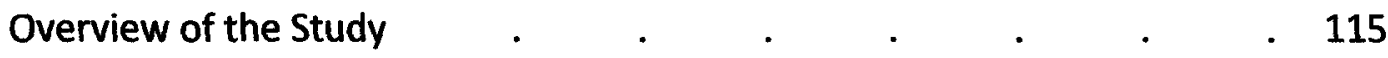

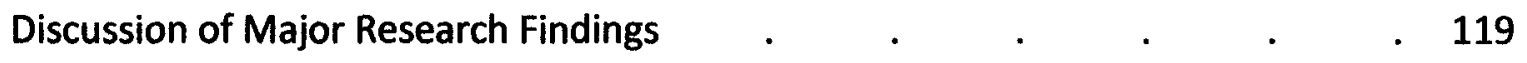

General Research Questions . $\quad$. $\quad$. $\quad$. 119

Ego Development - Research Question One . $\quad$. $\quad$. $\quad$. 119

Dabrowskian Developmental Level - Research Question Two . $\quad$. 121

Behavioral Characteristics - Research Question Three _ . . 123

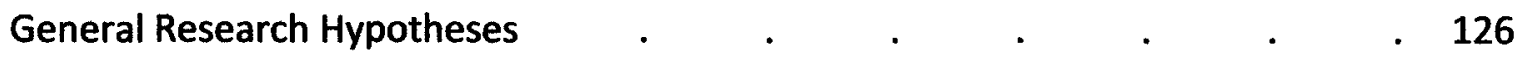

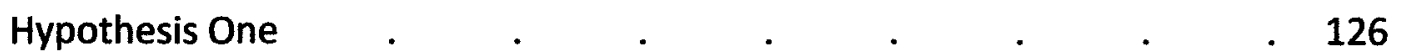

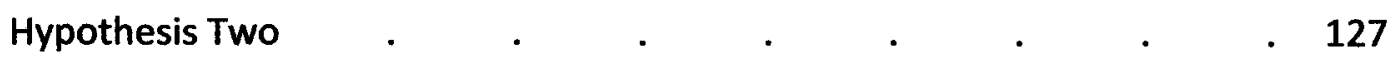

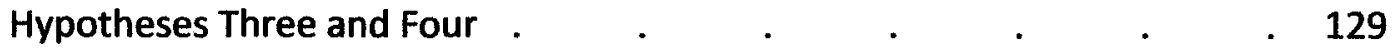

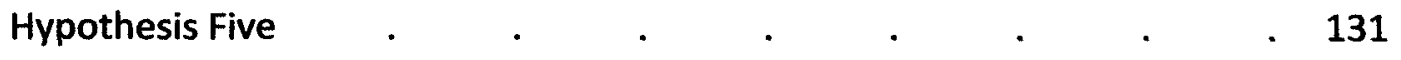

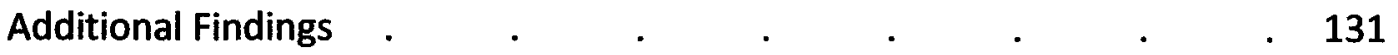

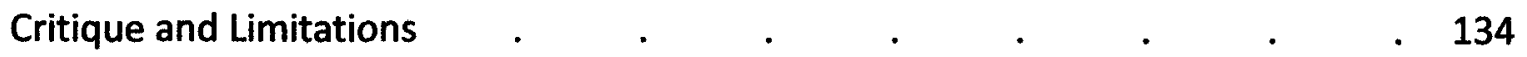

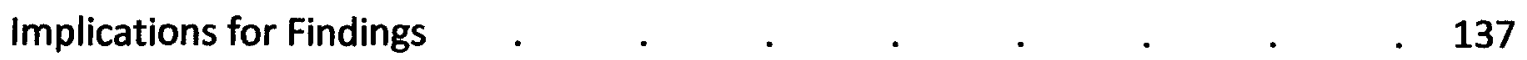




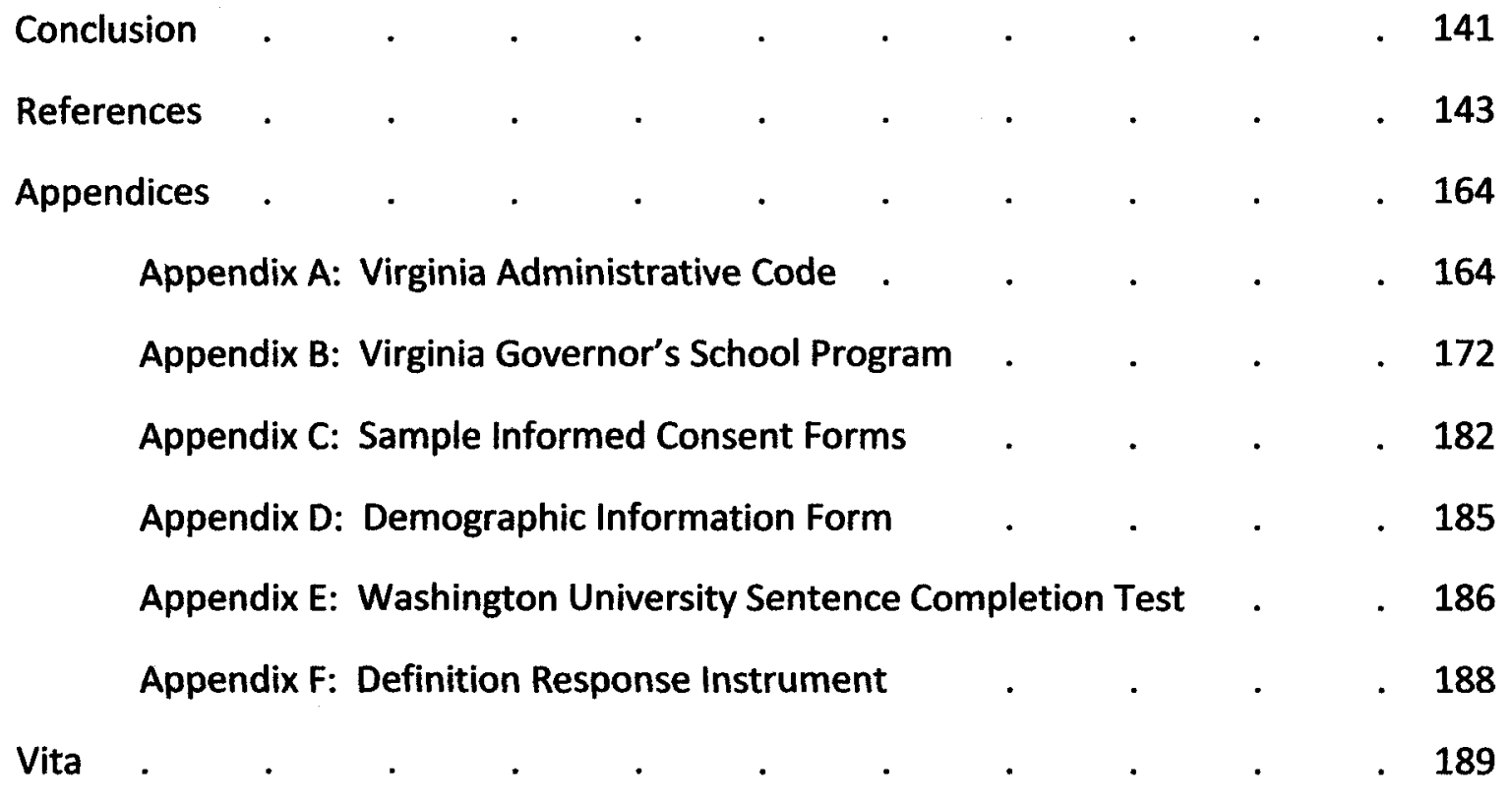




\section{LIST OF TABLES}

Table Number

Name

Page

1.1 A Comparison of Loevinger's Stages of Ego Development and

Dabrowski's Levels of Positive Disintegration _ . . . 21

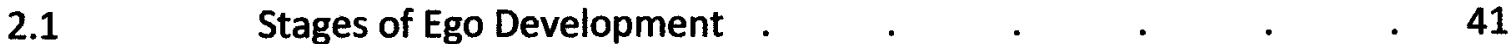

$2.2 \quad$ Summary of Dabrowskian Developmental Levels $\quad . \quad$ - $\quad 57$

3.1 Scoring Protocols for the Washington University Sentence

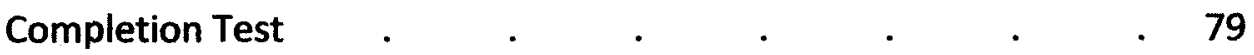

4.1 Total Sample by Gender, Age, Grade, and Ethnicity . 92

4.2 $\quad$ Ego Developmental Level of Gifted Adolescents ～. $\quad$ • $\quad$ - $\quad 94$

4.3 Washington University Sentence Completion Test . $\quad$ • $\quad 95$

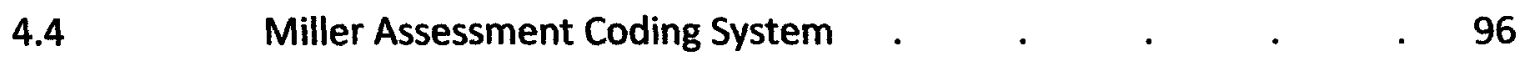

4.5 Dabrowskian Developmental Level of Gifted Adolescents . 98

4.6 Selected Behavioral Characteristics of Gifted Adolescents . $\quad$. 100

4.7 Distribution of Ego Levels: Comparison of Adolescent Samples $\quad$ - 103

4.8 Differences in Ego Development and

Dabrowskian Developmental Level by Gender and School . . 105

4.9 Differences in Clinical Assessment of Behavior

Internalizing Scores by Gender and School 106

4.10 Differences in Clinical Assessment of Behavior

Externalizing Scores by Gender and School . $\quad . \quad$. $\quad . \quad 108$

4.11 Distribution of Behaviors Exhibited by Gifted Adolescents as

Measured by the Clinical Assessment of Behavior . . 110

4.12 Significant Correlations among Demographic and

Measurement Variables $\quad . \quad \ldots \quad$. $\quad . \quad$. $\quad . \quad 112$ 


\section{LIST OF FIGURES}

Figure Number

Name

Page

4.1 Distribution of Clinical Behavioral Index (CBI) Scores for

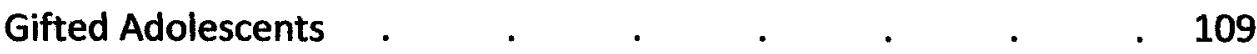

4.2 Distribution of Internalizing Behavior (INT) Scores for

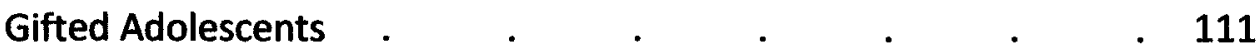




\title{
AN EXAMINATION OF THE RELATIONSHIPS BETWEEN EGO DEVELOPMENT, DABROWSKI'S THEORY OF POSITIVE DISINTEGRATION, AND THE BEHAVIORAL CHARACTERISTICS OF GIFTED ADOLESCENTS
}

\begin{abstract}
The purpose of this study was to explore the relationships between ego development, Dabrowski's theory of positive disintegration (TPD), and the social, emotional, and behavioral characteristics of gifted adolescents. Literature exploring the experiences of gifted individuals has often focused on asynchronous development, particularly during childhood and adolescence. Also discussed in the literature concerning gifted students are the unique social, emotional, and behavioral characteristics innate to the gifted population. However, there is still an unclear picture concerning the implications of this work as related to the specific counseling needs of gifted students, and little empirical support is provided. This study seeks to build, through a developmental lens, a more comprehensive base from which to conceptualize counseling and teaching approaches with gifted students. One hundred students at Governor's Schools in central and eastern Virginia were contacted for participation in this study. A valid sample of 70 students, well distributed across grade and gender, was obtained. The findings indicated that the ego levels of gifted students, as measured by the Washington University Sentence Completion Test (WUSCT), were slightly higher than those of typical adolescents. Empirical evidence of the level of development related to Dabrowski's TPD for gifted adolescents was provided, with the majority of respondents (70\%) falling within Dabrowski's Level II - Unilevel Disintegration, stage. Results also indicated that gifted students at Governor's Schools were relatively well adjusted, as measured by the Clinical Assessment of Behavior (CAB), and that the behaviors exhibited by gifted adolescents were normally distributed. While a slight positive correlation was found between ego development and level of development as related to Dabrowski's TPD, significance was not achieved. Relationships between ego development and degree of internalizing and externalizing behaviors exhibited were dependent upon a number of different factors, including gender and school attending. The study results are interpreted as indicating that while ego development and Dabrowski's TPD may share similarities, they are different constructs and further investigation is needed to best utilize these theories in designing appropriate and effective counseling and teaching intervention strategies for working with gifted adolescents. Limitations of the study and suggestions for future research are presented.
\end{abstract}

\section{CARRIE LYNN BAILEY}

DEPARTMENT OF COUNSELOR EDUCATION IN THE SCHOOL OF EDUCATION

THE COLLEGE OF WILLIAM AND MARY 
An Examination of the Relationships between Ego Development,

Dabrowski's Theory of Positive Disintegration, and the Behavioral Characteristics of Gifted Adolescents 


\section{Chapter One}

\section{Introduction}

"Giftedness is not a matter of degree but of a different quality of experiencing..."

(Piechowski, 2003)

The unique developmental needs of gifted adolescents is the primary focus of this study that aimed to explore the intersection of Loevinger's theory of ego development and Dabrowski's theory of positive disintegration as they pertain to gifted students' social, emotional, and behavioral traits and characteristics. This chapter provides an overview of the pertinent issues related to this topic, including the distinct social and emotional characteristics of gifted individuals, the domain of ego development, and the implications of Dabrowski's theory of positive disintegration (TPD) as they influence gifted adolescents and their experiences during this stage of their life. A brief description of cognitive developmental theory is provided, and serves as a framework for incorporating the specific developmental approaches that are the focus of this study. Chapter two offers a selected review of relevant research while chapter three outlines the methodology and research design employed.

\section{Description of the Problem}

Gifted individuals experience the world from a different perspective, with qualitative differences including intensities, sensitivities, idealism, perceptiveness, overexcitabilities, asynchrony, complexity, introversion, perfectionism, and moral concerns (Silverman, 2005). Silverman (2005) describes giftedness as a "different 
organization of the Self... an unusual mind coupled with unusual emotions [leading] to unusual life experience throughout the life cycle" (p. 2).

While researchers differ on the exact nature of "giftedness," the field of gifted education often defines giftedness as asynchronous development, "in which advanced cognitive abilities and heightened intensity combine to create inner experiences and awareness that are qualitatively different from the norm" (The Columbus Group, 1991, I 8). It is this qualitative difference that can render gifted children and adolescents particularly vulnerable along a number of social and emotional domains, thus requiring attention from parents, teachers, and counselors for optimal development to occur.

According to Sword (2001b), teachers and parents often focus on gifted children's intellect at the expense of their emotions. However, neglect of the emotional lives of children and adolescents can influence their intellectual achievement, as emotions are critical to the learning process and the full development of the individual (Sword, 2001b). By examining the experiences of gifted adolescents through both Dabrowski's framework and Loevinger's theory of ego development, we can expand our understanding of the complexities of emotional development in this population and better support their unique needs.

Loevinger's ego development theory offers a wealth of understanding relevant to an individual's emotional development throughout the lifespan. Dabrowski's theory of positive disintegration (TPD) provides a unique perspective regarding the role of an individual's sensitivities and intensities as related to their developmental potential and developmental growth. However, very little research has been done in the counseling 
field linking Dabrowski's TPD to other developmental theories and approaches, and ego development has not been specifically studied in gifted populations. Further, while the social and emotional development of gifted students has begun to gain more attention, much of the research literature is opinion-based with few empirical studies providing evidence and support. This research seeks to combine the available research in cognitive development (specifically ego development) with Dabrowski's theory of positive disintegration to build a more comprehensive base from which to conceptualize counseling and teaching approaches with the gifted students. A number of recently published (Ackerman, 2009; Daniels \& Piechowski, 2009; Kane, 2009; Mendaglio, 2008; Piechowski, 2008; Silverman, 2007) works concerning implications of Dabrowski's theory in the field of gifted education highlight the current relevance of this theory for understanding the developmental issues faced by gifted individuals. Many of these researchers highlight the need for qualitative and quantitative research studies that can provide the empirical evidence necessary to move understanding and application of the theory forward.

\section{Social and Emotional Characteristics and Behavioral Traits of Gifted Adolescents}

Research examining the social and emotional characteristics of gifted individuals has been mixed. While some research has indicated that gifted students are typically as well adjusted as other peers, it has also been shown that gifted students are vulnerable to a number of issues and situations that can hamper their cognitive, as well as affective, development (Colangelo \& Assouline, 2000). An overview of research concerning the social and emotional needs of gifted students (Neihart, Reis, Robinson, \& 
Moon, 2002) includes a wide range of issues, including asynchronous development, in which a student's cognitive development may outpace his or her social and emotional development (Silverman, 2007). In addition, researchers have focused on the impact of sensitivities, intensities, and overexcitabilities in gifted students' cognitive and affective development (Silverman, 2005).

Sword (2001a) describes the unique emotional, intellectual and social characteristics of gifted students, highlighting that not only do gifted children think differently from their peers, they feel differently as well. Piechowski (1992) explains these differences in feeling as intensities and an expanded field of subjective experience. He argues that intensity must be understood as a qualitatively distinct characteristic of gifted individuals that is not a difference of degree, but of a different quality of experiencing (Piechowski, 1992).

The plethora of research and texts devoted to developing an understanding of the specific social and emotional needs of gifted students underscore the obvious need for more empirical research devoted to this topic. Silverman's (1993) text outlining the counseling needs of the gifted and talented is still widely used in training programs for gifted educators. Numerous recent additions to the field outline the specific challenges faced by gifted and talented youth in the community, the schools, and at home (Cross, 2002; Delisle \& Galbraith, 2002; Mendaglio, 2008; Moon \& Reis, 2004; Neihart et al., 2002; Webb, 2005; Winner, 1997). Dockery (2005) echoes the Columbus Group's (1991) definition in summarizing the current understanding of these challenges for gifted youth; "Gifted children both think and feel differently as they experience life in an 
intense manner" (p. 15). Gifted youth differ from their chronological peers in numerous ways - cognitively, emotionally, and in the demonstration of psychological and developmental traits.

Cognitive differences exhibited by gifted students include an exceptional reasoning ability, insightfulness, perceptiveness, and advanced vocabulary, greater retention of information and a rapid learning rate (Lovecky, 1992). These students demonstrate a great desire for knowledge and understanding, as well as intense intellectual curiosity and a need for constant mental stimulation, which can prove challenging for them in traditional education settings (Silverman, 1993). Dockery (2005) identifies the added stress this can place on these students as they strive to balance their desire for learning through examination, exploration, understanding and mastery, without becoming overextended into too many activities at one time. Silverman (1993) further outlines challenges these students face as a result of their increased cognitive complexity, including those due to their keen insight and ability to understand multiple meanings and components of complex situations. Such students can encounter frustration when faced with problems or concerns for which they cannot discern a solution. Because of their cognitive and personality traits, gifted students often expect and require precision and can be less tolerant and capable of modulating their frustration when others do not hold the same standards (Santmire, 1990).

Cognitive complexity in gifted students extends into their emotional development and emotional reactions (Silverman, 1993). As with their intellectual pursuits, gifted students express greater intensity in their emotional responses. These 
students have higher levels of sensitivity and awareness, intuitively understanding complex emotions at young ages, but often lacking the resources with which to adequately cope with these emotions (Levine \& Tucker, 1986; Robinson, 2002). Research points to the dyssynchrony, or asynchronous development, common to gifted students as an underlying component that creates for these students' a qualitatively different experience, resulting in being out of step with their chronological peers and contributing to their heightened social and emotional stress (Miller \& Silverman, 1987; Silverman, 1993, 2002). Gifted children can experience asynchrony in rates of intellectual, cognitive, psychomotor and affective development that can result in stress as gifted students' intellectual and cognitive abilities outpace their emotional or social abilities. This dissonance may mean difficulties in affective regulation and seem out of place for adults who expect the gifted child's emotional abilities to meet his or her intellectual level (Dockery, 2005; Robinson, 2002; Silverman, 1993). Further outpacing of the child's cognitive abilities with respect to his or her physical abilities can cause frustration for the child who may not have the motor skills to create or produce what they can envision in their mind (Robinson, 2002).

Asynchronous development has social ramifications as gifted students, "by definition... have more of something, and they have it earlier than do their age-mates" (Delisle, 1990, p. 224). Thus, gifted students often experience social dyssynchrony as well, feeling out-of-step with their social context. This feeling, coupled with the gifted students' heightened awareness and understanding of their differences from peers can cause further dissonance and emotional stress. In addition, a gifted student's ability to 
think more abstractly and complexly may translate to an earlier quest for identity and individual values (Dockery, 2005; Gross, 2002; Silverman, 1993). Such students may not yet have had the experiences and support necessary to navigate and understand this process as it unfolds, encountering greater stress in trying to make sense of themselves in relation to those around them. "By virtue of being ahead in one or more domains, the degree of internal differences gifted children experience is usually greater than those encountered by [the average child]" (Robinson, 2002, p. xviii).

Rimm (2003) discusses the myths and realities encountered by gifted youth, outlining three unique pressures that many gifted students face. First, some gifted students experience the pressure of having to be the "smartest" or feeling a need to demonstrate extraordinary intelligent or perfection. Second, gifted students may feel a pull to be very creative or different in a manner that can sometimes be manifest through non-conforming or atypical behavior (Rimm, 2003). Third, gifted students, just as typical adolescents, are concerned about popularity and where they fit in with their peers (Rimm, 2003). These competing drives can cause students to silently underachieve in order to maintain peer support, or express themselves so differently that they painfully stand out and cause both teachers and peers to misperceive the aims of their behaviors. Cross (1997) further explored the psychological and social challenges faced by gifted adolescents, along with different coping mechanisms these students often employ as they attempt to better meet the expectations of their social environments. 
Some gifted students not only face the challenges inherent to their asynchronous development and giftedness, but also have added challenges as members of unique populations who have increased difficulties being identified and served inside the educational system. These gifted students may be considered at-risk due to a number of reasons, including undiagnosed or unrecognized learning disabilities or as gifted students who underachieve (Rimm, 2003). Many educators find it difficult to conceive of a bright child who would purposely underachieve or of a gifted student who has a learning disability. Further, these students often do not meet the criteria of giftedness as assessed on the state-provided gifted measures (Reis \& McCoach, 2000; Rimm, 2003). However, $10 \%$ to $20 \%$ of high school dropouts test in the gifted range (Rimm, 2003; Seeley, 1993). While precise definitions and exploration of the concepts of twice-exceptional students and underachieving gifted students are beyond the scope of this study, it is critical to note that these additional challenges can add to those already faced by gifted adolescents. One reason for underachievement is that gifted students' intellectual and affective needs are not being met inside the school building (Rimm, 2003). An additional group, at risk for underachievement, includes culturally and linguistically diverse gifted students (Ford, 1996; Reis \& McCoach, 2000). These students are often overlooked and misunderstood in the educational setting, have been underrepresented in gifted identification programs by as much as 30 to $70 \%$ (Ford \& Thomas, 1997), and thus are in danger of feeling doubly out-of-sync with their educational peers. 
All populations of gifted students have been found to face a number of issues and concerns as they move through their childhood and adolescent years (Colangelo \& Assouline, 2000; Neihart et al., 2002; Roedell, 1984; Silverman, 1993, 2005; Sword, 2001, 2003). Along with the challenge of balancing their inherent uneven development, additional common concerns include struggling with perfectionism (Parker \& Mills, 1996), coping with unrealistic expectations of themselves and others (Lind, 1998), intense sensitivities (Silverman, 1993, 2005), questions of identity formation (Grant \& Piechowski, 1999; Sanborn, 1979), alienation and social pressures (Robinson, 2002; Roedell, 1984), dealing with inappropriate learning environments (Delisle, 1995; Sword, 2003), existential depression (Webb, 1998), and role conflict (Ford \& Thomas, 1997; Johnson, 1992; Kerr, 1994), along with the "everyday" struggles of navigating adolescence.

In addition to these common issues and concerns, gifted students constantly encounter myths and mixed messages from parents, teachers, and peers. Prevalent among these in the education setting are conflicting messages and expectations related to intelligence, gender, social class and ethnicity (C. Tieso, personal communication, 2008). A common myth that continues to be perpetuated in society and education is that, because gifted students are gifted, this endowment enables them to cope with any challenges that life may hand them (Coleman \& Cross, 2001; Delisle \& Galbraith, 2002). This myth is exacerbated by those gifted students who are able to hide how they feel even if they are under great stress, appearing to have it all together when they are, in fact, ready to drop of exhaustion from performing at such high levels (Delisle \& 
Galbraith, 2002). A second myth that builds upon this notion is that gifted students do not need to work hard because things "just come to them" (Coleman \& Cross, 2001). Many gifted students, themselves, believe in this fallacy and struggle when they are faced with tasks in for which they are unprepared or uncertain how to proceed.

Benjamin Bloom (in Delisle \& Galbraith, 2002) counters these mixed messages and myths, stating that "no matter what the initial characteristics (or gifts) of the individuals, unless there is a long and intensive process of encouragement, nurturance, education and training, the individuals will not attain extreme levels of capability" ( $p$. 28). Coleman and Cross (2005) describe the internal conflict that gifted students experience:

Much of the conflict in gifted students' lives is a consequence of their advanced developmental rate accompanied by the emergence of more complex abilities and interests, which is incongruent with the behavioral expectations set out for them. The source of conflict is not something inherent in the traits of gifted children, but rather in the interplay between the individual and his or her surroundings. (p. 11)

Hence, it is incumbent upon educators, parents, and counselors to recognize this conflict and clarify the mixed messages that are constantly being conveyed to the gifted students. It is our role to assist gifted students in understanding the dynamics of this internal conflict and their position in the social environment, as well as to provide gifted students with the encouragement, nurturance, and education necessary for their optimal development. 


\section{Theoretical Rationale}

\section{Cognitive Developmental Theory}

Ego development and Dabrowski's theory of personality development both fall under the overarching umbrella of cognitive developmental theories and are based on the principles that individuals move through a set of qualitatively distinct stages over the course of their lifespan (Sprinthall, 1994). These theories describe individuals in terms of their thought processes and the influence of those thought processes on their behavior, focusing on how individuals make meaning out of their experiences.

Researchers have focused on domain-specific functions of this overarching developmental process, building upon the work done by Piaget (1961) in his initial construction of cognitive developmental theory. These theories have been explored across a number of domains and utilized by counselors and educators as a way of understanding the meaning-making structures inherent in the thoughts, actions, emotions, and behaviors of those with whom they work. Primary theories that fall under this umbrella include Kohlberg's (1975) work with moral development, Hunt's (1975) model of conceptual development, Perry's (1971) study of intellectual development, and Loevinger's (1976) work on ego development.

While an extensive overview of these theories is not necessary for the purpose of this study, a few of the key assumptions and principles inherent to the cognitive developmental framework are noted. A central premise of cognitive developmental theories is that reasoning, affect and behavior are strongly associated with the level of complexity of psychological functioning (Foster \& McAdams, 1998). In these 
developmental theories, movement occurs across a continuum from least complex to more complex, leading to qualitative transformations in the individual's world view (Gielen, 1991). A key assumption states that higher levels of development are equated with greater complexity and more adaptive functioning (Borders, 1998; Kohlberg, 1984). Each new developmental stage, or meaning-making system, is "more comprehensive, more differentiated, and more effective in dealing with the complexities of life than its predecessors" (Cook-Greuter \& Soulen, 2007, p. 182). Research has repeatedly shown that "higher is better" and that upward movement on this continuum allows individuals to evaluate situations from multiple perspectives, increase their behavioral repertoire, decrease their tendencies toward stereotyping others, and facilitate the integration of conflicting information (Labouvie-Vief, Hakim-Larson, \& Hobart, 1987). A final basic assumption of cognitive developmental theories is that humans have an intrinsic potential and motivation for growth (Sprinthall, 1994). Theorists posit that growth is not automatic, but is dependent upon the interaction of the individual and the environment and that significant experiences are necessary for forward growth to occur (Hunt, 1978). Cognitive developmental theories have been utilized in the conceptualization of several counseling and educational interventions. A developmental perspective provides both counselors and clients powerful explanation and insight into conflicts within the self and conflicts with others (Cook-Greuter \& Soulen, 2007), as well as allowing a framework for matching counseling and educational approaches to the specific developmental needs of the individual. An specific type of intervention utilizing this matching approach the deliberate psychological education (DPE) model (Sprinthall 
\& Mosher, 1978), which seeks to promote the psychological development of participants so that they are better equipped to deal with the stressors they may face throughout life (Sprinthall, 1991; Sprinthall \& Scott, 1989). Research provides evidence that adolescent growth can be enhanced through interaction with caring, skilled adults and peers in the context of well-planned and executed interventions that utilize the DPE model (Faubert, Locke, Sprinthall, \& Howland, 1996). The DPE model has been used specifically to promote interpersonal relations ego development in adolescents, resulting in an increase in interpersonal awareness, internalization of standards for moral judgment, greater understanding of the complexities and paradoxes of life, psychological causation, and individuality for participants (Sprinthall, Hall, \& Gerler, 1992). Such a model may prove particularly useful in promoting ego development among gifted adolescents, thus there is a need for research to extend studies to this population.

\section{Loevinger's Theory of Ego Development}

Ego development is an abstract concept, born out of work done across a number of fields, and defined as "the evolution of meanings that the [individual] imposes upon inner experience and perceptions of people and events, a sequence of increasingly mature stages of functioning across the domains of personal relationships, impulse control, moral development, and cognitive style" (Hauser, Powers, \& Noam, 1991, p. 6). Loevinger (1976) viewed ego development as a "master trait," encompassing all other domains as the organizing structure of personality. It has been described as being made up of interwoven, inseparable strands from other developmental domains such as 
cognitive development, moral development, conceptual development, and interpersonal relationship development (Lee \& Snarey, 1988). Ego development is conceptualized as a frame for how the self, others, and the environment are perceived and interpreted, thereby guiding the individual's behavior (Borders \& Fong, 1989). Loevinger (1976) has described it as a developmental scale of psychological maturation beginning in childhood and a major source of individual difference in adult personality organization (McDonald, 2006).

Loevinger viewed "ego" as a process and outlined levels of development that describe the individual's manner of being in the world (Hy \& Loevinger, 1996), moving from more egocentric, dependent behavior to an orientation that considers the relationship of self to others. There are eight stages identified through letter/number combinations starting at E2 (Impulsive) and moving to E9 (Integration). This sequence is hierarchical and cumulative, with each stage building upon the previous stage along a continuum of increasing conceptual complexity, self-awareness and independence (Loevinger, 1976). Through differentiation, integration and adaptation, individuals move toward being less dependent, less manipulative and more mutually oriented. At higher stages, relationships with others deepen and the individual takes on new roles. These more mature levels of ego development allow an individual to be better able to differentiate self from others, norms, and ideals, allowing a "richer and more inward sense of self" to emerge (Labouvie-Vief, 1993). As an individual grows better able to differentiate self from others, his or her ability to reflect on self and the world increases (Hy \& Loevinger, 1996). 
Ego development is an adaptive process, related to cognitive complexity, that helps us understand how individuals construct and make meaning of their lives. During the earliest stages of development, one's adaptation centers on attachment to others and then progresses to the control of impulses and an appreciation of rules. These conditions are conducive to the child's needs being met. As a child begins to experience group pressure to look beyond these hedonistic tendencies, the child enters the Conformist stage. At this stage, individuals adapt to group-centered standards, which are usually in congruence with what is conventional and socially acceptable. As an individual begins to interact with different groups, he or she is exposed to different standards, and may experience disequilibrium as he or she struggles to adapt adequately to competing loyalties.

The transition into the Self-aware stage involves an expanding ability to conceptualize the inner self, and an increasing distinction between the self and the group. At this stage, the individual adapts by seeing that there may be alternate possibilities to different situations, and he or she begins to choose behaviors and manage inner conflict in response to this more complex environment. The Conscientious stage marks the individual's ability to integrate self-evaluated standards based upon personal beliefs, convictions, and values. An individual at this stage strives to live up to his or her own ideals while also thinking beyond his or her own personal concerns to those of society. Those at the Individualistic stage are more tolerant of individual difference, and more adaptive in the ability to navigate many differentiated roles. The Autonomous stage describes individuals who are able to recognize other's 
needs for autonomy and the complexity surrounding people and situations. Individuals at the autonomous level are tolerant and strive for self-fulfillment (Hy \& Loevinger, 1996).

Loevinger (1994) has resisted the assertion that higher stages are "better" than lower stages of ego development, viewing personality functioning based on introspection and complexity as hallmarks of psychological maturity, but not necessarily indicative that the individual will be happier or better adjusted. Rather, individuals at higher levels of ego development are better able to adapt to new environmental conditions than those at lower levels. Cognitive development is a necessary, but insufficient component of growth as ego development occurs through maturation, socialization, education, more complex roles, self-exploration, and often following stressful or positive life changes. Ego development provides an extremely useful construct for understanding how gifted adolescents understand self in relation to others and make meaning of their world.

\section{Dabrowski's Theory of Positive Disintegration}

While Dabrowski's theory of positive disintegration (TPD) has not been traditionally considered under the umbrella of cognitive developmental theories, it shares a number of similarities and has been described at various points in the literature as a theory of moral development, a theory of emotional development, and a theory of personality development. Piechowski (2003), the researcher most often cited for invigorating study of the theory within the field of gifted education, states that it is not easy to classify Dabrowski's theory. In the broadest sense, the theory is about the "inner 
life of the person and the development that takes place there," and "relationships with others and the relationship to the larger community" (Piechowski, 2003, p. 314). Hence, it shares with Loevinger's construction of ego development a focus on understanding the inner experiences of the individual and how those experiences impact the self in relation to others. Dabrowski's levels of development describe a process of maturation that involves transformations in the person's self.

Dabrowski's theory of positive disintegration delineates five levels of personality development along a continuum from low (egocentric) to high (altruistic), explains the process by which development occurs along these levels, and identifies individual characteristics that are equated to developmental potential ( $0^{\prime}$ Connor, 2002). The hallmark of Dabrowski's theory is that development to higher levels is achieved through a process of inner conflict, described as a disconnect between "what is" and "what ought to be" in oneself (Dabrowski, in Piechowski, 1975). "Positive maladjustment," defined as conflict with expectations of one's environment that are incompatible with one's growing awareness of and striving towards a higher set of values (Dabrowski, 1970 ), is viewed as a necessary component in the process of developmental growth. Dabrowski described this development as a two-fold process. First, the disintegration of more primary mental organizations, such as those aimed at gratifying biological needs and conforming to societal norms, occurs. This is followed by the re-integration of these mental structures at a higher level of functioning, in which the individual transcends these more basic needs and becomes truly autonomous (Mendaglio, 2008). Inherent to these higher levels is the development of a hierarchy of individual values and emotional 
reactions with the ultimate goal being the attainment of an individualized personality ideal.

Within this view of development, Dabrowski identified three factors. The first factor consists of hereditary elements such as various instincts, constitutional elements that he refers to as "overexcitabilities," and dynamisms or autonomous inner forces combining instincts, intellect, emotions and innate inner drives. Overexcitabilities are defined as heightened physiological experiencing of stimuli resulting from increased sensitivities. Dabrowski hypothesized that the greater the overexcitability, the more intense the day-to-day experiences of life are felt and the greater the impact they will have on the individual's developmental trajectory. This component of Dabrowski's theory has generated a significant portion of the current research with his work, and holds a wealth of potential implications for research and practice in the fields of both education and counseling.

The second factor considered by Dabrowski's TPD concerns the effects of the social environment. This factor considers that it is the combination of one's hereditary elements within the context of a nurturing social environment that is most conducive to optimal developmental growth (Mendaglio, 2008). Thus, the second factor includes the social influences brought to bear by individuals and groups of people (Dabrowski \& Piechowski, 1996).

The final, "Third Factor," is the most ambiguous and difficult to operationally define, but is conceptualized as the force that drives individuals to become more selfdetermined (Dabrowski, 1973) and can be likened to an individual's inner motivation for 
growth. In this factor, Dabrowski differs from other developmental theorists in that he does not believe this factor to be present in all individuals (Dabrowski \& Piechowski, 1996). According to Dabrowski, this third factor "represents those autonomous processes which a person brings into [his or her] development, such as inner conflict, self-awareness, choice and decision in relation to personal growth, [and] conscious inner psychic transformation" (Dabrowski \& Piechowski, 1996, p. 14).

Dabrowski felt that each individual is born with a set capacity for development, which he called "developmental potential" and described as a "constitutional endowment which determines the character and extent of mental growth possible for a given individual" (Dabrowski, 1972, p. 293). He felt that this developmental potential, related to the first factor, does not change throughout the lifespan, however the extent to which a person has achieved his or potential and the degree to which his or her potential seems evident can vary (Piechowski, 1978).

Dabrowski outlined five developmental levels that have been summarized by Piechowski (2003) and are presented alongside Loevinger's stages of ego development as outlined in the Hy and Loevinger (1996) revision manual in Table 1.1. 
Table 1.1:

A Comparison of Loevinger's Stages of Ego Development and Dabrowski's Levels of Positive Disintegration

\section{LOEVINGER'S EGO DEVELOPMENT}

(Hy \& Loevinger, 1996)

\section{DABROWSKI'S POSITIVE DISINTEGRATION}

(Piechowski, 2003)

IMPULSIVE (E2)

- Impulsive, egocentric

- Dependent

- Preoccupied with bodily feelings

- Cognitive simplicity and lack of psychological insight

- Dichotomistic thinking

\section{SELF-PROTECTIVE (E3)}

- Opportunistic

- Manipulative

- Preoccupied with control

- Lack sense of responsibility

- Seek immediate gratification/materialistic

\section{CONFORMIST (E4)}

- Respect for rules

- Cooperative, loyal

- Preoccupied with appearances, behavior and social acceptance

- Shift to group centeredness

- Tolerance of differences NOT a feature

- Inner emotions perceived in simple terms

SELF-AWARE (E5)

- Exceptions allowable

- Helpful, self-aware

- Preoccupied with feelings, adjustment

\section{LEVEL I: PRIMARY INTEGRATION}

- "Dog-eat-dog mentality"

- Dominant concern with self-protection and survival

- Self-serving egocentrism

- Instrumental view of others

\section{LEVEL II: UNILEVEL DISINTEGRATION}

- "A reed shaken in the wind" - Matthew, $\mathrm{XI}, 7$

- Lack of inner direction

- Inner fragmentation - many selves

- Submission to the values of the group

- Relativism of values and beliefs

- UNILEVEL DYNAMISMS:

- Ambivalences - fluctuations between opposite feelings, mood shifts

- Ambitendencies - changeable and conflicting courses of action

- "Second Factor" - susceptibility to social opinion, feelings of inferiority toward others 
- Feelings describe self in relation to others

- Sense of distinction between self and group

- Realization of multiple possibilities

\section{CONSCIENTIOUS (E6)}

- Self-evaluated standards, self-critical

- Intense, responsible

- Preoccupied with motives, achievements

- Internalization of morality

- Tolerance for and understanding of alternate viewpoints becomes possible

- Capacity for reflection

- Able to perceive broader social context of situations and concepts

INDIVIDUALISTIC (E7)

- Tolerant

- Mutual mode of relating

- Preoccupied with individuality, developmental roles

- Growing tolerance and respect for individual differences

- Awareness of inner conflict

AUTONOMOUS (E8)

Includes the characteristics of E7 AND...

\section{LEVEL III: MULTILEVEL DISINTEGRATION}

- "I regard the better but follow the worse." - Marcus Tullius Cicero

- Sense of the ideal but not reaching it

- Moral concerns

- Higher versus lower in oneself

- MULTILEVEL DYNAMISMS: ways of critically perceiving and evaluating the world, others, and oneself - leading to the work of inner transformation

- Hierarchy of Values and Social Conscience - empathy, 'what is' contrasted with 'what ought to be'; positive maladjustment, protest against violation of ethical principles

- Emotionally Charged Self-Reactions and Self-Judgments - dissatisfaction with oneself, anger at what is undesirable in oneself; inferiority toward oneself, not realizing one's potential; disquietude with oneself, disharmony in one's inner state of being; astonishment with oneself; shame over deficiencies and others' view of one's moral standard; guilt over moral failure

LEVEL IV: ORGANIZED MULTILEVEL DISINTEGRATION

- "Behind tranquility lies conquered unhappiness" - Eleanor Roosevelt

- Self-actualization

- Ideals and actions agree

- Strong sense of responsibility on behalf of others' well-being and inner growth

- DYNAMISMS OF INNER RESTRUCTURING:

- Subject-object in oneself - critical 
- Coping with conflict

- Interdependent mode of relating

- Preoccupied with self-fulfillment

- Acknowledgement of and means to cope with inner moral conflict among duties, desires and needs

- Aware of multifaceted complexities of real people in real situations

- High tolerance for ambiguity and paradoxes of life

INTEGRATED (E9)

Includes the characteristics of E8 AND...

- Cherishing individuality

- Preoccupied with identity

- Reconciliation of conflicting demands examination of one's motives and aims

- "Third Factor" - executive power of choice and decision in one's inner life; active will in self-regulation and selfdetermination

- Responsibility-empathic responsiveness to social needs

- Inner psychic transformation inner restructuring at a deep level with lasting consequences beyond return to lower level

- Education-of-oneself

- Autopsychotherapy - self-designed and preventative measures

- Self-control-regulating development and keeping in check interfering processes

- Autonomy - confidence in one's development; freedom from lower level drives and motivations

\section{LEVEL V: SECONDARY INTEGRATION}

- "A magnetic field in the soul" - Dag Hammarskjold

- Life inspired by a powerful ideal such as equal rights, world peace, universal love and compassion, sovereignty of all nations

- Personality ideal - the ultimate goal of development, the essence of one's being

- DYNAMISMS CONTINUING ACROSS LEVELS:

- Creative Instinct

- Empathy

- Inner conflict

- Identification - with higher levels and Personality Ideal

- Dis-identification - distancing from lower levels and drives

- Disposing and directing centerstatus of will

Very few individuals are theorized to reach either Loevinger's (1976) Integrated

(E9) stage or Dabrowski's Level V. Both of these levels are marked by the achievement

of an integrated sense of identity or "personality ideal." Dabrowski's TPD has been 
validated through qualitative research and rich case studies (Dabrowski, 1966, 1967, 1970, 1972; Dabrowski \& Piechowski, 1977, 1996; Piechowski, 1978, 1990, 2003, 2008); however, few empirical studies specifically examine the levels of development along the TPD continuum.

\section{Purpose of the Study}

Uneven development is a universal characteristic of giftedness, with gifted children and adolescents in any cultural context having greater discrepancies among various facets of development than average youth (Silverman, 2007). The National Association for Gifted Children (NAGC, 1995) highlights that "gifted and talented children, because of heightened intellectual and social-emotional needs, may experience difficulties that require professional intervention" (१ 6). They assert that it is imperative that those providing such services have expertise in understanding the impact of giftedness on development. However, in-depth examinations of gifted students' experiences in specific developmental domains have been limited, particularly in conjunction with how these developmental domains may be influencing the social, emotional, and behavioral experiences of these students during adolescence. Ego development enabled a focus upon the social and emotional development of gifted adolescents, and provided a framework for understanding the ways in which gifted adolescents make sense of themselves in relation to others and their social context. Dabrowski's TPD provided a framework for better understanding the sensitivities and overexcitabilities inherent to gifted adolescents and the impact these characteristics may have upon their developmental potential and developmental growth. Hence, this 
study aimed to examine gifted adolescents' development through the domains of both ego development and Dabrowski's conception of developmental growth as frameworks that could provide better understanding of the qualitatively different ways in which gifted students experience and understand the world.

As indicated by Noam (1998), individuals at lower levels of ego development have a tendency to utilize more externalizing coping behaviors while individuals at higher levels of ego development tend to utilize more internalizing coping behaviors. This study sought to determine if these tendencies hold true for a gifted adolescent population through examining the impact of developmental domains on the specific behaviors exhibited by gifted adolescents in the school setting, thus providing counselors and educators a more comprehensive understanding of the strengths, weaknesses and needs of gifted children and adolescents. This more comprehensive understanding of the unique social-emotional characteristics and behaviors expressed by gifted adolescents may enable the design of more effective and appropriate intervention and counseling approaches specific to this population.

Specifically, the purpose of this study was to examine the following research questions:

1. What are the ego development levels of gifted adolescents?

2. What are the developmental levels, as related to Dabrowski's theory of positive disintegration, of gifted adolescents?

3. What are the exhibited behavioral characteristics of gifted adolescents in the school context? 


\section{Definition of Terms}

Ego Development: A cognitive developmental theory, proposed by Jane Loevinger, that outlines a continuum of developmental stages through which individuals progress over the lifespan, spanning impulsivity, manipulation, conformity, autonomy, and interdependence. Loevinger (1976) regards ego development as the central dimension of personality, too encompassing and too fluctuating in its manifestations to precisely describe with a formal definition (Westenberg, Blasi, \& Cohn, 1998). Ego development has been linked with adaptation, coping, and many social behaviors, thus is particularly relevant to understanding reciprocal relations between adolescents in numerous settings (Hauser, Powers, \& Noam, 1991).

Developmental Potential: Dabrowski (1972) defined developmental potential as the endowment that governs the possible extent and character of an individual's inner psychic growth. He viewed development as a multilevel-hierarchical-continuum that progresses from a lower, primitive level to a higher, advanced level based upon an individual's experiences of positive disintegration.

Positive Disintegration: The twofold process by which Dabrowski proposed that personality is achieved. First, disintegration of primitive mental organization focused on gratifying biological needs and mindless conformity to societal norms must occur. This is then followed by a process of re-integration at a higher level of functioning at which the individual transcends biological determinism, becomes autonomous, and creates a hierarchy of values (Mendaglio, 2008). 
Dabrowskian Developmental Level: The level of development exhibited by an individual in relation to the five levels of development described by Dabrowski's theory of positive disintegration.

Operational Definition of Giftedness: In the state of Virginia, gifted and talented students are defined as:

... those students in public elementary and secondary schools beginning with kindergarten through graduation whose abilities and potential for accomplishment are so outstanding that they require special programs to meet their educational needs. These students [are] identified by professionally qualified persons through the use of multiple criteria as having potential or demonstrated abilities and have evidence of high performance capabilities, which may include leadership, in one or more of the following areas: intellectual aptitude, specific academic aptitude, technical and practical arts aptitude, [or] visual and performing arts aptitude. (Virginia Department of Education, 2005; Appendix A)

Regional Academic-Year Governor's School: The Virginia Department of Education established a Governor's School Program in 1973 in order to provide gifted students academically and artistically challenging programs beyond those offered in their home schools (Virginia Department of Education, 2008). The state currently has 18 established Academic-Year Governor's Schools that provide students with acceleration and exploration in areas ranging from the arts, to government and international studies, and to mathematics, science and technology throughout the academic school year. The 
Academic-Year Governor's Schools in Virginia operate in a variety of formats as joint schools managed by a regional board of representatives from participating school divisions. These governing boards establish the policies for the school, including those regulating admission. "While these processes differ from school to school, all applicants are assessed using multiple criteria by trained evaluators who have experience in gifted education..." (Virginia Department of Education, 2008; Appendix B).

Criteria for screening and identification of gifted adolescents: The Virginia Administrative Code (Virginia Department of Education, 2005; Appendix A) provides specific guidelines in determining the eligibility of students for programs for the gifted. This eligibility is based on multiple criteria established by the school division and designed to seek out high aptitude in all populations.

Multiple criteria shall include four or more of the following categories: (1) Assessment of appropriate student products, performance, or portfolio; (2) Record of observation of in-classroom behavior; (3) Appropriate rating scales, checklists, or questionnaires; (4) Individual interview; (5) Individual or group aptitude tests; (6) Individual or group achievement tests; (7) Record of previous accomplishments; (8) Additional valid and reliable measures or procedures. (Virginia Department of Education, 2008)

The code further delineates that the measures used to determine eligibility must be related to those that the program is designed to serve and that each school division shall establish a uniform procedure with common criteria for screening and identification of gifted students. As the Governor's Schools' stated missions are to serve 
the needs of gifted students identified for the program, this research proposal will follow those guidelines. Thus, students who have been identified as gifted and eligible for Governor's School programs in the state will meet the operational definition of giftedness for the purpose of this study.

\section{General Research Hypotheses}

This study aimed to develop a greater understanding of the relationships between ego development, development as related to Dabrowski's theory of positive disintegration (TPD), and the behavioral impact of the unique social and emotional characteristics of gifted adolescents. While gifted adolescents operate at higher levels of cognitive development, the asynchronous development assumed inherent to gifted individuals led to speculation that they are not necessarily significantly advanced in other developmental domains. This study expanded upon our understanding of the asynchronous nature of development in gifted adolescents by specifically exploring the developmental domains of ego development and development as conceptualized by Dabrowski's TPD. Exploration of the behavioral characteristics exhibited by gifted adolescents in the schools furthered our understanding of the distribution of behavioral concerns this population may experience during their adolescent years. Correlational analyses examining the relationships between ego development, Dabrowskian developmental level and behavioral characteristics were conducted in seeking to address the following hypotheses: 
I. The range and distribution of gifted adolescents' levels of ego development as measured by the Washington University Sentence Completion Test (WUSCT) will not differ significantly from established adolescent norms.

II. There will be a moderate positive correlation between gifted adolescents' stage of ego development as measured by the Washington University Sentence Completion Test (WUSCT) and their Dabrowskian developmental level as measured by the Definition Response Instrument (DRI).

III. There will be a significant positive correlation between gifted adolescents' ego development as measured by the Washington University Sentence Completion Test (WUSCT) and their degree of internalizing behavior as measured by the Clinical Assessment of Behavior Teacher Rating Scale (CAB-T).

IV. There will be a significant negative correlation between gifted adolescents' ego development and their degree of externalizing behavior as measured by the Clinical Assessment of Behavior Teacher Rating Scale (CAB-T).

V. There will be a normal distribution of behaviors exhibited by gifted adolescents as measured by the Clinical Assessment of Behavior Teacher Rating Scale (CAB-T).

\section{Sample Description and Data Gathering Procedures}

A correlational study examining ego development, development as related to Dabrowski's TPD, and the exhibited behavioral traits of gifted adolescents was conducted. The study looked specifically at the relationships among these three 
domains in order to construct a more comprehensive understanding of the developmental processes experienced during adolescence for gifted students. The sample consisted of 70 gifted students at regional academic-year governor's schools throughout Virginia. Students were randomly selected from the school population by a liaison at the school and invited to participate. Data was collected at scheduled testing sessions throughout the school year as coordinated with the administration and guidance departments at each of the participating schools. Measurement instruments included the Washington University Sentence Completion Test (Hy \& Loevinger, 1996), the Definition Response Instrument (Gage, Morse, \& Piechowski, 1981), and the Clinical Assessment of Behavior (Bracken \& Keith, 2004). The obtained data were analyzed using descriptive statistics, correlational analyses, analyses of variance, and multivariate analyses of variance to determine the direction and magnitude of the relationships between the measures, as well as to assess for significant differences between groups (Gall, Gall, \& Borg, 2005).

\section{Limitations of the Study}

The following potential limitations existed for this study:

1. While attempts were made to reduce selection bias by randomly selecting potential participants for the current study, the students who chose to participate may be significantly different from those who did not choose to participate.

2. The students used in the study came from only two Governor's Schools with different academic foci and different admission criteria. These students represented a limited number of school districts within the state of Virginia. While all students were 
identified as gifted according to the standards of the state of Virginia, individual school districts vary in their interpretation of these standards. Thus, the results are not necessarily generalizable to all gifted adolescents throughout the country.

3. The Hawthorne effect may have played a role in external validity as both the students being measured and the teachers rating the students' behaviors may have been influenced by the knowledge that they were participants within the study.

4. Due to the nature of the study, it was impossible to control for all extraneous variables and the results may be impacted by variables other than ego development and development as related to Dabrowski's theory of positive disintegration.

5. The results provide a greater understanding of the developmental processes during adolescence for gifted students, but do not provide direct information regarding effective counseling strategies and interventions. Reasonable assumptions were drawn from the data, but specific intervention testing was beyond the scope of this study.

\section{Ethical Considerations}

All participants in this study, as well as their guardians, were fully informed of the purpose of the study and the voluntary nature of their participation. No individual identifying information was maintained with the data collected in this study. Master lists of participants were kept only by the contact individuals at the schools in order to disseminate the results to those participants at the conclusion of the study. Individuals who request information regarding the results will be provided with a summary of the findings. The researcher's dissertation committee, the Human Subjects Research 
Committee of The College of William and Mary, and the individual school's administrations approved the study.

\section{Summary}

This chapter provided an overview of the current issues faced by gifted learners during the period of adolescent development. It outlined the relevance of cognitive developmental theory, specifically the domain of ego development, and Dabrowski's theory of positive disintegration in seeking to establish a more comprehensive view of development in gifted adolescents. The theoretical connection between stages of development and the unique social-emotional characteristics and behaviors expressed by gifted adolescents were briefly addressed. The purpose and hypotheses for the study were stated, definition of terms was provided, a description of the sample given, data gathering procedures described, and limitations and ethical considerations were explored. Chapter two will review the pertinent literature related to the problem and the relevant theoretical rationale for the study. This study is intended to contribute to the literature by examining the relationships between ego development, development as related to Dabrowski's theory of positive disintegration and the behavioral impact of the unique social and emotional characteristics of gifted adolescents. 


\section{Chapter Two}

\section{Review of the Literature}

In support of the need for research focused on the developmental needs of gifted adolescents, chapter two provides a brief review of relevant scholarly literature. This review includes an overview of the unique social and emotional characteristics of qualities of gifted adolescents. The concepts of ego developmental theory and Dabrowski's theory of positive disintegration (TPD) are presented and examined in terms of how these constructs may improve understanding of the developmental experiences of gifted youth. These theoretical perspectives are discussed in relation to the behavioral traits of this population as observed in the school environment and possible implications of the research are provided.

\section{Introduction}

Gifted individuals experience the world from a different perspective, with qualitative differences including intensities, sensitivities, idealism, perceptiveness, overexcitabilities, asynchrony, complexity, introversion, perfectionism, and moral concerns (Silverman, 2005). Silverman (2005) describes giftedness as a "different organization of the Self... an unusual mind coupled with unusual emotions [leading] to unusual life experience throughout the life cycle" (p. 2).

While researchers differ on the exact nature of "giftedness," this study centered upon the definition proposed by the Columbus Group (1991) which identifies giftedness as asynchronous development, "in which advanced cognitive abilities and heightened intensity combine to create inner experiences and awareness that are qualitatively 
different from the norm" (१ 8). It is this qualitative differentness that can render gifted children and adolescents particularly vulnerable along a number of social and emotional domains, and thus requires attention from parents, teachers, and counselors in order for optimal development to occur. In seeking to better understand the gifted adolescent's experience of this asynchronous development, this study examined two developmental domains pertinent to the emotional growth of gifted children and adolescents.

\section{Social and Emotional Characteristics of Gifted Adolescents}

Neihart (1999) explored the impact of giftedness on psychological well being and found evidence to support two contrasting views. Her examination of studies conducted over the past 50 years in the field of giftedness found studies that contend that giftedness enhances resiliency as well as studies that provide evidence for increased vulnerabilities in gifted individuals. She gathered studies that examine psychological well-being of gifted individuals across a number of domains: global measures of adjustment, self-concept, depression, anxiety and suicide, social competence, deviant behavior, and psychiatric disorders. The prevailing view within the research literature fluctuated between a view asserting that gifted children are generally better adjusted that their non-gifted peers and alternately a view that gifted students are more at-risk for adjustment problems.

While each of the studies examined had its own set of challenges and limitations, an issue prevalent in many of the studies was the difficulty in obtaining a non-biased, representative sample of gifted students. Primary to this issue is the lack of a unified 
definition of "giftedness" as well as the variety of ways in which gifted students are identified. Many studies base their samples upon teacher recommendations which are inherently biased, thus this approach may eliminate from the sample those students who do not fit the nominating teacher's view of what constitutes "giftedness." Other study samples are selected based upon arbitrary identification guidelines that vary across school settings. Further complicating this issue is the wide range of ages included in study samples that are compacted into group scores in which developmental differences are not considered. A final area of consideration that Neihart (1999) found to be relevant to sampling issues was the domain area of the students' giftedness. Gifted students are a diverse group and students whose primary area of giftedness is in the creative realm have been found to have markedly different characteristics than those who are primarily mathematically or verbally gifted.

Neihart (1999) concludes that gifted children are neither more nor less at-risk for psychological problems than their peers. She suggests that the research identifies three factors that are related to gifted students' psychological well-being: (1) the type and degree of giftedness, (2) educational fit, and (3) the child's personal characteristics. While Neihart does not elaborate on specific characteristics included in this third area, she touches upon self-perceptions, temperament and life circumstances. This study seeks to add to this factor an understanding of the unique developmental characteristics of the gifted child and how these interact with the child's type and degree of giftedness, as well as to broaden our understanding of the gifted child's educational and social contexts. 
Silverman (1997) also tackles the difficulties inherent to studying this group, particularly the lack of a consistent, unified definition of giftedness. Her body of work has focused on the asynchronous nature of giftedness and takes a child-centered perspective, building upon the theoretical foundations laid by Hollingworth, Terrassier, Dabrowski, and Vygotsky (Silverman, 1997). She cites the definition put forth by the Columbus Group (1991) as the hallmark of gifted individuals and their experience of the world:

Giftedness is asynchronous development in which advanced cognitive abilities and heightened intensity combine to create inner experiences and awareness that are qualitatively different from the norm. This asynchrony increases with higher intellectual capacity. The uniqueness of the gifted renders them particularly vulnerable and requires modifications in parenting, teaching and counseling in order for them to develop optimally. (Silverman, 1997, p. 39) Silverman examines research that outlines components of this asynchrony which include uneven development, complexity, intensity, heightened awareness, risk of social alienation, and vulnerability and offers this perspective as a lens through which to "understand the inner experience of gifted individuals throughout the life span and a sound framework for responding to developmental difference of this group" (Silverman, 1997, p. 36).

In contrast to Neihart's (1999) views that gifted individuals are neither more nor less at-risk than their non-gifted peers, Silverman asserts that the very nature of giftedness stresses the vulnerability of gifted individuals. Numerous researchers have 
demonstrated that the asynchronous nature of development in this population puts them out-of-sync with their contemporaries both internally and externally (Silverman, 1997). External asynchrony is defined as the lack of fit of the gifted child with other same-age children and with the age-related expectations of the culture (Terrassier, 1985). Internal asynchrony has been described as the degree to which a child's mental abilities differ from those of other children of his or her chronological age. The mental abilities of gifted individuals do not only develop at an accelerated rate, they are of a qualitatively different nature, involving greater cognitive complexity and emotional intensity that lead to a heightened awareness within the child for which they may not be emotionally mature enough to understand.

While a concern central to the construct of asynchrony in gifted individuals is a mismatch between their cognitive and emotional development, remarkably little research has been done to empirically examine the intersection of these domains in the developmental experiences of this population. Much of the current research in the field of gifted education focuses primarily on the cognitive realm. However, examining the role of emotional development in conjunction with cognitive and physical development provides a holistic view regarding how asynchronous development impacts the experiences of gifted individuals. By focusing on the inner self, as advocated by Silverman (1997), this study begins to explore the emotional and personality developmental domains of gifted adolescents and how they impact behavior within the educational environment, thus enabling us to become more responsive to the individual differences inherent to this population. 


\section{Ego Development}

Ego development is an abstract concept born out of the work done across a

number of fields. Hauser, Powers, and Noam (1991) define ego development as "the evolution of meanings that the [individual] imposes upon inner experience and perceptions of people and events, a sequence of increasingly mature stages of functioning across the domains of personal relationships, impulse control, moral development, and cognitive style" (p. 6). Loevinger (1976) viewed ego development as a unifying frame of reference, or "master trait," encompassing all other domains as the organizing structure of personality. Ego development encompasses changes in character, impulse control, conscious preoccupation, interpersonal relations, and cognitive styles. As such, it provides a frame for how the self, others and the environment are perceived and interpreted, thereby guiding the individual's behavior (Borders \& Fong, 1989).

Loevinger's positions of ego development describe the individual's manner of being in the world, and move from more egocentric, dependent behavior to an orientation that considers the relationship of self to others (Hy \& Loevinger, 1996). While the model includes nine qualitatively distinct developmental milestones representing increasingly mature organization of the self and the environment, the first stage is ego formation that occurs during infancy and Loevinger's work did not involve this stage. Thus, eight stages are identified through letter/number combinations starting at E2 (Impulsive) and moving to E9 (Integration). Loevinger conceptualized a hierarchical and cumulative sequence of stages, with each stage building upon the 
previous stage along a continuum of increasing conceptual complexity, self-awareness and independence (Loevinger, 1976). Through the process of differentiation, integration and adaptation, the individual moves toward being less dependent, less manipulative and more mutually oriented. At higher stages, relationships with others deepen and the individual takes on new roles. These more mature levels of ego development allow and individual to be better able to differentiate self from others, norms, and ideals, allowing a "richer and more inward sense of self" to emerge (Labouvie-Vief, 1993). As an individual grows better able to differentiate self from others, his or her ability to reflect on self and the world increases (Hy \& Loevinger, 1996).

In their most recent published update and revision, Hy and Loevinger (1996) provide a brief summation of the stages and their characteristics, which are presented in Table 2.1. 
Table 2.1

Stages of Ego Development (adapted from Hy \& Loevinger, 1996)

E2 - IMPULSIVE: impulsive and egocentric; dependent; preoccupied with bodily feelings

E3 - SELF-PROTECTIVE: opportunistic; manipulative; preoccupied with control

E4 - CONFORMIST: respect for rules; cooperative, loyal; preoccupied with appearance, behavior and social acceptance

E5 - SELF-AWARE: exceptions allowable; helpful, self-aware; preoccupied with feelings, adjustment

E6 - CONSCIENTIOUS: self-evaluated standards, self-critical; intense, responsible; preoccupied with motives, achievements

E7 - INDIVIDUALISTIC: tolerant; mutual mode of relating; preoccupied with individuality, developmental roles

E8 - AUTONOMOUS: coping with conflict; interdependent mode of relating; preoccupied with self-fulfillment

E9 - INTEGRATED: cherishing individuality; preoccupied with identity

Ego development is an adaptive process, related to cognitive complexity, that helps us understand how individuals construct and make meaning of their lives. At the earliest stages of development, one's adaptation centers on attachment to others and then progresses to the control of impulses and an appreciation of rules. During the Impulsive stage the child is focused on the immediate satisfaction of physical needs. Social interactions and encounters with the environment are viewed as strict 
dichotomies and the child's interpersonal style is receptive, dependent, and egocentric. The ability to delay gratification is not realized until the child enters the Self-Protective stage as they gain a minimal level of impulse control. Individuals at this stage are often wary and defensive when interacting with others, have limited ability to take responsibility for their actions, and often view interpersonal relations as exploitative.

As a child begins to experience group pressure to look beyond these hedonistic tendencies, the child enters the Conformist stage. Movement into this stage is commonly observed during adolescence and is marked by an increased identification with the group, and adaptation to group-centered standards, which are usually in congruence with what is conventional and socially acceptable. High value is placed on appearance, reputation, and social acceptance. Gender roles are usually quite conventional and emotions clichéd (Bursik \& Martin, 2006). However, as an individual begins to interact with different groups, he or she is exposed to different standards, and may begin to experience disequilibrium as he or she struggles to adapt adequately to competing loyalties.

Thus, the transition into the Self-aware stage involves an expanding ability to conceptualize the inner self, and an increasing distinction between the self and the group. At this stage, the individual adapts by seeing that there may be alternate possibilities to different situations, and he or she begins to choose behaviors and manage inner conflict in response to this more complex environment. The Conscientious stage marks the individual's ability to integrate self-evaluated standard based upon personal beliefs, convictions, and values. An individual at this stage strives 
to live up to his or her own ideals while also thinking beyond his or her own personal concerns to those of society. Those at the Individualistic stage are more tolerant of individual difference, and more adaptive in their ability to navigate many differentiated roles. Tolerance for individual differences continues to evolve and there is a growing understanding of psychological causation. The Autonomous and Integrated stages describe individuals who are able to recognize other's needs for autonomy and the complexity surrounding people and situations. Individuals at these levels strive for selffulfillment, and are marked by increasing levels of autonomy, morality, and tolerance for ambiguity (Hy \& Loevinger, 1996).

Loevinger (1994) has resisted the assertion that higher stages are "better" than lower stages of ego development, viewing personality functioning based on introspection and complexity as hallmarks of psychological maturity, but not necessarily indicative that the individual will be happier or better adjusted. Rather, individuals at higher levels of ego development are better able to adapt to new environmental conditions than those at lower levels. While, Loevinger resisted this "higher is better" premise, higher developmental levels have been positively related to adjustment, the ability to nurture, responsibility, tolerance, a capacity for leadership and a lack of aggression (White, 1985). Hence, at higher levels individuals appear more adaptable and better equipped to cope with a number of situations and life experiences.

Hauser, Powers, and Noam (1991) explored the paths of ego development taken by 130 adolescents, both high school students and psychiatric patients, as a means to analyze the "kaleidoscopic changes" (p. vii) of this developmental phase as they relate 
to the relationships inherent to these adolescents' lives. A central task of adolescence is that of separating from the family and connecting with outside social groups, as well as reconnecting with the family in new ways. Adolescents vary dramatically in their coping ability, with vast differences exhibited in "impulse control, autonomy, and relationships with family and peers" (Hauser, Powers, \& Noam, 1991, p. 4).

Hauser et al. (1991) describe several key dimensions of ego development: internal versus external locus of control, selflessness versus egocentrism, and narcissism versus healthy connections with others. They note that earlier stages tend to be marked by a sense of external control, limited abilities to relate to others, and an egocentric view of the environment while later stage move the adolescent towards more internal control, a greater appreciation of differences among others, and more intimate and collaborative relationships (Hauser, Powers, \& Noam, 1991).

In their study, Hauser et al. (1991) describe six developmental trajectories observed in their adolescent sample: profound arrest, steady conformist, progressive, accelerated, moratorium, and regressive. They elaborate on how each of these paths might shape the adolescents' social interactions and guide their resolution of conflicts. Of interest to the current study is the range of ego development trajectories that will be shown in our sample of gifted youth and they extent to which this will impact upon their behavioral characteristics in the social, school setting.

Hauser and Safyer (1994) explored associations between ego development and emotion communication during adolescence, finding more complex emotional expression combinations present in a greater amount with individuals at higher levels of 
ego development. They specifically found greater incidence of enthusiasm, affection, anxiety and neutrality at higher ego levels with greater expression of sadness and anger at lower ego levels. From these data, a new question emerged, "do adolescents at more advanced stages of ego development express more enthusiasm and affection in relationships?" (Hauser \& Safyer, 1994, p. 496). In the current study, this question may provide a connection between an adolescent's level of ego development and the adolescent's developmental level according to Dabrowski's theory of positive disintegration and the corresponding construct of overexcitabilities.

In spite of the widely purported view of adolescence as a period of emotional turbulence, Hauser and Safyer (1994) acknowledge our limited understanding of emotional development in adolescence, and cite epidemiological studies that indicate a comparable rate of emotional disturbance between adolescent and adult populations. Ego development is proposed as a useful perspective for illuminating several interconnected developmental aspects of adolescence. The authors propose a number of ego development trajectories that are analogous to a range of adolescent growth curves. The accelerated trajectory is of particular relevance to the current study as it explores the experiences of "unusually mature" or gifted adolescents. Characteristics of this sub-group of adolescents include precocious insight about themselves and their surroundings, being attuned to others' feelings far earlier than their peers, an ability to perceive the complexity of personal relationships and attend to subtle aspects of their own inner lives, and a highly sensitive and differentiated response to various settings and relationships. 
The study examined stages and paths of ego development as they unfolded during the adolescent years for a sample of 146 predominantly middle-class White boys and girls from a public high school and an inpatient psychiatric hospital setting. Subjects were administered the Washington University Sentence Completion Test (WUSCT), a measure with favorable reliability and validity (Loevinger, 1985), in order to assess individual ego development. This was followed with a semi- structured interview approximately one month later, which was analyzed with the Adolescent Emotion Coding System (AECS) to explore emotion communications.

Findings included greater emotion diversity as well as emotion conflict with higher levels of ego development. The data also indicated higher levels of specific emotions at more advanced ego development stages, including an increase in anxiety. Hauser and Safyer (1994) speculate that this higher anxiety in more advanced ego stages may be due to the greater awareness of complexities and uncertainties that individuals at these stages possess, and that a cost of this heightened awareness is an increase in anxiety. This finding may tie in with higher levels of development as related to Dabrowski's TPD, as the presence of such inner conflict is what enables advancement along Dabrowski's developmental continuum. The authors assert that more extensive analysis and exploration needs to be done to most effectively understand the connection between ego development and specific emotion communication and experience, as well as to examine the interplay between these emotional processes, behaviors, and interpersonal relationships. Hauser and Safyer (1994) further advocate for the use of alternate sources of data about the individual's emotional experiences 
and communications as well as a merging of qualitative and quantitative methods to most fully comprehend such a central aspect of the lives of adolescents. Linking gifted adolescents' experiences along the ego development continuum with their experience relative to Dabrowski's TPD will enable us to gain a broader understanding of the mechanisms that impact upon behavior and development for gifted students during this life stage.

Westenberg and Gjerde (1999) explore ego development in the transition from adolescence to young adulthood across a 9-year interval from age 14 to age 23 for an initial sample of 104 participants from an urban setting, heterogeneous with respect to social class, parental educational background, and racial identification. Ego development was assessed using the WUSCT (Loevinger, 1985) adolescent version at age 14 and the WUSCT adult versions at age 23.

Findings demonstrated four ego levels represented at age 14, ranging from the Self-protective (E3) through the Conscientious level (E6). At age 23, six ego levels were represented ranging from the Self-protective (E3) through the Autonomous level (E8). Modal levels were given for gender at each age and scores were analyzed for group gains in mean ego score, variability in ego level scores as a function of age, relative consistency in ego level scores over time, the impact of the Self-aware stage, and intraindividual patterns of ego development. Results supported the authors' main hypotheses that across the nine-year time span, (a) ego development increases; (b) the range and variability of ego level scores increases; (c) longitudinal stability of ego level 
within the sample is moderate or low; (d) on average, development slows down once the Self-aware level has been reached; and (e) regression in ego level is relatively rare.

Potentially relevant to the current study, a more detailed exploration of the findings reveals that the distinction between being moderately mature or precocious at age 14 had disappeared by age 23 . The authors propose that once the Self-aware stage has been reached that the more precocious 14 year olds make significantly less progress in comparison with their less advanced peers - or that those who were at lower stages at age 14 made relatively more progress by age 23 . While the sample in this study does not necessarily reflect the gifted adolescent population, it does provide insight as to how this process may unfold for them as well. Westenberg and Gjerde (1999) suggest "a developmental paradox: the developmentally most advanced adolescents appear at risk for developmental arrest, whereas more moderately mature adolescents appear to progress more easily to higher ego levels" (p. 247). Thus, a more moderate rather than high adolescent ego level appears advantageous, reinforcing Silverman's (1997) contention that due to the asynchronous nature of their development, gifted individuals are more in need of support and guidance in order for optimal development to occur.

Westenberg and Gjerde (1999) underscore the need for continued to research to explain their findings, citing the unanticipated nature of the above results and questions unanswered by this study, including, "If there is a general pull towards the Self-aware level, how then are some individuals able to move beyond this level?” (p. 249). Loevinger (1976) sees the transition toward the Conscientious level as a major shift likely dependent upon internal pacers, such as intelligence or personality traits. Perhaps 
exploring ego development in conjunction with the traits inherent to Dabrowski's theory of positive disintegration will shed light on possible contributors towards movement beyond the Self-aware stage, providing those internal pacers and stimuli necessary for more advanced ego development.

Recklitis and Noam (1999) examined coping strategies utilized by adolescents in conjunction with their level of ego development, specifically looking at the relationship of coping to psychopathology. In their study of adolescent psychiatric patients they distinguished between internalizing symptoms (e.g. depression, withdrawal) and externalizing symptoms (e.g. aggression, delinquency), hypothesizing that coping strategies could be delineated by the types of symptoms with which they were associated. Loevinger's stages were used as a means to unite diverse developmental strands and to address issues relevant to coping and adaptation. Recklitis and Noam (1999) proposed that ego development would be significantly related to coping behaviors, with "the more active and interactive strategies being associated with higher levels of ego development, and the passive, avoidant and emotionally reactive strategies being related to lower levels of ego development" (p. 89).

Results demonstrated that the behaviors used to cope with stress have significant implications for adjustment and mental health, with avoidant and negatively reactive coping strategies more likely to be associated with behavioral problems of all kinds (Recklitis \& Noam, 1999). Their results also demonstrate the developmental nature of coping behaviors, supporting the view that coping is not only a quantitative response to stress but is tied to "the ways in which individuals organize and make 
meanings of themselves and important relationships" (p. 98). The authors acknowledge the complex relationships between developmental organization and behavior, emphasizing the need for further exploration of these issues across a number of both clinical and non-clinical populations (Recklitis \& Noam, 1999). Their hypothesis that two styles of coping would be found and that these would correspond to internalizing and externalizing behavioral distinctions was not strongly supported, although some associations did follow this pattern. They did find that a relationship between coping strategies and ego development varied with gender. This finding is of potential clinical relevance in that different intervention strategies may need to be developed for females and males. As this study (Recklitis \& Noam, 1999) was conducted using self-report measures with a psychiatrically hospitalized study, it will be interesting to examine whether this relationship holds true using a teacher rating scale for a non-psychiatric, gifted adolescent sample.

Cognitive development is a necessary, but insufficient component of growth as ego development occurs through maturation, socialization, education, more complex roles, self-exploration, and often following stressful or positive life changes. While Bursik and Martin (2006) did not specifically explore the relationship between ego development and intelligence, they did investigate ego development differences in adolescent academic orientations and academic achievement, an area of particular relevance for the current study. Their study consisted of a sample of 142 male and female high school students who were assessed for level of ego development using the 
WUSCT, along with self-report measures assessing academic locus of control, learning orientation, and grade orientation.

Specifically, this study was designed to examine whether increasing individual differences in ego development during adolescence were associated with differential modes of approaching academic tasks and varied academic outcomes (Bursik \& Martin, 2006). The researchers noted potential effects due to differential timing of maturation for boys and girls, as well as gendered patterns of socialization, thus they examined their data for gender differences. Previous research on adolescent ego development has found that during the high school years both girls and boys tend to cluster around the Conformist (E4) and Self-aware (E5) stages, with most of the distribution falling between the Self-protective (E3) and Conscientious (E6) stages (Gfellner, 1986; Westenberg \& Gjerde, 1999). Gender differences have been consistently found with girls demonstrating higher ego development through high school (Cohn, 1991; Gfellner, 1986; Mabry, 1993), but research has also suggested that these differences diminish as individuals leave adolescence and enter young adulthood (Bursik, 1995; Redmore, 1983).

The researchers described controlling for the influence of verbal intelligence, reporting moderate associations between ego development and vocabulary (Cohn \& Westenberg, 2004; Westenberg, Jonckheer, Treffers, \& Drewes, 2004) as well as research demonstrating small to moderate positive correlations between ego development and intelligence (Cohn \& Westenberg, 2004; Cramer, 1999; Hauser, 1976; Westenberg \& Block, 1993). However, the Cohn and Westenberg (2004) meta-analysis 
conducted to determine whether ego development was equivalent to intelligence found a range of correlations between .20 and .34 , concluding that ego development and intelligence are not interchangeable constructs. This finding is of critical importance to the current study for obvious reasons, as controlling for intelligence would, in essence, negate one of the primary rationales for the study. Bursik and Martin (2006) also cite studies demonstrating an association among ego development and a number of dispositional variables measuring the adaptive capacities of individuals including ego resiliency, psychological mindedness, and intellectualism (Westenberg \& Block, 1993), openness to experience (Bursik, 1999), and empathy (Carlozzi, Gaa, \& Liberman, 1983). However, little empirical research examining behavioral outcomes was found. The current study will provide a small piece of insight into this area of exploration.

Results of the Bursik and Martin (2006) study demonstrated that ego level was a significant predictor of academic achievement after controlling for the effects of verbal intelligence and gender, a finding of particular significance for the current study on a sample of participants attending Governor's Schools that are known for the high level of academic achievement displayed by their students. The findings also revealed a greater distribution and variability of ego stages among adolescent boys compared with girls. Researchers postulated a number of potential explanations including differential socialization experiences throughout childhood as well as differences in biological maturation tendencies between boys and girls during adolescence. Future directions are proposed including intervention studies aimed at fostering ego development, or individual and group therapy to facilitate perspective taking skills and fostering 
tolerance for individual differences for those students at lower ego stages, particularly adolescent boys (Bursik \& Martin, 2006). A question left unanswered is the role of cognitive competencies and accommodative skills needed to move adolescents forward in their ego development, "why do some adolescents seek out new learning experiences that others may find daunting?" (Bursik \& Martin, 2006, p. 14). Loevinger $(1976,1998)$ asserts that increased intelligence does not necessarily translate into advanced ego development, but "are certain cognitive competencies or styles required in order to reach specific stage in Loevinger's model?" (Bursik \& Martin, 2006, p. 14). The current study may help to address these questions in pairing the examination of ego development with the developmental process and components outlined by Dabrowski's theory of positive disintegration.

\section{Dabrowski's Theory of Positive Disintegration}

Dabrowski (1972) defined developmental potential as the endowment that governs the possible extent and character of an individual's inner psychic growth. As such, Dabrowski outlined the following components that comprise an individual's developmental potential: psychic overexcitabilities, special abilities and talents, and autonomous factors. Piechowski (in Mendaglio, 2008) clarifies the relationship of developmental potential to giftedness:

Giftedness is a multifaceted phenomenon involving the interplay of specific talents, favorable environmental events, and unique personality characteristics. The concept of developmental potential broadens the conception of giftedness by addressing the personality correlates of high ability. The model binds the 
goals of education to self-actualization and [advanced] development, rather than merely to productivity in adult life. (p. 170)

Dabrowski 's theory of positive disintegration (TPD) delineates five levels of personality development along a continuum from low (egocentric) to high (altruistic), explains the process by which development occurs along these levels, and identifies individual characteristics that are equated to developmental potential ( $O^{\prime}$ Connor, 2002). The hallmark of Dabrowski's theory is that development to higher levels is achieved through the process of inner conflict, described as a disconnect between "what is" and "what ought to be" in oneself (Dabrowski, in Piechowski, 1975). This "positive maladjustment" is considered a necessary component of the process of developmental growth. Dabrowski described the process of this development as a two-fold process. First, the disintegration of more primary mental organizations such as those aimed at gratifying biological needs and conforming to societal norms occurs. Re-integration of these mental structures at a higher level of functioning follows, in which the individual transcends these more basic needs and becomes truly autonomous (Mendaglio, 2008). Inherent to these higher levels is the development of a hierarchy of individual values and emotional reactions with the ultimate goal being the attainment of an individualized personality ideal.

Within this view of development, Dabrowski identified three factors (Mendaglio, 2008) that contribute to an individual's developmental potential. The first factor consists of hereditary elements such as various instincts, constitutional elements that he refers to as "overexcitabilities," and dynamisms or autonomous inner forces combining 
instincts, intellect, emotions and innate inner drives. Overexcitabilities are defined as heightened physiological experiencing of stimuli resulting from increased sensitivities. Dabrowski hypothesized that the greater the overexcitability, the more intense the dayto-day experiences of life are felt and the more of an impact they will have on the individual's developmental trajectory. This component of Dabrowski's theory has generated a significant portion of the current research with his work, and holds a wealth of potential implications for both the education and counseling fields that will be touched upon later.

The second factor considered by Dabrowski's TPD concerns the effects of the social environment. The combinations of one's hereditary elements within the context of a nurturing social environment are most conducive to optimal developmental growth (Mendaglio, 2008). Thus, the second factor includes the social influences brought to bear by individual and groups of people (Dabrowski \& Piechowski, 1996).

According to Dabrowski and Piechowski (1996) the "[Third Factor] represents those autonomous processes which a person brings into [his or her] development, such as inner conflict, self-awareness, choice and decision in relation to personal growth, [and] conscious inner psychic transformation" (p. 14). This factor is the most ambiguous and difficult to operationally define, but is conceptualized as the force that drives individuals to become more self-determined (Dabrowski, 1973) and can be likened to an individual's inner motivation for growth.

Fundamental to the conception of Dabrowski's TPD is that behavior, thought and emotion have qualitatively different expressions at different levels of development 
(Ackerman, 2009). Dabrowski described this phenomenon as "multilevelness" in which the expression of behavior, thought, and emotion are based on individual and group values, some considered higher while others are considered lower. It is through the individual's construction of a hierarchy of values that developmental growth occurs (Dabrowski, 1970). Prior to the development of a hierarchy of values, individuals experience a unilevel personality structure generally influenced by biological and environmental forces and unconscious in nature. Through the critical process of positive disintegration, an individual begins to build a multilevel structure of personality, described as conscious, authentic, including the development of a hierarchy of values, and influenced by autonomous forces (Ackerman, 2009). In unilevel disintegration, present at the lower stages, conflicts are horizontal with opposing tendencies of equal value, relative, and governed by moment and circumstance. In multilevel disintegration, which takes place at higher stages, the conflicts are vertical, with opposing tendencies of lower and higher values and a characteristic of autonomous direction and choice (Piechowski, 1975).

Dabrowski (1972) outlined a number of internal processes, in addition to the three broad factors, that must be active to facilitate developmental growth. He defined these processes as dynamisms, biological or mental forces that control behavior and development. Dynamisms include instincts, drives, and intellectual processes combined with emotions and can be active in only one developmental level, or take on varying forms across developmental levels. Dabrowski described these developmental levels as structural conceptualizations with characteristic tendencies at each level, including type 
of internal conflict experienced, influence and expression of particular dynamisms, and different manifestation of the three factors.

A brief summary of the five developmental levels of the theory of positive disintegration as outlined by Piechowski (2003) are presented in Table 2.2.

Table 2.2

Summary of Dabrowskian Developmental Levels (adapted from Piechowski, 2003)

LEVEL I: PRIMARY INTEGRATION

- Individuals are governed by the "first factor" and are primarily influenced by heredity, impulses, and/or social, environmental forces.

- This level is marked by selfishness and egocentrism; individuals generally seek self-fulfillment above all through "ends justify the means" behavior.

LEVEL II: UNILEVEL DISINTEGRATION

- This level is characterized by a lack of inner direction, submission to the values of the group, relativism of values and beliefs, and the prevalence of ambivalences and ambitendencies.

- The "second factor" serves as the organizing principle of this level with social factors primary to the individual.

LEVEL III: MULTILEVEL DISINTEGRATION

- Within this level, individuals begin to get a sense of the ideal, of moral concerns, and of the existence of conflicting values within oneself.

- Individual's inner contrast between "what is" and "what ought to be" is responsible for the process of positive maladjustment that unfolds at level.

LEVEL IV: DIRECTED MULTILEVEL DISINTEGRATION

- The individual begins to move towards self-actualization and holds a strong sense of responsibility on behalf of others' well-being and inner growth.

- The "third force" becomes the primary motivator of growth, spurring individuals to work towards agreement between their actions and their ideals.

LEVEL V: SECONDARY INTEGRATION

- The "personality ideal" is achieved and individuals experience harmony and are at peace with themselves. Lower forms of motivation have been destroyed and are replaced by higher forms of empathy, autonomy, and authenticity. 
Ackerman (2009) describes four fundamental differences between Dabrowski's TPD and other developmental theories. First, she states that in TPD, development is unrelated to physical maturation, thus it is not automatic and one's age is not an indication of one's developmental level. Further, not all individuals start at the lowest level while some will not likely progress beyond the lowest levels. The second difference Ackerman stresses is the critical role of emotion in TPD. Dabrowski (1970) felt that "the emotional sphere at every level of development is the decisive factor that determines and controls human activity" (p. 112).

Dabrowski's view of psychoneurosis and conflict is the third fundamental difference and perhaps most relevant to the field of counseling. Dabrowski felt that many conflicts and forms of mental illness generally thought to have negative developmental consequences were, in actuality, necessary for positive developmental growth (Ackerman, 2009). He stressed that inner conflict was particularly significant as this provoked the disequilibrium necessary to move an individual forward. However, it is also important to note that his definition differed from many in that he viewed psychoneurosis as those processes, syndromes, and functions that express inner and external conflicts, and that he saw this as positive maladjustment of an individual in the process of accelerated development (Dabrowski, 1972). The final difference that Ackerman (2009) highlights, and attributes to Dabrowski's experiences during both world wars, is that Dabrowski held strong beliefs regarding the non-relativistic worth of different values, in which he felt it unreasonable to put all conceptions of right and wrong on equal footing. Components of Dabrowski's theory will begin to be explored in 
relation to ego development and the behaviors expressed by the gifted adolescents in the current study. While Loevinger's (1976) developmental theory defines ego as the core component of one's personality, Dabrowski theorists are likely to view ego as one piece of a more complex developmental process.

Mendaglio and Tillier (2006) provide an overview of the literature within the past 20 years focused on the application of Dabrowski's theory of positive disintegration (TPD) to the study of gifted individuals. Although few empirical studies have been conducted and are primarily focused on Dabrowski's notion of overexcitabilities, the recent upsurge of interest and study of the theory positions it at the forefront of future study in the realm of gifted education. Past research has explored TPD in relation to gifted individual's emotional sensitivity and intensity (Fiedler, 1998); in concert with issues of psychological well-being and mental health (Cash, 1999; Flint, 2001); as a means of identification of gifted individuals (Tieso, 2007); to identify creative personality characteristics (Schiever, 1985); to counsel gifted individuals (Hazell, 1999; Mendaglio, 1998; Ogburn-Colangelo, 1989); and to assess and describe social and emotional needs of adolescents (Gust, 1996; Tieso, 1999). The authors of these studies advocate for future research to focus not only on specific aspects of TPD but to examine the larger context of developmental potential.

A number of studies were outlined that focused primarily on the area of overexcitabilities (OE), a construct within the larger TPD that is more clearly operationally defined and for which reliable and valid measurement instruments have been developed. Mendaglio and Tillier (2006) indicate that the findings support a 
specific OE profile of elevated imaginational, intellectual, and emotional OE's in gifted adults but findings have been less clear in studies involving gifted children and adolescent populations.

A brief account of Dabrowski's $(1967,1972)$ own studies with gifted youth is also provided and highlights his focus on the relationship between superior abilities and psychoneurosis, which Dabrowski defined as "a more of less organized form of growth through positive disintegration" (1972, p. 303). Dabrowski's definition of developmental potential grew out of his work with 80 youth (aged 8 to 23) that were intellectually gifted, creatively gifted and developmentally delayed. His methods included an intricate combination of medical and psychological assessments and indepth qualitative explorations of the experiences of those individuals within his sample.

Piechowski (2003), a student of Dabrowski, continued research in this area and is often credited with bringing Dabrowski's theory to the attention of those within the field of gifted education. Miller (2008) has also examined and extended Dabrowski's TPD, providing an overview of research done with TPD from a sociological perspective focused on emotional management and emotional development. She highlights Dabrowski's view that the role of emotions equals, or surpasses, that of cognition in the transformation of the individual from lower to higher levels of development.

Miller (2008) briefly touches upon prior social and emotional developmental perspectives, including Loevinger's (1976) theory of ego development, as well as initial research done in examining Dabrowski's levels of emotional development. Early work in this area included an investigation of integrated developmental theories including those 
of Kohlberg, Loevinger, and Dabrowski (Greene, 1982; Schmidt, 1977); personal growth in graduate students from both Jungian and Dabrowskian models (Lysy, 1979); in-depth case study explorations of self-actualization in eminent, gifted individuals (Brennan, 1987; Tyska, 1980); and emotional experiences of gifted individuals (Beach, 2004; Hazell, 1982; Piechowski, 1975; 1978; 1979). She describes her own introduction to TPD in work with Silverman and Falk on the development of a more standardized analysis system for the Definition Response Instrument (DRI) that had been constructed to measure level of development along Dabrowski's theory of positive disintegration (TPD). However, as she further describes, much of the fleshing out of Dabrowski's theory has been done through more qualitative methodologies such as extensive case studies and textual analysis of eminent historical cases. Miller (2008) concludes with a call for more research, with additional predictors, more comparisons with other measures, more diverse sample groups and from a variety of profession perspectives to provide greater depth and breadth of understanding the emotional development of gifted individuals.

The most recent edition of the Roeper Review (April, 2009), a leading journal in the field of gifted education, was devoted entirely to the exploration of Dabrowski's theory of positive disintegration (TPD). Within this edition, an extensive overview of the theory was provided (Ackerman, 2009), TPD was explored qualitatively as a basis for research on assisting development (Mróz, 2009), a in depth case analysis of an individual at Dabrowski's level five was presented (Piechowski, 2009), a comparison of Dabrowski's concept of positive maladjustment with chaos theory was presented (Laycraft, 2009), and the perspectives and priorities of leading researchers in this area 
were presented (Kane, 2009). Key points highlighted in the introduction included an emphasis on the importance of emotion as a determining element in developmental growth and the critical nature of disintegrative experiences as a necessary component for progression to higher developmental levels (Ackerman \& Moyle, 2009).

Falk (in Kane, 2009) details the four main components of Dabrowski's theory as "multilevelness (differentiating higher from lower), developmental potential, developmental level, and positive disintegration as a developmental process" (p. 73). Daniels (in Kane, 2009) spoke to the role that teacher and counselors should take in working with this population, stressing that it is essential that gifted youth be heard, understood, and their growth facilitated so that they may fulfill their potential. Miller (in Kane, 2009) specifies that this encouragement of growth can best be accomplished through better understanding of the concepts of multilevelness and developmental potential, and by supporting the positive expression of overexcitabilities in children.

These thoughts are echoed by others (Kane, 2009) who assert the importance of understanding positive disintegration for professionals outside the field of gifted education. A clear message is given that individuals in the process of positive disintegration, "those who are experiencing confusion, feelings of inadequacy, anxiety, depression, and other so-called mental illnesses... should not be dismissed, 'cured,' or medicated away. Individuals, gifted and non-gifted alike, need to be understood and supported through these difficulties as they move forward on their developmental paths" (Ackerman, in Kane, 2009; p. 75). Moyle (in Kane, 2009) emphasized the importance of Dabrowski's theory in reframing mental health, stressing that an 
individual's mental health must be assessed in terms of development, with an individual's strivings and potential in mind. She further emphasized the need for professionals to consider symptoms in a multilevel context and to take up Dabrowski's call to "prevent marginalization and squandering of human potential, [rejecting] the automatic pathologizing of individuals who [don't] operate smoothly within their societies" (p. 76).

Ackerman (2009) provides an overview of application of theory of positive disintegration in counseling and educational settings, as well as in everyday life. Lind (2001) provided strategies for dealing with issues that may cause concern for overexcitable individuals and those who live or work with them. Ackerman and Kane (2002) viewed TPD from a broader perspective, presenting reasons why it can be helpful to teach children and adults about the theory and its components. Knowledge of TPD can provide individuals with a greater understanding of their inner experiences and feelings of being different as well as provide insight into how individuals of all types differ in their perceptions of the world.

While a small number of individuals (Amend, 2009; Mendaglio, 2002; Moyle, 2002; Silverman, 1990) have explored the use of Dabrowski's theories in counseling gifted individuals Ackerman (2009) echoes assertions made by other researchers that more empirical studies need to be done as counseling gifted individual has received less attention than educational applications. Dabrowski's theory of positive disintegration is not a theory only for the gifted but is a "detailed and profound view of personality development that applies to the broad diversity of people and the environments from 
which they come" (Ackerman, 2009, p. 93). Thus, the relevance of examination of developmental levels as related to Dabrowski's theory of positive disintegration for the current study is abundantly clear.

\section{Gifted Adolescents and Behavioral Characteristics}

Recent work with ego development has included examining the implications that the theory may hold for analyzing clinical issues (Hauser, Powers, \& Noam, 1991) as central constructs of the theory include behaviors and attitudes involved in impulse control, anticipation, responsibility taking, social judgment, and cognitive complexity. Many of the issues, challenges and vulnerabilities identified in research with gifted students hinge upon underpinnings common to ego development theory and the manner in which individuals perceive themselves in the world. Thus, ego development seems a particularly appropriate lens through which to examine gifted children and adolescents' construction of identity and meaning-making structures with Loevinger's theory providing a framework for understanding the expression of clinical issues at various developmental levels. Noam (1992) has found that higher ego levels may relate to greater incidences of internalizing disorders, while lower levels tend to relate more to externalizing disorders.

A study recently conducted in Germany (Krettenauer, Ullrich, Hofmann, \& Edelstein, 2003) examined the impact of externalizing and internalizing behavior problems in childhood and adolescence on adult personality and ego development, finding that both types of behavior problems were inversely associated with ego-scores in adulthood, even when SES, gender, and level of education were controlled. 
Externalizing behavior problems were specifically related to ego-level attainment below Conformity $(\leq E 3)$ while internalizing behavior problems predicted the failure to move beyond Conformity ( $\geq E 6$ ). Knowledge that behavioral problems may systematically predict adult ego-level attainment can inform the development of intervention programs designed to promote ego development in childhood and adolescence, as well as foster the development of more effective coping mechanisms to minimize the issues related to behavioral problems (Krettenauer et al., 2003). Confirmation of such a link between internalizing and externalizing behavior problems with the current study sample could strengthen the understanding of this relationship.

Gandolfo Carlisle (2004) examined the role of ego development and depression in the expression of internalizing and externalizing symptoms with a sample of 374 high school students. Students at the Pre-conformist stage (SE3) reported significantly greater externalizing symptoms that students at higher levels ( $\geq E 4)$. However, a similar relationship was not found between levels of ego development and internalizing symptoms. These findings support the need for further examination of similar associations within the gifted adolescent population to assess how ego development may relate to the social, emotional and behavioral characteristics expressed by these students.

Dabrowski's theory has been extensively linked in the literature to the social and emotional issues faced by gifted children and adolescents, providing a "framework that is particularly relevant for understanding the complex personalities of the gifted" (Ogburn-Colangelo, 1989, p. 87). However, as outlined earlier in this chapter, little 
empirical evidence exists on how the unique set of social-emotional characteristics displayed by gifted youth may interact with developmental levels. Mróz (2009) specifically identifies the need for research to examine the transition from Level II to Level III, when individuals are actively breaking down their unilevel structures of personality through the process of positive disintegration and attempting to rebuild their personality into a multilevel structure.

While Dabrowski's levels are not necessarily aligned with age and developmental norms not established, it is reasonable to assume that a number of students in the current sample may fall within or near this range. In previous autobiographical research studies, adolescence has been found to be a time when these disintegrative states surface as defenses against negative emotions or as attempts to compensate for frustrated emotional needs (Mróz, 2009). Thus, a need to more fully understand this process and potential implications are necessary in order to develop early intervention approaches aimed at forestalling disturbances in the process of development and promoting more optimal developmental growth. This study examined the interactions between ego development and development as related to Dabrowski's theory of positive disintegration as they are manifested by the behavioral traits exhibited by gifted adolescents in the school environment.

The Clinical Assessment of Behavior (CAB) provides a "balanced framework of competence-based and problematic or clinical scales, making it useful for strengthbased evaluation of children and adolescents" (Bracken \& Keith, 2004, p. 3). This instrument is a comprehensive, highly reliable behavior rating scale that has forms for 
both parents and teachers to rate the behavior of children across a number of intrapersonal and interpersonal domains. This particular rating instrument was chosen as it is based upon a multifaceted and developmental view of adjustment (Bracken \& Keith, 2004) and can simultaneously provide indicators of critical internalizing and externalizing behaviors as well as social skills, competence, and adaptive behaviors.

Bracken and Brown (2006) examined the use of the Clinical Assessment of Behavior for exploring both positive and negative adaptive behaviors in a sample of 45 gifted students and 45 regular education students, concluding that gifted students displayed overall better behavioral adjustment than their peers. Highlighting the inconsistency in defining and identifying gifted populations, the authors propose the use of the $C A B$ as a component of the identification process for gifted and talented students. Considerations for the possible tendency of teachers to base their ratings upon preconceived notions of giftedness were addressed and significant reliability and validity established. Reviewing the history of research in the field of gifted education, the $C A B$ is offered as an alternative that is more culturally sensitive than previous identification methods that focused solely on intellectual giftedness as measures by intelligence tests.

Results of the study found that gifted and talented students' mean scores were not statistically different from the mean scores of non-gifted students on scales measuring internalizing and externalizing problem behaviors and adaptive behaviors, "suggesting in broad terms the gifted students were as well adjusted as their non-gifted peers" (Bracken \& Brown, 2006, p. 117). However, significant mean score difference 
were found on the Competence scale, indicating higher levels of perceived and rated competence behaviors among the gifted and talented students. The gifted and students also demonstrated significantly higher mean scores on adaptive clusters in the areas of Executive Function and Gifted and Talented. These findings are considered cautiously in regards to the current study as the CAB design established significant correlations between these scales for all populations. However, these research findings provide a comparison gifted and talented sample in examining the behavioral characteristics of gifted students using the $C A B$ teacher rating scales.

An alternate explanation for elevated behavioral ratings unable to be explored in the current study, but worth noting, is an information management model (IMM) first proposed by Coleman and Cross (1988) as a means to anticipate and understand gifted students' psychological and social experiences and behaviors. Cross (1997) reexamined this model with regards to salient components of the research base on the psychological and social aspects of educating gifted students, including the psychological and social needs of gifted students, school-based issues common to gifted students, and the social coping strategies gifted students employ in school settings.

Cross (1997) discussed critical issues for gifted students including those issues common to all students, overexcitabilities, asynchronous development, perfectionism, self-criticism, and multipotentiality. While an extensive review of his model is beyond the focus of this study, the overarching theme is potentially relevant. This model proposes that gifted students employ social coping strategies to better fit the expectations of their environment. Essentially, early in their development, gifted 
students receive messages from others highlighting their differentness, these students desire "normal" social interactions, they learn that when others discover their giftedness they will be treated differently, and they learn they can manage information about themselves that will enable them to maintain a greater amount of social latitude (Cross, Coleman, \& Terhaar-Yonkers, 1991). The IMM relies on a social cognitive framework in outlining gifted students' behaviors along a continuum of visibility (Cross, 1997) based upon their interpretation of the mixed messages received regarding giftedness and where they desire to be viewed by others socially. While this model is not postulated to be concerned with specific problem and adaptive behaviors, it may be relevant to how others perceive, and thus rate the behavior of gifted students and should be considered in the interpretation of study results.

\section{Summary}

Uneven development is a universal characteristic of giftedness, with gifted children and adolescents in any cultural context having greater discrepancies among various facets of development than average youth (Silverman, 2007). However, indepth examinations of gifted students' experiences in particular domains have been limited. Little research has been done in the counseling field linking Dabrowski's TPD to other developmental theories and approaches, and ego development has not been specifically studied in gifted populations. Dabrowski's TPD is at the forefront of current research in the field of gifted education (Mendaglio, 2008). Research in the field of counseling has established a theoretical foundation for the utility of cognitive developmental approaches in conceptualizing and constructing counseling 
interventions. Ego development, conceptualized as a "master trait" (Loevinger, 1976), encompasses not only the social and emotional development of the individual, but their moral, conceptual and personality development as well. Thus, the relational focus of ego development theory situates it as an ideal lens through which to examine the social and emotional characteristics of gifted students. Linking each of these developmental domains to gifted adolescents' behavior will further broaden our understanding of the unique characteristics and experiences of this population.

The current study examined the developmental needs of gifted adolescents by combining available research in cognitive development (specifically ego development) with Dabrowski's theory of positive disintegration to build a more comprehensive base from which to conceptualize counseling approaches and interventions for working with the gifted population. It was proposed that a thorough examination of the differences and similarities between these two theories as they relate to the behavior and experiences of gifted adolescents could enable counselors to bridge the two theories, providing a stronger framework for understanding the breadth and depth of the developmental processes experienced by gifted adolescents. Such an understanding will enable practitioners to tailor counseling interventions and educational strategies best suited to these individual's unique social, emotional, and developmental needs. 


\section{Chapter Three}

\section{Research Methodology}

The purpose of this chapter is to describe the design and methodology used in the study. Included are the following: population, sample, data collection procedures, instrumentation, research design, research questions and hypotheses, and data analyses. Specific ethical considerations will also be discussed.

\section{Population and Sample}

The study's target population was gifted adolescents that had been identified through the selection process inherent to their admission at various regional academicyear Governor's schools throughout the state of Virginia. The Virginia Department of Education (1996) defines gifted students as those students "whose abilities and potential for accomplishment are so outstanding that they require special educational programs to meet their educational needs." Identification of gifted students is based upon multiple criteria outlined in the Virginia Plan for the Gifted (1996), and includes general intellectual aptitude, specific academic aptitude, technical and practical arts aptitude, and visual and performing arts aptitude. Virginia's Governor's School Program is specifically charged with the task of providing services to gifted students throughout the state and an eligibility process is established at each school to screen and identified gifted students according to that school's specific requirements. Eligibility for these Governor's School programs is based on multiple criteria, including four or more of the following categories: (1) assessment of appropriate student products, performance, or portfolio; (2) record of observation of in-classroom behavior; (3) appropriate rating 
scales, checklists, or questionnaires; (4) individual interview; (5) individual or group aptitude tests; (6) individual or group achievement tests; (7) record of previous accomplishments; and (8) additional valid and reliable measures or procedures (Virginia Department of Education, 2008). For the purpose of this study, those students who had been identified as gifted and eligible for Governor's School programs in the state met the operational definition of giftedness utilized in this study.

The convenience sample was derived from an accessible population of students at the Maggie L. Walker Governor's School for Government and International Studies (MWGS) in Richmond, Virginia and from the Chesapeake Bay Governor's School for Marine and Environmental Science (CBGS) in Glenns, Virginia. The school districts and locales from which these schools receive students range from small rural communities to large urban areas, and thus represent a student population of diverse socioeconomic and ethnic backgrounds. Further, because of the different foci of each school, a sample of gifted students across diverse domains will be ensured. A liaison at each school randomly selected students that were invited to participate in the study, thus a wide cross-section of students were chosen, helping to address sampling issues that may arise with a more restrictive sampling technique.

The sample in the present study consisted of 100 participants, with 60 students invited to participate from MWGS and 40 invited to participate from CBGS. Of those invited, 70 chose to participate and completed the instrumentation. The sample consisted of both male and female students from grades 9 through 12 . All students were considered to be representative of gifted students as this is the primary criterion 
for admission to each of the schools. Gall, Gall, and Borg (2005) state that "inferential statistics can be used with data collected from a convenience sample if the sample is carefully conceptualized to represent a particular population" (p. 510). The selected sample captured both the prerequisites of giftedness and adolescence.

\section{Data Collection Procedures}

\section{Method}

The first step taken was to obtain permission from each of the participating school districts to conduct the study at a time most convenient to the needs of the students and school during the course of the 2008-2009 academic school year. The researcher worked in collaboration with an identified liaison at each school to select the student sample and communicate with the students' parents. Parents of selected students received a description of the study and consent forms for their gifted adolescent to take part in the study. Teachers of the selected students also received informed consent forms prior to their participation in completing behavioral ratings for student participants. Testing dates and times were set in conjunction with the school's schedules, with a number of testing dates scheduled at each school in order to enable greater participation. Prior to the scheduled testing dates, the researcher distributed informational letters to parents, students and teachers to encourage participation and address concerns that participants, parents or teachers might have. Each potential participant was given the researcher's contact information and encouraged to communicate any questions and concerns either through the school representative or directly with the researcher. 
Once parental consent forms were received, specific testing session times were scheduled for each participant. Testing sessions were approximately 45 minutes in duration, during which participants were informed of their rights as volunteers and the study's purpose and procedures were discussed. Student informed consent forms, demographic surveys, the Washington University Sentence Completion Test (WUSCT), the Definition Response Instrument (DRI), and writing utensils were distributed. At the onset of each testing session, directions were read and participants were encouraged to ask questions regarding any uncertainties. All instruments, other than the informed consent forms, which were collected separately, were coded only with a unique student identification code to ensure participant anonymity and confidentiality. Instruments were collected upon completion and the student participants were debriefed, thanked for their participation, and informed how the results would be made available to them at the completion of the study. In conjunction with the school, students at MWGS were granted community service credit for their time and participation. Participants at CBGS were given the opportunity to enter their name into a random drawing for one $\$ 25$ Barnes \& Noble gift certificate to be awarded at the conclusion of the data gathering stage.

Following the test administration dates, teacher volunteers were sought to complete the Clinical Assessment of Behavior Teacher Rating Scale (CAB-T) for each of the student participants. In order to maintain consistency, ensure a breadth of teacher input, and avoid overburdening any particular teacher; homeroom teachers were recruited to complete the behavioral rating scales. A brief letter of request was sent to 
these teachers via the school liaison, informing them of the study, their rights as volunteers and the study's general purpose and procedures. In addition, teachers who participated were eligible to enter their name into a drawing for one $\$ 25$ Barnes \& Noble gift certificate at each school. Teachers that chose to participate were then asked to complete the informed consent forms and the CAB-T for a specified student, who was identified by name in the letter, but only by student identification code on the CAB-T rating form. They were ensured of confidentiality both for their ratings and for the student's information. Teachers were asked to return the completed informed consent forms and CAB-T rating forms to the school liaison. When all forms were collected, the teacher volunteers were debriefed, informed of the individual chosen in the gift certificate drawing, thanked for their participation, and informed that the results would be made available to them upon completion of the study.

\section{Data Handling Procedure}

All hard data was carefully stored in a secure file cabinet organized by school. The school liaison coordinated all communication between the researcher and the students, parents, and teachers. Other than the informed consent forms all data was identified only by unique student identification codes. Access to the informed consent forms was limited to only the researcher. Access to the instrument data was limited to only the researcher and the research team that scored the instruments. All digital information and data was also maintained in a secured file accessible only to the researcher. 


\section{Instrumentation}

Five instruments were used to collect necessary information for completing this study. Specifically, they are as follows: (1) informed consent form, (2) demographic information form, (3) Washington University Sentence Completion Test (WUSCT), (4) Definition Response Instrument (DRI), and (5) Clinical Assessment of Behavior Teacher Rating Scales (CAB-T).

\section{Informed Consent Form}

The informed consent form explained the activities requested of the participants, summarized the study's procedures, and described how the results were to be used. This form, along with the accompanying cover letter, informed participants of their right to withdraw from the study at any time. Contact information was provided and both parents and participants were encouraged to communicate any questions or concerns. On each consent form, space was provided for the parent, student, or teacher to sign and date to mark their consent. On the teacher volunteer forms, space was provided for them to sign and date, indicating their consent to participate. Two copies were given; one copy was returned to the researcher and the other copy kept by the participants for his or her records. A copy of each of the informed consent forms can be found in Appendix $C$.

\section{Demographic Information Form}

A brief demographic information form was used to obtain the following data for each student participant: (1) age, (2) gender, (3) ethnicity, (4) grade in school, and (5) school attending. Through use of an alphanumeric coding system, participant's 
demographic information was matched with his or her WUSCT, DRI and CAB-T forms.

The information derived for the form was used to determine the impact of these specific demographic variables on ego development, level of development as related to Dabrowski's theory of positive disintegration, and behavioral characteristics. A copy of the demographic information form can be found in Appendix D.

\section{The Washinqton University Sentence Completion Test}

The Washington University Sentence Completion Test (WUSCT) developed by Loevinger and Wessler (1970) was used to assess the students' levels of ego development. This study utilized the shortened form of WUSCT in order to meet the time constraints imposed by testing during the school day. The WUSCT (short form) is a semi-projective test consisting of 18 sentence stems with different versions provided for males and females. Although there us some loss of reliability in using the shortened form of the WUSCT, there is no impact upon the validity (Foster \& Sprinthall, 1992; Novy \& Francis, 1992). Further, while the WUSCT was developed for adult men and women it has been used internationally in a number of studies with adolescents supporting the cross-age and cross-national validity of ego development theory (Westenberg, Jonckheer, Treffers, \& Drewes, 1998). A youth form of the instrument has been developed (SCT-Y), however the scoring manual for this instrument is still under development and is not expected to be completed by the conclusion of this study (Westenberg, personal communication, 2008). Hence, the currently accepted form was used, taking special note of differences in the scoring that have been discussed in the literature (Westenberg et al., 1998) which are primarily evident in the Impulsive, Self- 
Protective, and Conformist levels. Westenberg et al. (1998) report the majority of these differences have arisen with subjects younger than 16. As our sample consisted of adolescents between the ages of $14-18$, these differences should remain minimal. Numerous studies conducted with children and adolescents (Cohn, 1991; D' Andrea, 1984; Westenberg \& Block, 1993) have shown the instrument to be reliable and valid within this age range. Further, Westenberg et al. (1998) state that none of the studies they have reviewed have reported shortcomings in the model or scoring manual when used with young population.

Thus, the WUSCT (short-form) was distributed and students were asked to complete each of the stems. The completed sentence stems were then coded and scored, identifying the respondent's individual way of reasoning about his or her actions, motivations and personal relationships (Hy \& Loevinger, 1996). The completed WUSCTs were scored by two independent raters trained in accordance with the most current training manual (Hy \& Loevinger, 1996), and in consultation with an expert rater. Inter-rater reliability was established during the training process and confirmed in the scoring and analysis of the actual study instruments. Each item on the WUSCT was individually scored for ego stage and used to derive the continuous item sum score (ISS) and the total protocol rating (TPR) indicating ego stage. The TPR represents the core level of functioning of the student and is determined by applying the ogive rules that account for the total distribution of scores across the 18 stems (Bursik \& Martin, 2006). 
Table 3.1

Scoring Protocols for the WUSCT

\begin{tabular}{|c|c|c|c|c|}
\hline Stage & Name & $\begin{array}{l}\text { Item } \\
\text { Sum }\end{array}$ & Automatic Ogive & Explanation of Ogive \\
\hline E8 & Autonomous & $109-118$ & $\begin{array}{l}\text { No more than } 16 \text { ratings at } \\
\text { E7 }\end{array}$ & $\begin{array}{l}2 \text { or more E8 or } \\
\text { higher }\end{array}$ \\
\hline E7 & Individualistic & $101-108$ & $\begin{array}{l}\text { No more than } 15 \text { ratings at } \\
\text { E6 }\end{array}$ & $\begin{array}{l}3 \text { or more E7 or } \\
\text { higher }\end{array}$ \\
\hline E6 & Conscientious & $91-100$ & $\begin{array}{l}\text { No more than } 12 \text { ratings at } \\
\text { E5 }\end{array}$ & $\begin{array}{l}6 \text { or more E6 or } \\
\text { higher }\end{array}$ \\
\hline E5 & Self-Aware & $82-90$ & $\begin{array}{l}\text { No more than } 9 \text { ratings at } \\
\text { E4 }\end{array}$ & $\begin{array}{l}9 \text { or more E5 or } \\
\text { higher }\end{array}$ \\
\hline E4 & Conformist & $76-81$ & $\begin{array}{l}\text { No more than } 6 \text { ratings at } \\
\text { E3 }\end{array}$ & $\begin{array}{l}9 \text { or more E4 or } \\
\text { higher }\end{array}$ \\
\hline E3 & Self-Protective & $68-75$ & At least 3 ratings at $\mathrm{E} 3$ & 3 or more E3 or lower \\
\hline
\end{tabular}

Previous studies conducted with the WUSCT have provided ample evidence of the instrument's validity and reliability (D’Andrea \& Daniels, 1992; Gilmore \& Durkin, 2001; Loevinger, 1979; Loevinger, 1998; and Loevinger \& Wessler, 1970). Reliabilities for the individual items on the WUSCT range from .47 to .93 and inter-rater agreement for self-trained raters and been reported to fall between .86 and .90 (Loevinger \& Wessler, 1970), comparable to that of professionally trained raters whose inter-rater agreement ranged from .89 to .92 . In the training and subsequent scoring of actual instruments for this study, Rater 1 established inter-rater reliability with the expert rater with $91.9 \%$ agreement across the 18 stems and $90 \%$ agreement for TPR using an established coding set. Rater 2 established inter-rater reliability with the expert coder 
with $90.8 \%$ agreement across the 18 stems and $90 \%$ agreement for TPR. Between Rater 1 and Rater 2, a 93.8\% inter-rater reliability across 18 stems was established with a 90\% agreement for TPR. Loevinger and Wessler (1970) reported inter-rater reliability to be between .86 and .90 on TPR agreement for self-trained raters. Thus, strong inter-rater reliability was achieved in the scoring of the study WUSCT protocols. Internal consistency of the instrument has also been tested with Loevinger and Wessler (1970) reporting an alpha coefficient of .91 for all 36 items.

A recent review of the validity of the WUSCT (Gilmore \& Durkin, 2001) provides substantial empirical support for the instrument's external validity as well as the conceptual soundness of both ego development theory and the WUSCT. The instrument's construct and concurrent validity has been established by several studies that have examined ego development in relation to other developmental stage assessments such as moral development and attitude and behavioral measures (Lee \& Snarey, 1988; Loevinger, 1979). However, two possible areas of concern that must be considered include the areas of verbal fluency and socioeconomic status. A high correlation previously has been identified between the length of the completed sentences and the scored ego level of response, as well as higher scores found for respondents of higher socioeconomic status (Gilmore \& Durkin, 2001). While other researchers have questioned the existence of these relationships (John, Pals, \& Westenberg, 1998), disagreement persists. Thus, close attention was paid in the coding, scoring and interpretation of the protocol responses and in conjunction with an examination of the individual responder's demographic data to these areas. Despite the 
concern of overlapping of ego development with other such constructs, there appears to ample evidence of the use of the WUSCT as a valid measure of ego development (MCDonald, 2006). A copy of the WUSCT (short-form) can be found in Appendix E.

\section{Definition Response Instrument}

The Definition Response Instrument (DRI) is a six-item, free response questionnaire developed by Gage, Morse, and Piechowski (1981) for the purpose of measuring the level of developmental as conceptualized by Dabrowski's (Dabrowski \& Piechowski, 1977) theory of positive disintegration (TPD). The six statements of the DRI describe themes that underlie the developmental dynamisms central to TPD and include: (1) susceptibility to the influence of others, (2) personal conflict, (3) inferiority, (4) dissatisfaction, (5) self-observation, and (6) personality ideal. The students were read instructions requesting that they openly and honestly describe personal experiences in written responses to each of the statements. Previous methods of assessment for Dabrowskian developmental levels have included neurological examinations, clinical interviews, autobiographical essays, and intelligence tests, but the process was lengthy, cumbersome and lacked empirical backing. Focusing on the most relevant of Dabrowski's theoretical constructs and assessment measures led to the development of the DRI, an empirically tested instrument based upon the individual's written responses to verbal stimuli that elicited the individual's personal history of emotional experiences, and crucial life events (Miller, 1985). In the development of the instrument, convergent and discriminant validity were established and shown to be comparable to previous methods of assessing the same concepts (Gage et al., 1981). The DRI consists of 
statements designed to elicit material that can be coded for developmental dynamisms, a central construct of Dabrowski's levels of development. Internal consistency of the DRI items has been found to be .71 (Miller, 1985).

A number of studies have since demonstrated the acceptability of the DRI as an instrument to be used to discriminate levels of development as defined by TPD (Beach, 2004; Brennan, 1987; Gage et al., 1981; Lysy, 1979; and Miller, 1985). Miller (1985) expanded upon the initial DRI instrument and coding procedure in her development of an updated content analysis coding system, the Miller Assessment Coding System (MACS). Extensive work with the instrument has increased systemization and objectivity in the scoring process, thus improving interrater reliability to a range between .77 and .80 (Miller, 1985). This categorical system also permits the instrument to be more sensitive to the theoretical constructs of each of the TPD developmental levels (Miller \& Silverman, 1987). The simplified coding system has been designed to be "objective, systematic, and theoretically relevant" (Miller, 1991, p. 1) with coding categories derived from the dynamisms and descriptions of levels in Dabrowski's TPD (Dabrowski \& Piechowski, 1977).

The most recently revised (1991) edition of the Miller Assessment Coding System was used in training the individual raters, along with personal communication and clarification from the coding system's author (Miller, personal communication 2008). The raters worked together through the training process outlined by Miller (1985) and a number of practice instruments were scored to establish inter-rater reliability. Average inter-rater reliabilities utilizing this system and training have been reported as .72 
(Miller \& Silverman, 1987). In this study, an inter-rater reliability was established between Rater 1 and Rater 2 with 76.7\% agreement across the individual items using a coding set of 15 DRI protocols. In addition, the Pearson correlation found when all protocols were compared was $r=.94, p<.01$. Thus, relative to past use of this instrument a sufficient degree of inter-rater reliability was established. A copy of the Definition Response Instrument (DRI) can be found in Appendix F.

\section{Clinical Assessment of Behavior}

The Clinical Assessment of Behavior (CAB) was designed by Bracken and Keith (2004) to measure both adaptive and problematic behaviors of children and adolescents from age 2 to 18 years. The $C A B$ is available in parent (CAB-P), parent-extended (CAB$P X)$, and teacher (CAB-T) rating forms. The teacher version (CAB-T) was chosen for use in this study, as the focus of this inquiry is behavioral characteristics exhibited by gifted adolescents within the school context. The CAB-T is a 70-item instrument on which teachers rate "how often has the student engaged in the behavior lately," (Bracken \& Keith, 2004, p. 1) on a Likert-type scale from 1 (always or very frequently) to 5 (never). The instrument has been found to be valid across a wide range of geographic and racial/ethnic backgrounds (Beran, 2006). Following the collection of the instruments from the participating schools, responses were manually entered into a computer scoring system and computed to derive a total behavioral index score, scale scores, cluster scores, raw scores, standardized T scores, and percentile ranks. This study focused examination on the Clinical Internalizing (INT) and Externalizing (EXT) behavior 
scales, the overall Clinical Behavioral Index (CBI) and Gifted and Talented (GAT) subscale.

Three forms of reliability were considered in the construction of the instrument (Bracken \& Keith, 2004). Internal consistency as measured by Cronbach's alpha ranges from .92 to .99 on the teacher rating form. Test-retest reliability for teacher ratings ranged from .89 to .95 across the scales with the highest reliability for the total scaled score. Inter-rater reliability between teacher and parent ratings was only moderate, ranging from .44 to .58 , and is suggested to be skewed as children are likely to exhibit different behaviors across different contexts (Bracken \& Keith, 2004). However, since this study will only examine students via the teacher rating form in one context, the low interrater reliability between parents and teachers will not impact the results. Interrater reliability between different teacher raters has not been reported in the literature.

Content validity and the structure of the scale have been supported by the authors with factor analysis and principle components analysis results (Bracken \& Keith, 2004). Criterion-related validity was established through comparison with the Behavior Assessment System for Children (Reynolds \& Kamphaus, 2004) and the Devereux Scales of Mental Disorders (Naglieri, LeBuffe, \& Pfeiffer, 1994), with corresponding scales found to be highly correlated and supported by a number of clinical studies (Beran, 2006). This specific instrument was chosen based upon its strengths as a short, easily administered, and scored tool that can provide clear data regarding the nuances of behavioral characteristics of gifted adolescents. It was also selected because of the inclusion of a specific gifted and talented behavioral scale. The items included on the 
$C A B$ were derived from a comprehensive content review including review of pertinent literature relating to childhood and adolescent development and adjustment, review of item content on existing instruments, examination of current diagnostic criteria based upon the Diagnostic and Statistical Manual of Mental Disorders - Fourth Edition (DSMIV, American Psychiatric Association, 1994), consideration of current behaviors of concern and interest, and suggestions from colleagues (Bracken \& Keith, 2004). Bracken and Brown (2006) propose use of the instrument as a complement to traditional screening methods for gifted and talented students and suggest the benefits of the instrument in providing information about gifted students' levels of competence, executive functioning, and behaviors related to gifted and talented functioning as well as information about students' psychosocial health and adjustment.

\section{Research Design}

The purpose of this study was to determine, through a descriptive design, the relationship between gifted adolescents' ego development as measured by the Washington University Sentence Completion Test, Dabrowskian developmental level as measured by the Definition Response Instrument, and exhibited behavioral characteristics as indicated by teachers in completion of the Clinical Assessment of Behavior. As a descriptive study, analyses consisted of descriptive statistical analyses, one-way analyses of variance, bivariate and multivariate correlational analyses on the WUSCT, DRI and CAB-T data. Descriptive statistics were utilized to determine means and standard deviations for the obtained data, and correlational analyses were employed to determine relationships between the variables. As age, gender, ethnicity, 
grade level, and school attending may also impact the analyses these variables were examined through correlational analyses, multiple analyses of variance (MANOVAs) and follow-up analyses of variance (ANOVAs). Multiple analyses of variance (MANOVAs) were used to assess the statistical significance of the effects one or more of the independent variables may have on the dependent variables, and to guard against Type I error (Grimm \& Yarnold, 2006). When indicated, follow-up univariate analyses of variance (ANOVAs) were conducted to determine significant differences. Independent variables were age, gender, ethnicity, grade in school, and school attended. Dependent variables were level of ego development, level of development as related to Dabrowski's theory of positive disintegration, and overall Behavioral Index (CBI), Internalizing (INT), Externalizing (EXT), Social Skills (SOC), Competence (COM), and Gifted and Talented (GAT) subscales on the CAB-T.

General Research Questions

General research questions addressed by this study follow. (1) What are the ego development levels of gifted adolescents as measured by the WUSCT? (2) What are the Dabrowskian developmental levels of gifted adolescents, as measured by the DRI? (3) What are the exhibited behavioral characteristics of gifted adolescents in the school context as indicated by teacher responses on the CAB-T?

General Research Hypotheses

I. The range and distribution of gifted adolescents' levels of ego development as measured by the Washington University Sentence Completion Test (WUSCT) will not differ significantly from established adolescent norms. 
II. There will be a moderate positive correlation between gifted adolescents' stage of ego development as measured by the Washington University Sentence Completion Test (WUSCT) and their Dabrowskian developmental level as measured by the Definition Response Instrument (DRI).

III. There will be a significant positive correlation between gifted adolescents' ego development as measured by the Washington University Sentence Completion Test (WUSCT) and their degree of internalizing behavior as measured by the Clinical Assessment of Behavior Teacher Rating Scale (CAB-T).

IV. There will be a significant negative correlation between gifted adolescents' ego development and their degree of externalizing behavior as measured by the Clinical Assessment of Behavior Teacher Rating Scale (CAB-T).

V. There will be a normal distribution of behaviors exhibited by gifted adolescents as measured by the Clinical Assessment of Behavior Teacher Rating Scale (CAB-T).

Data Analysis

Data were analyzed first using descriptive statistics to determine means and standard deviations. The Pearson product-moment correlation, analysis of variance (ANOVA) and multivariate analyses of variance (MANOVA) were utilized to measure the magnitude and direction of relationship between the variables of ego development, Dabrowskian development and behavior, as well as to assess for significant differences between groups. The alpha was set at .05 for establishing statistical significance. When 
significant differences were determined from the MANOVA, follow-up post hoc tests were conducted to specify which variables are significantly impacting each other.

Grimm and Yarnold (2006) describe the one of the uses of bivariate and multivariate analyses of variance (MANOVAs) as an attempt to understand or explain the nature of a phenomenon for purposes of testing or developing theories. Further, "[MANOVAs] determine the statistical significance of differences among groups of subjects... by determining whether there is significant prediction of subject's scores on the dependent variable from knowledge of their group membership" (Grimm \& Yarnold, 2006, p. 20). Thus, multivariate analyses of variance, along with follow-up univariate analyses of variance (ANOVAs) were conducted to test for the effects of gender, age, ethnicity, grade, and school attending.

\section{Ethical Considerations}

In accordance with Section E of the American Counseling Association Ethical Code (1995), and the Human Subjects Board of The College of William and Mary, all necessary precautions were considered in protecting the welfare of the participants. Participants and their parents were provided with a thorough explanation of the study's procedures and written informed consent collected from each student and his or her parent(s). Emphasis was placed on the voluntary nature of participation and it was explained that individuals may discontinue their participation in the study, without penalty, at any time. Confidentiality was ensured through the use of coding on all instrumentation and data. None of the research material contains identifying information that can be traced to anyone in particular. Sound instrumentation was used 
in an appropriate manner and was scored and interpreted by qualified individuals.

Upon completion of the study, results were made available to all participants.

\section{Summary}

The preceding chapter has outlined the research design and methodology used in conducting the current study. Little research has been done in the counseling field linking Dabrowski's theory of positive disintegration to other developmental theories and approaches, particularly the domain of ego development. Further, while ego development has been linked to social and emotional growth and subsequent expressed behaviors throughout the lifespan, it has not been specifically studied in gifted adolescent populations. This research design examined the relationships among these variables in order to gain a more comprehensive view of development in gifted adolescents. This study contributed to the body of research literature by expanding upon the current knowledge and understanding of this population in the gifted education and counseling fields. Results and discussion may provide insight into more effective and appropriate education and counseling interventions aimed at best meeting the affective and developmental needs of gifted students. 


\section{Chapter Four}

\section{Analysis of Results}

This chapter presents a statistical analysis of the results of the current study that explores the relationships between ego development, development as related to Dabrowski's theory of positive disintegration, and the behavioral impact of the unique social and emotional characteristics of gifted adolescents. First, a brief description of the sampling procedure is presented. Additionally, an overview of the demographics of the sample is described and data analyses for the research questions and research hypotheses are provided. An alpha level of .05 was used for all statistical tests unless otherwise specified. Discussion of the results and implications of the findings will be discussed in chapter five.

\section{Sampling Procedures}

During the months of November and December 2008, the researcher contacted five regional Governor's Schools across the state requesting their participation in the current research study. Two schools consented to allow the researcher access to their student population as potential participants. Once the sites for data collection had been identified, the researcher worked in collaboration with a school liaison at each site to randomly select and contact 100 potential participants. Forty potential participants were randomly selected and contacted from Governor's School A and 60 potential participants were randomly selected and contacted from Governor's School B. The selected students and their parents were mailed a cover letter with a Parent Informed Consent Form and asked to return the form either to the school liaison or in an enclosed 
self-addressed envelope. Once the Parent Informed Consent Forms were collected, the researcher worked collaboratively with the school liaison to schedule testing sessions that were minimally invasive to the students' work during the school day, or immediately after school. In these testing sessions, participants were first asked to review and sign the Student Informed Consent Form. Students were then asked to complete a testing packet comprised of a short demographic form, the Washington University Sentence Completion Test (WUSCT) - Short Form, and the Definition Response Instrument (DRI).

\section{Descriptive Data}

\section{Demographics}

Of the 100 students contacted through the two regional Governor's Schools, 70 participated in the current study. The participants were fairly evenly distributed between the two schools. $44.3 \%$ (31) of the participants were from School A, and $55.7 \%$ (39) were from School B. Numerous testing sessions were held at each school to ensure optimal participation. The study instruments were fully completed by $100 \%$ of the participants.

As reported in Table 4.1, the participants were evenly divided by gender with $50 \%(35)$ of the sample females and $50 \%$ (35) males. The ages of the students ranged from $14-18$, and were normally distributed across this range: $11.4 \%$ (8) were $14,20 \%$ (14) were $15,30 \%(21)$ were $16,27.1 \%(19)$ were 17 , and $11.4 \%(8)$ were 18 years of age. These students were also well distributed across grade levels with $17.1 \%(12)$ in grade $9,28.6 \%(20)$ in grade $10,32.9 \%(23)$ in grade 11 , and $21.4 \%(12)$ in grade 12. 
Pertaining to ethnicity, $88.6 \%(62)$ of the participants identified themselves as

Caucasian, while 7.1\% (5) identified themselves as African-American and $4.3 \%$ (3)

identified themselves as Asian-American.

Table 4.1

Total Sample by Gender, Age, Grade, and Ethnicity $(N=70)$

\begin{tabular}{|c|c|c|}
\hline & Frequency & Percent \\
\hline \multicolumn{3}{|l|}{ Gender } \\
\hline Male & 35 & 50.0 \\
\hline Female & 35 & 50.0 \\
\hline Total & 70 & 100.0 \\
\hline \multicolumn{3}{|l|}{ Age } \\
\hline 14 & 8 & 11.4 \\
\hline 15 & 14 & 20.0 \\
\hline 16 & 21 & 30.0 \\
\hline 17 & 19 & 27.1 \\
\hline 18 & 8 & 11.4 \\
\hline Total & 70 & 100.0 \\
\hline \multicolumn{3}{|l|}{ Grade } \\
\hline 9 & 12 & 17.1 \\
\hline 10 & 20 & 28.6 \\
\hline 11 & 23 & 32.9 \\
\hline 12 & 15 & 21.4 \\
\hline Total & 70 & 100.0 \\
\hline \multicolumn{3}{|l|}{ Ethnicity } \\
\hline African American & 5 & 7.1 \\
\hline Caucasian & 62 & 88.6 \\
\hline Asian American & 3 & 4.3 \\
\hline Total & 70 & 100.0 \\
\hline
\end{tabular}


Ego Development - Research Question One

The construct of ego development was measured using the 18-item short-form version of the WUSCT, with each participant completing the appropriate gender specific form. The WUSCTs were scored by the author and another doctoral candidate after participating in the self-training procedures outlined in Measuring Ego DevelopmentSecond Edition (Hy \& Loevinger, 1996), and confirming inter-rater reliability with an expert rater. A 93.8\% agreement rate across 18 stems was established between Rater 1 and Rater 2, with a $90 \%$ agreement for TPR.

As outlined in chapter two, ego levels for the WUSCT range from the Impulsive level (E2) to the Integrated level (E9). Research question one asked, "What are the ego development levels of gifted adolescents as measured by the WUSCT?" The results of the WUSCT $(M=5.31, S D=.941, M d n=5.00$, Mode $=5)$ indicated that scores for the sample population ranged across five levels, from the Self-protective level (E3) to the Individualistic level (E7). The frequency and percentage of scores for the sample population are displayed in Table 4.2. The Self-protective level (E3) represented the smallest group in the sample with just four respondents (5.7\%). The Conformist level (E4) was represented at $8.6 \%(N=6)$. The highest numbers were found in the Selfaware level (E5) with $41.4 \%(N=29)$ of the respondents. There were also a high number of respondents scoring at the Conscientious level (E6), 37.1\% ( $N=26)$. A small number of the research sample, $7.1 \%(N=5)$ were found at the Individualistic level (E7). There were no respondents either at the lowest level, Impulsive (E2) or at the two highest levels, Autonomous (E8) and Integrative (E9). 
While the WUSCT was developed by Loevinger (1976) and normed on a population of women, it has since been revised for use with men and women across a wide age range (Loevinger, 1985). While these norms were not specifically reported in different age ranges such as childhood, adolescence, and adulthood, they do provide a comparison sample that has been widely used in the research literature. In this revision (1985), the mean ego score was found to be $5.75(S D=1.46)$ for women and 5.58 $(S D=1.25)$ for men, with an overall mean equal to 5.68. Table 4.3 illustrates the distribution of mean ego scores for the current sample according to gender.

Table 4.2

Ego Developmental Level of Gifted Adolescents $(N=70)$

\begin{tabular}{cll}
\hline Ego Level & Frequency & Percent \\
\hline E3 Self-Protective & 4 & 5.7 \\
E4 Conformist & 6 & 8.6 \\
E5 Self-Aware & 29 & 41.4 \\
E6 Conscientious & 26 & 37.1 \\
E7 Individualistic & 5 & 7.1 \\
Total & 70 & 100.00 \\
\hline
\end{tabular}


Table 4.3

Washington University Sentence Completion Test $(N=70)$

\begin{tabular}{llll}
\hline Instrument & N & Mean & SD \\
\hline WUSCT & 70 & 5.31 & \\
Sample & 35 & 5.51 & .941 \\
$\quad$ Female & 35 & 5.11 & .853 \\
Male & 804 & 5.68 & .993 \\
Loevinger (1985) & 350 & 5.75 & \\
Female & 454 & 5.58 & 1.46 \\
Male & & 1.25 \\
\hline
\end{tabular}

Dabrowskian Developmental Level - Research Question Two

Dabrowskian developmental level was measured using the revised Definition

Response instrument (DRI) and scored following the procedures outlined in the revised Miller Assessment Coding System (MACS) Manual (Miller, 1991). The DRI is a six item, free response questionnaire developed by Gage, Morse, and Piechowski (1981) for determining an individual's level of development relative to Dabrowski's TPD. The six questions attempt to elicit themes that underlie six of the most critical of the thirty dynamisms described by Dabrowski as relevant to an individual's developmental potential and developmental growth (Dabrowski \& Piechowski, 1977). Those six themes include: (1) Susceptibility to the influence of others, (2) Personal Conflict, (3) Inferiority, (4) Dissatisfaction, (5) Self-Observation, and (6) Personality Ideal. Table 4.4 illustrates primary themes and subcategories at each level. 
Table 4.4

Miller Assessment Coding System (Miller, 1991)

\begin{tabular}{llccc}
\hline Level of Development & $\begin{array}{c}\text { Feelings toward } \\
\text { Values }\end{array}$ & $\begin{array}{c}\text { Feelings toward } \\
\text { Self }\end{array}$ & $\begin{array}{c}\text { Feelings toward } \\
\text { Others }\end{array}$ \\
\hline I & Primary Integration & Self-serving & Egocentric & Superficial \\
II & Unilevel Disintegration & Stereotypical & Ambivalent & Adaptive \\
III & $\begin{array}{l}\text { Spontaneous Multilevel } \\
\text { Disintegration }\end{array}$ & Individual & Inner conflict & Interdependent \\
IV & $\begin{array}{l}\text { Organized Multilevel } \\
\text { Disintegration }\end{array}$ & Universal & Self-directed & Democratic \\
V & $\begin{array}{l}\text { Secondary Integration } \\
\text { Transcendent }\end{array}$ & Inner peace & Communionistic \\
\hline
\end{tabular}

In using the MACS, each response was rated individually, coded by major theme and then assigned a level according to the corresponding subcategory. Hence, each item was ultimately assigned a numerical value between 1.0 and 5.0. If multiple themes were present within a response, each theme was coded and a numerical average was calculated for that response. Once all items were coded and assigned values, an average level score for the total protocol was calculated (Miller, personal communication 2008). Each protocol was scored by two trained raters and the reported value is an average of the two ratings.

Scores on the DRI produce a developmental index that ranges from 1.0 to 5.0 and represent the five levels of Dabrowski's TPD, with higher scores indicating growth towards higher levels of development. A developmental index below 1.5 indicates developmental Level I. An index score between 1.5-2.49 indicates Level II, while an 
index score between $2.5-3.49$ indicates Level III. Level IV index scores fall between 3.5 - 4.49 and an index score greater than a 4.5 is indicative of Level $V$ development (Lysy, 1979; Miller, personal communication, 2009).

Research question two asked, "What are Dabrowskian developmental levels of gifted adolescents, as measured by the DRI?" The results of the DRI for the 70 respondents in the current study $(M=2.0, S D=.527, M d n=2.0)$ indicated that scores for the sample population ranged across four levels, from Level I-Primary Integration $(1.0-1.49)$ to Level IV - Organized Multilevel Disintegration (3.5 - 4.49), with our sample having scores ranging from 1.0 to 3.83. The frequency and percentage of scores for the sample population are displayed in Table 4.5. A number of respondents $(N=13$, 18.6\%) had developmental indices indicative of Level I - Primary Integration. Level II Unilevel Disintegration represented the majority of the respondents $(N=49,70 \%)$. A small number of respondents $(N=6,8.6 \%)$ scored within Level III - Spontaneous Multilevel Disintegration, and 2 respondents had developmental index scores that indicated Level IV - Organized Multilevel Disintegration. 
Table 4.5

Dabrowskian Developmental Level of Gifted Adolescents $(N=70)$

\begin{tabular}{lccc}
\hline Level of Development & DRI score & Frequency & Percent \\
\hline I- Primary Integration & $1.0-1.49$ & 13 & 18.6 \\
& & 13 & 18.6 \\
\cline { 2 - 4 } II - Unilevel Disintegration & $1.5-1.99$ & 23 & 32.9 \\
& $2.0-2.49$ & 26 & 37.1 \\
& & 49 & 70 \\
\cline { 2 - 4 } III - Spontaneous Multilevel & $2.5-2.99$ & 4 & 5.7 \\
Disintegration & $3.0-3.49$ & 2 & 2.9 \\
& & 6 & 8.6 \\
\cline { 2 - 4 } IV - Organized Multilevel & $3.5-3.99$ & 2 & 2.9 \\
Disintegration & $4.0-4.49$ & 0 & 0 \\
& & 2 & 2.9 \\
\hline Total & & 70 & 100 \\
\hline
\end{tabular}

Only a small number of studies utilizing the DRI can be found in the literature, many of which focus on establishing and confirming the validity of the instrument. Therefore, no normative samples have been found with which to compare these results. Behavioral Characteristics - Research Question Three

The Clinical Assessment of Behavior - Teacher Rating scale (CAB-T) was used to assess the emotional and behavioral characteristics exhibited by the participants within the school environment. A computerized scoring program yields T-scores across a number of domains, those that were of primary value for the purpose of this inquiry included the CAB total scale score (CBI), the Internalizing Behaviors (INT) scale, and the 
Externalizing Behaviors (EXT) scale. Other scales of interest for the current study include the Social Skills (SOC) scale, the Competence (COM) scale, and the Gifted and Talented (GAT) scale. The INT subscale measures behaviors that comprise the CAB's Anxiety and Depression clusters, while the EXT subscale measures behaviors that comprise the CAB's Anger, Aggression, Bullying, and Conduct Problems clusters. The SOC scale and the COM scale are adaptive scales that measures behaviors comprising the CAB's Executive Function and Gifted and Talented clusters. The GAT proposes to add a "unique behavioral component to the identification and assessment of gifted and talented students" (Bracken \& Keith, 2004, p. 25). Table 4.6 provides a summary of the data.

The CBI provides a total summation of all of the items and "represents the best estimate of the examinee's overall level of adjustment" (Bracken \& Keith, 2004, p. 19). For the $\mathrm{CBI}$ scale, scores between $0-59$ reflect overall behavioral adjustment that is considered within the normal range. According to Bracken and Keith (2004), "it may seem counterintuitive that scores significantly below the normative mean would be considered normal on the Clinical scales and clusters, but such scores represent an overall level of behavioral adjustment that is relatively free of difficulties or problems" (p. 19). Therefore, all clinical scale and cluster scores (CBI, INT, and EXT) below a T-score of 60 are considered favorably as an indication of relatively normal or healthy levels of adjustment. T-scores for these scales and clusters between $60-69$ indicate "mild clinical risk," from 70-79 "significant clinical risk," and scores greater than 80 indicate "very significant clinical risk." On the adaptive scales and clusters (SOC, COM, and GAT), high T-scores are interpreted as reflecting good overall adaptive functioning or adaptive 
strengths. Conversely, scores below the normal range suggest adaptive behavioral weaknesses.

Table 4.6

Selected Behavioral Characteristics of Gifted Adolescents $(N=70)$

\begin{tabular}{lcccccc}
\hline Clinical Assessment of Behavior Scale & Mean & Median & Mode & SD & Range \\
\hline Behavioral Index (CBI) & 42.01 & 41.00 & 40 & 6.57 & $28-58$ \\
Internalizing Behaviors (INT) & 41.66 & 40.00 & 35 & 8.23 & $26-72$ \\
Externalizing Behaviors (EXT) & 40.43 & 40.00 & 33 & 6.76 & $29-56$ \\
Social Skills (SOC) & 56.97 & 58.00 & 59 & 7.26 & $42-72$ \\
Competence (COM) & 56.97 & 57.00 & 53 & 8.71 & $36-80$ \\
Gifted and Talented (GAT) & 57.03 & 57.50 & 65 & 7.52 & $39-74$ \\
\hline
\end{tabular}

Research question three asked, "What are the exhibited behavioral characteristics of gifted adolescents in the school context, as indicated by teacher responses on the CAB-T? " Behavioral Index (CBI) scores from our respondents indicate an overall healthy and adaptive level of functioning $(M=42.01, S D=6.57, M d n=41.00$, Mode $=40$ ), with no CBI scores in the clinical risk range. Internalizing (INT) scores ranged from $26-72$, thus a few respondents $(N=3)$ scored within the clinical risk range. However, the overall INT scores were within the normal range $(M=41.66, S D=8.23$, $M d n=40.00$, Mode $=35)$. Externalizing $(E X T)$ scores ranged from $29-56$ with all respondents falling within the normal range $(M=40.43, S D=6.76, M d n=40.00$, Mode $=33$ ). The participants in the current study averaged at the high end of the 
normal range for Social Skills (SOC), Competence (COM), and Gifted and Talented (GAT) behaviors, a finding in line with the specific population and sample focused upon in this inquiry. Social Skills (SOC) scores $(M=56.97, S D=7.26, M d n=58.00$, Mode $=59)$ ranged from $42-72$, Competence (COM) scores $(M=56.97, S D=8.71, M d n=57.00$, Mode $=53)$ ranged from $36-80$, and Gifted and Talented $(G A T)$ scores $(M=57.03$, $S D=7.52, M d n=57.50$, Mode $=65)$ ranged from $39-74$.

\section{Data Analysis Specific to Research Hypotheses}

This investigation incorporated five general research hypotheses that evolved from the literature pertaining to the theoretical constructs of ego development and Dabrowski's theory of positive disintegration as they relate to the behavioral characteristics of gifted adolescents. The participants' responses to selected instrumentation regarding these constructs were scored and analyzed in order to test the following hypotheses. When appropriate, multivariate analyses of variance (MANOVAs) and follow-up univariate analyses of variance (ANOVAs) were conducted to test for the effects of gender, age, ethnicity, grade, and school attending on the stated research hypotheses. While these do not enable the determination of causation, such analyses permit a greater understanding of the nature of phenomenon by identifying those factors with which it occurs (Grimm \& Yarnold, 2006). Hypothesis One

The range and distribution of gifted adolescents' levels of ego development as measured by the Washington University Sentence Completion Test (WUSCT) will not differ significantly from established adolescent norms. 
In an attempt to address the issue of the applicability of Loevinger's

developmental model and scoring manual to children and adolescents, Westenberg et al. (1998) embarked upon a large-scale examination of studies conducted with an adolescent population that specifically focused on ego development and supported the cross-age and cross-national validity of ego development theory. They followed this examination with two subsequent studies of children, adolescents, and young adults aged $8-25$ from both inpatient and outpatient settings. The results were broken down into three age cohorts; the distribution of subjects from the relevant age cohort, $13-18$ $(N=1144)$, is presented in Table 4.7 alongside the current study data.

Also presented in Table 4.7 are the results from a more recent study (Bursik \& Martin, 2006) that examined the relationship between ego development and academic achievement for a group of adolescent students $(N=142)$ from a public high school in setting similar to that of our study. In the Bursik and Martin (2006) study, the sample of 64 male students and 78 female students ranged in age from $15-19(M=16.4)$. The ethnic breakdown of this sample (Caucasian - 89\%, Hispanic - 4\%, African American $1 \%$, and Asian American - $2 \%$, with $4 \%$ not indicating their race) was also very similar to the ethnic distribution in the current study sample (Caucasian - 89\%, African American 7\%, and Asian American - 4\%). 
Table 4.7

Distribution of Ego Levels: Comparison of Adolescent Samples

\begin{tabular}{llllllllll}
\hline Sample & E2 & E3 & E4 & E5 & E6 & E7 & Mean & SD \\
$\%$ & & & & & & &
\end{tabular}

Westenberg et al. (1998)

Age $13-18(N=1144)$

6.6

30

$42.5 \quad 16.6$

$3.3<1$

3.79

Bursik and Martin (2006)

Ages $15-19(N=142)$

$\begin{array}{llll}7.7 & 20.4 & 22.5 & 36.6\end{array}$

$12<1$

4.27

1.17

Current Study - Bailey (2009)

Ages $14-18(N=70)$

8.

41.

37.1

7.1

$5.31 \quad .941$

Examination of the current study data demonstrated a normal distribution of ego development levels with a slight negative skewness (skewness = -.569); the Mean for the current study data was $5.31(S D=.941)$. While the Bursik and Martin $(2006)$ sample also demonstrated a normal distribution of ego developmental levels with a slight negative skewness (skewness $=-.266$ ), the Mean for that sample was 4.27 $(S D=1.17)$, more than a full level beneath our sample. The Mean for the Westenberg, et al (1998) sample was 3.79, significantly lower than the current sample $(M=5.31)$. Thus, the first hypothesis was not supported.

Hypothesis Two

There will be a moderate positive correlation between gifted adolescents' stage of ego development as measured by the Washington University Sentence Completion 
Test (WUSCT) and their Dabrowskian developmental level as measured by the Definition Response Instrument (DRI).

Statistical analyses using a Pearson product moment correlation were conducted to examine the relationship between DRI scores and WUSCT scores as measured by both the summed protocol scores (SUM SCT) and the total protocol rankings (TPR SCT). A significant positive correlation at the .05 alpha level was not found between scores on the DRI and the summed protocol WUSCT scores $(r=.221, p=.066)$ or between scores on the DRI and the total protocol WUSCT rankings $(r=.165, p=.173)$.

An initial multivariate analysis of variance (MANOVA) was conducted to assess for possible effects one or more of the independent variables may have on the dependent variables, and to guard against Type I error (Grimm \& Yarnold, 2006). Wilks' lambda was chosen as the test statistic, and results of the MANOVA indicated significant differences for males and females, as well as for School A and School B. Thus, follow-up univariate analyses of variance (ANOVAs) were conducted.

A one-way analysis of variance (ANOVA) on the SUM SCTs indicated a significant gender difference in ego development, $F(1,69)=4.209, p<.05$. An ANOVA on the DRI scores also found a significant gender difference in Dabrowskian developmental level, $F(1,69)=9.021, p<.01$. Further ANOVAs revealed significant school differences in ego development as measured by both the SUM SCTs $(F=8.105, p<.01)$ and the TPR SCTS $(F=4.097, p<.05)$, as well as a significant school difference in Dabrowskian developmental level as measured by the DRI $(F=7.511, p<.01)$. Thus, bivariate correlational analyses were run to examine the relationships between DRI scores and 
SUM SCT and TPR SCT scores while controlling for school and gender. No statistically significant correlations were found. Table 4.8 summarizes the differences between SUM SCT, TPR SCT, and DRI scores by both gender and school. No other factors were found to significantly impact the DRI, SUM SCT and TPR SCT scores. The second hypothesis was not confirmed by the research data.

Table 4.8

Differences in Ego Development and Dabrowskian Developmental Level by Gender and School

\begin{tabular}{llll}
$\begin{array}{l}\text { Female } \\
(N=35)\end{array}$ & $\begin{array}{l}\text { Male } \\
(N=35)\end{array}$ & $\begin{array}{l}\text { School A } \\
(\text { Female }=15, \\
\text { Male }=16)\end{array}$ & $\begin{array}{l}\text { School B } \\
(\text { Female }=20, \\
\text { Male =19) }\end{array}$ \\
\hline
\end{tabular}

$\begin{array}{lllll}\text { Ego Development } & & & & \\ \text { Mean SUM SCT } & 91.06 & 87.11 & 86.10 & 91.46 \\ \text { (SD) } & (7.61) & (8.45) & (6.56) & (8.71) \\ \text { Mean TPR SCT } & 5.51 & 5.11 & 5.06 & 5.51 \\ (S D) & (.853) & (.993) & (.814) & (.997)\end{array}$

Dabrowskian Development

\begin{tabular}{lllll} 
Mean DRI & 2.18 & 1.82 & 1.81 & 2.14 \\
$(S D)$ & $(.596)$ & $(.377)$ & $(.507)$ & $(.501)$ \\
\hline
\end{tabular}

Hypothesis Three

There will be a significant positive correlation between gifted adolescents' ego development as measured by the Washington University Sentence Completion Test (WUSCT) and their degree of internalizing behavior as measured by the Clinical Assessment of Behavior (CAB). 
Statistical analyses using a Pearson product moment correlation were conducted to examine the relationship between the $C A B$ Internalizing Behavior Scale (INT) and the WUSCT scores as measured by both the SUM SCT and TPR SCT ratings. A significant positive correlation at the .05 alpha level was not found either between CAB INT scores and SUM SCT scores $(r=-.011, p=.930)$ or between CAB INT scores and TPR SCT scores $(r=.031, p=.799)$. A multivariate analysis of variance (MANOVA) was conducted to determine the significance of the demographic variables gender, age, ethnicity, grade, and school on the CAB INT Score. No significant differences were found. However, earlier MANOVA and follow-up ANOVAs indicated a significant gender difference in ego development, $F(1,69)=4.209, p<.05)$ and significant school differences in ego development as measured by both the SUM SCTS $(F=8.105, p<.01)$ and the TPR SCTS $(F=4.097, p<.05)$. Thus, correlational analyses were run to examine the relationships between CAB INT scores and SUM SCT and TPR SCT scores while controlling for school and gender. A summary of the mean CAB INT scores for each of these groups is presented in Table 4.9.

Table 4.9

Differences in Clinical Assessment of Behavior Internalizing Scores by Gender and School

\begin{tabular}{ccccc}
\hline & $\begin{array}{r}\text { School A } \\
(N=31)\end{array}$ & \multicolumn{2}{c}{$\begin{array}{c}\text { School B } \\
(N=39)\end{array}$} \\
\hline CAB Internalizing Behaviors & Mean & SD & Mean & SD \\
Females $(N=15, N=20)$ & 45.27 & 10.131 & 40.90 & 6.569 \\
Males $(N=16, N=19)$ & 39.75 & 6.039 & 41.21 & 9.432 \\
\hline
\end{tabular}


No significant correlations were found when controlling for gender. When controlling for school, a significant positive correlation $(r=.452, p=.011)$ was found for students from School A between the CAB INT score and the SUM SCT score, as well as for between CAB INT and the TPR SCT score $(r=.386, p=.032)$. Thus, hypothesis three was only confirmed for students at School A.

Hypothesis Four

There will be a significant negative correlation between gifted adolescents' ego development and their degree of externalizing behavior as measured by the Clinical Assessment of Behavior (CAB-T).

Statistical analyses using a Pearson product moment correlation were conducted to examine the relationship between the CAB Externalizing Behavior Scale (EXT) and the WUSCT scores as measured by both the SUM SCT and TPR SCT ratings. A significant positive correlation at the .05 alpha level was not found either between CAB EXT scores and SUM SCT scores $(r=-.131, p=.279)$ or between CAB EXT scores and TPR SCT sCores $(r=-.140, p=.248)$. A multivariate analysis of variance (MANOVA) was conducted to determine the significance of the demographic variables gender, age, ethnicity, grade, and school on the CAB EXT Score. No significant differences were found. However, as previously outlined, earlier MANOVA and follow-up ANOVAs indicated a significant gender difference in ego development, $F(1,69)=4.209, p<.05)$ and significant school differences in ego development as measured by both the SUM SCTs $(F=8.105, p<.01)$ and the TPR SCTs $(F=4.097, p<.05)$. Thus, correlational analyses were run to examine the relationships between CAB EXT scores and SUM SCT and TPR SCT scores while 
controlling for school and gender. A summary of the mean CAB EXT scores for each of these groups was presented in Table 4.10.

Table 4.10

Differences in Clinical Assessment of Behavior Externalizing Scores by Gender and School

\begin{tabular}{ccccc}
\hline & $\begin{array}{r}\text { School A } \\
(N=31)\end{array}$ & \multicolumn{2}{c}{$\begin{array}{c}\text { School B } \\
(N=39)\end{array}$} \\
\hline CAB Externalizing Behaviors & Mean & SD & Mean & SD \\
Females $(N=15, N=20)$ & 43.00 & 6.590 & 40.15 & 6.098 \\
Males $(N=16, N=19)$ & 39.50 & 6.000 & 39.47 & 8.058 \\
\hline
\end{tabular}

No significant correlations were found when controlling for school. When controlling for gender, a significant negative correlation $(r=-.342, p=.044)$ was found for males between the CAB EXT score and the TPR SCT score, but this was not found to be significant for the SUM SCT score $(r=-.264, p=.104)$. Thus, hypothesis four was only confirmed for males on the WUSCT total protocol ratings (TPR SCT). Hypothesis four was not confirmed for females, or for the WUSCT summed scores (SUM SCT). Hypothesis Five

There will be a normal distribution of behaviors exhibited by gifted adolescents as measured by the Clinical Assessment of Behavior (CAB-T).

The Clinical Behavior Index (CBI), which provides a total scale score and "represents the best estimate of the examinee's overall level of adjustment" (Bracken \& Keith, 2004, p. 19), was used in examining this hypothesis. The respondents' distribution on this scale is illustrated in Figure 4.1. Statistical information for the 
distribution of the CBI along with that of the relevant subscales, (INT, EXT, SOC, and COM), is presented in Table 4.11.

Figure 4.1

Distribution of Clinical Behavioral Index (CBI) scores for Gifted Adolescents

Histogram

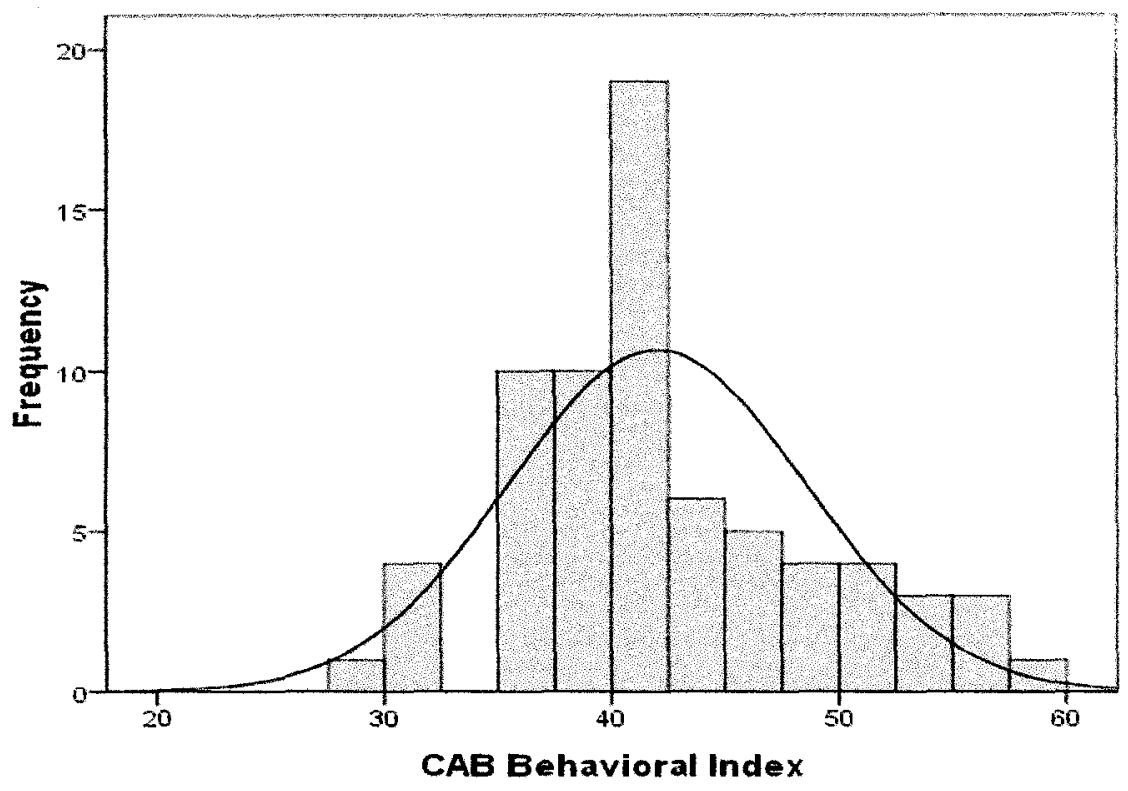

Mean $=42.01$
Std. Dev. $=15.560$

Skewness was calculated to determine the extent to which the distribution of

values deviates from symmetry around the mean. A zero $(0)$ value represents an evenly balanced distribution while a positive skewness indicates a greater number of smaller values and a negative skewness a greater number of higher values (George \& Mallory, 2007). In the current study sample the skewness for the Clinical Behavior Index (CBI) was .494, indicating that our sample had a higher percentage of low CBI scores relative to the norm. As the CAB scores are given as T-scores, this is also evidenced by the sample mean $(M=42.01)$ which is beneath the normed mean $(M=50)$. However, a 
"value between \pm 1.0 is considered excellent for most psychometric purposes, but a value between \pm 2.0 is in many cases also acceptable" (George \& Mallory, 2007, p. 99). Kurtosis was calculated to determine the "peakedness" or the "flatness" of the distribution. As with skewness, a kurtosis value between \pm 1.0 is considered excellent (George \& Mallory, 2007). In the current study sample the kurtosis for the Clinical Behavior Index ( $\mathrm{CBI})$ was -.125 . Therefore, the skewness and kurtosis values for our sample do not indicate that it falls outside of the parameters of a normal distribution. Thus, hypothesis five is supported by the data for the current sample.

Table 4.11

Distribution of Behaviors Exhibited by Gifted Adolescents as Measured by the Clinical Assessment of Behavior $(N=70)$

\begin{tabular}{lccccccc}
\hline & Mean & Median & Mode & SD & Range & Skewness & Kurtosis \\
\hline Behavioral Index (CBI) & 42.01 & 41.00 & 40 & 6.57 & $28-58$ & .494 & -.125 \\
Internalizing Behaviors (INT) & 41.66 & 40.00 & 35 & 8.23 & $26-72$ & 1.202 & 2.830 \\
Externalizing Behaviors (EXT) & 40.43 & 40.00 & 33 & 6.76 & $29-56$ & .295 & -.575 \\
Social Skills (SOC) & 56.97 & 58.00 & 59 & 7.26 & $42-72$ & -.352 & -.286 \\
Competence (COM) & 56.97 & 57.00 & 53 & 8.71 & $36-80$ & .038 & .113 \\
Gifted and Talented (GAT) & 57.03 & 57.50 & 65 & 7.52 & $39-74$ & -.318 & -.335 \\
\hline
\end{tabular}

\section{Additional Findings}

Analyses of the distribution of the current study sample on the related behavioral scales revealed that the Externalizing scale $(M=40.43$, skewness $=.295$, kurtosis $=-.575)$, the Social Skills scale $(M=56.97$, skewness $=-.352$, kurtosis $=-.286)$, the Competence scale $(M=56.97$, skewness $=.038$, kurtosis $=.113)$, and the Gifted and 
Talented scale $(M=57.03$, skewness $=-.318$, kurtosis $=-.335)$ all were consistent with a normally distributed sample. However, the Internalizing scale $(M=41.66$, skewness $=1.202$, kurtosis $=2.830$ ) appeared much more positively skewed with a much more peaked distribution as is illustrated in Figure 4.2, falling outside the acceptable range of a normal distribution.

Figure 4.2

Distribution of Internalizing Behavior (INT) scores for Gifted Adolescents

\section{$C A B$ Internalizing}

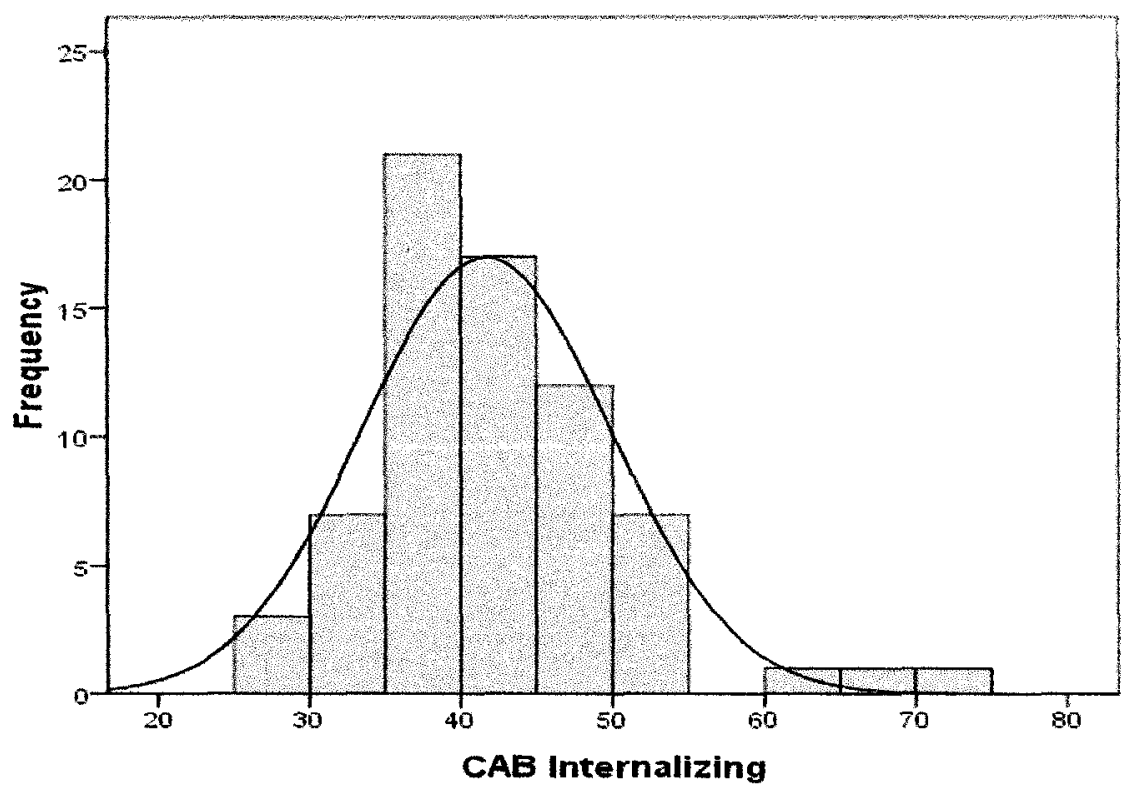

Mean $=41.66$
std. Dev $=8.23$
$N=70$

In order to gain a more comprehensive understanding of the current study sample, additional analyses were conducted to assess for possible relationships not considered in the original hypotheses. Pearson product moment correlations were run between all variables and examined for potential significant relationships. A summary of those relevant to the current study is provided in Table 4.12. 
Table 4.12

Significant Correlations among Demographic and Measurement Variables $(N=70)$

\begin{tabular}{|c|c|c|}
\hline & Pearson $r$ & Significance $p$ \\
\hline \multicolumn{3}{|l|}{ Gender * } \\
\hline with Ego (SUM SCT) & -.241 & .044 \\
\hline with Dabrowskian Development (DRI) & -.342 & .004 \\
\hline with $\mathrm{CAB}$ - Behavioral Index (CBI) & -.300 & .012 \\
\hline with CAB - Competence scale (COM) & .267 & .025 \\
\hline with CAB - Gifted and Talented (GAT) & .314 & .008 \\
\hline \multicolumn{3}{|l|}{ Age } \\
\hline with $\mathrm{CAB}$ - Competence scale (COM) & -.260 & .030 \\
\hline \multicolumn{3}{|l|}{ School** } \\
\hline with Ego (SUM SCT) & .326 & .006 \\
\hline with Ego (TPR SCT) & .238 & .047 \\
\hline with Dabrowskian Development (DRI) & .315 & .008 \\
\hline \multicolumn{3}{|l|}{ Ego Development } \\
\hline SUM SCT with TPR SCT & .931 & .000 \\
\hline SUM SCT with Gender & -.241 & .044 \\
\hline SUM SCT with School & .326 & .006 \\
\hline TPR SCT with School & .238 & .047 \\
\hline \multicolumn{3}{|l|}{ Dabrowskian Developmental Level (DRI) } \\
\hline with Gender & -.342 & .004 \\
\hline with School & .315 & .008 \\
\hline with $\mathrm{CAB}$ - Behavioral Index (CBI) & .252 & .036 \\
\hline with CAB - Gifted and Talented (GAT) & -.240 & .045 \\
\hline \multicolumn{3}{|l|}{ Clinical Assessment of Behavior } \\
\hline CBI with Gender & -.300 & .012 \\
\hline CBI with DRI & .252 & .036 \\
\hline COM with Age & -.260 & .030 \\
\hline COM with Gender & .267 & .025 \\
\hline GAT with Gender & .314 & .008 \\
\hline GAT with DRI & -.240 & .045 \\
\hline
\end{tabular}

* Negative correlations reflect toward females, Positive correlations reflect toward males

** Negative correlations reflect toward School A, Positive correlations reflect toward School B 
As gender and school were found to significantly impact ego development as measured by the SUM SCT and Dabrowskian developmental level as measured by the DRI follow-up analyses were run controlling for each of these variables. In further examining the relationship between Dabrowskian developmental level (DRI) and Internalizing Behaviors (INT) while controlling for gender, a significant relationship was found for males $(r=.355, p=.036)$, but not for females $(r=-.014, p=.935)$. In examining this relationship between DRI and INT while controlling for school, a significant relationship was found for School A $(r=.385, p=.033)$, but not for School B $(r=.036, p=.828)$.

The mean differences between these groups on Internalizing Behaviors have been illustrated in Table 4.9 and the differences on ego development and Dabrowskian developmental level have been illustrated in Table 4.8. In analyzing the relationship between Dabrowskian developmental level (DRI) and Gifted and Talented Behaviors (GAT) as measured by the CAB, a straightforward Pearson product moment correlation shows a significant negative relationship $(r=-.240, p=.045)$. However, when examining this relationship while controlling for gender and school, no significant correlations are found. This pattern was also found when examining DRI in relation to the $C A B$ Behavioral Index (CBI). While a straightforward Pearson product moment correlation shows a significant positive relationship $(r=.252, p=.036)$, no significant correlations were found when controlling for gender and school. 


\section{Summary}

This chapter provided a description of the sample population that participated in the current research study on a number of demographic variables and reported the sample means for each of the areas under investigation. The results of correlation analyses examining the nature of relationships between the variables were presented. This chapter also reported the results of the data analysis procedures, including Pearson product moment correlation, multiple analyses of variance (MANOVAs), and one-way analyses of variance (ANOVAs) used in testing the research hypotheses. The following chapter will provide a discussion of the results relative to the research literature on ego development, development as related to Dabrowski's theory of positive disintegration, and the behavioral characteristics of gifted adolescents. It will also address limitations of the study, possible implications, and suggestions for future research. 


\section{Chapter Five}

\section{Discussion and Conclusion}

\section{Introduction}

Results of this study contribute to the understanding of developmental theories as they relate to the experience of gifted individuals during adolescence. This chapter presents a discussion of the results from the study and how they impact the current literature in the field regarding ego development, Dabrowski's theory of positive disintegration and the behavioral characteristics of gifted adolescents. It begins with a brief overview of the study and a review of the research methodology. The results of the research questions and hypotheses are discussed in terms of the major constructs and in light of the literature reviewed in chapter two. Possible limitations of the study, implications of the findings, and potential avenues for future research are discussed. Overview of the Study

The focus of this study was to examine the relationship among ego development, development as related to Dabrowski's theory of positive disintegration, and behavior exhibited by gifted adolescents. While numerous researchers have discussed uneven development, or asynchronous development, as a universal characteristic of giftedness (Delisle, 1990; Dockery, 2005; Neihart et al., 2002; Silverman, 2007; Sword, 2003) in-depth examinations of gifted students' experiences in specific developmental domains has been limited. Also often discussed in the literature concerning gifted students are the unique social, emotional, and behavioral characteristics innate to the gifted population (Colangelo \& Assouline, 2000; Cross, 
2002; Lovecky, 1992; Webb, 2005). However, there is still an unclear picture concerning the implications of this work as related to the specific counseling needs of gifted students. One perspective researchers argue is that gifted students are as well adjusted, or better adjusted than their typical peers, while the other researchers highlight the specific vulnerabilities and challenges faced by this population (Colangelo \& Assouline, 2000; Robinson, 2002; Silverman, 2005).

Regardless of which perspective one takes, counselors are called to apply "mental health, psychological, or human development principles" that address wellness and personal growth, as well as pathology (ACA, 1997). In addition to typical counseling skills, those who work with gifted clients should have a solid knowledge of the issues facing this population in various contexts (Thomas \& Ray, 2006). Thus, it is imperative for counselors working with this population to seek an understanding of the unique social and emotional issues facing gifted adolescents and their families (Cross, 2001; Moon et al., 1998; Neihart et al., 2002). The National Association for Gifted Children (NAGC) specifies that

Educational and counseling programs must provide all children with opportunities to develop understanding of themselves and their role in society. Because, by definition, gifted children differ significantly from others, these programs should be responding to the social-emotional or affective characteristics that distinguish gifted students from others. Furthermore, since significant differences also exist within the gifted population, appropriate 
services need to be designed and implemented to respond to individual differences. (NAGC, 1995, ๆ 3)

Further, the American School Counseling Association (2005) defines an effective school counseling program as one that is "comprehensive in scope, preventative in design, and developmental in nature" (p. 13) and addresses the needs of all students within the school setting. Thus, it is incumbent upon the counseling profession to develop a greater understanding of this unique population, and to strive to provide these students with services that consider the impact of giftedness on their development and psychological health.

The literature presented in chapter two outlined the current conceptual understandings related to ego development, Dabrowski's theory of positive disintegration, and the social, emotional, and behavioral issues faced by gifted adolescents. In response to the need for more empirical research in exploring the connections between developmental theories and the challenges faced by gifted adolescents, the researcher proposed examining the intersection between these three domains. Ego development enabled a focus upon the social and emotional development of gifted adolescents, and provided a framework for understanding the ways in which gifted adolescents make sense of themselves in relation to others and their social context. Dabrowski's TPD provided a framework for better understanding the sensitivities and overexcitabilities inherent to gifted adolescents and the impact these characteristics may have upon their developmental potential and developmental growth. Hence, this study aimed to examine gifted adolescents' development through 
the domains of both ego development and Dabrowski's conception of developmental growth as frameworks that could provide better understanding of the qualitatively different ways in which gifted students experience and understand the world.

As indicated by Noam (1998), individuals at lower levels of ego development have a tendency to utilize more externalizing coping behaviors, while individuals at higher levels of ego development tend to utilize more internalizing coping behaviors. This study sought to determine if these tendencies hold true for a gifted adolescent population through examining the impact of developmental domains on the specific behaviors exhibited by gifted adolescents in the school setting, thus contributing to the literature a more comprehensive understanding of the strengths, weaknesses and needs of gifted children and adolescents.

This exploratory study consisted of a random sample of 100 students drawn from two regional Governor's Schools in central and eastern Virginia. The sample consisted of students aged $14-18$, and was well distributed across grade and gender. While the sample was primarily Caucasian (88.6\%), this distribution is consistent with the ethnic make-up of the participating schools. The participants completed a general demographic form, the Washington University Sentence Completion Test (WUSCT) short-form, and the Definition Response Instrument (DRI). These instruments were scored and the data was analyzed using Pearson product moment correlations, one-way analyses of variance (ANOVAs), and multivariate analyses of variance (MANOVAs) to test the research hypotheses and provide evidence for the general research questions. The 
results were presented in chapter four. The following section provides a discussion of the research findings.

\section{Discussion of Major Research Findings}

General Research Questions

\section{Ego Development-Research Question One}

As there is little to no data in the research literature examining ego development in gifted populations, the first research question sought simply to establish a baseline understanding of what the ego development levels of gifted adolescents are for the current sample. As this will be discussed again in detail with relation to adolescent samples in Hypothesis One, here we simply present the distribution of scores and attempt to give a general picture of the expression of ego development for the current sample. Participants displayed a normal distribution and ranged across five levels, from the Self-protective level (E3) to the Individualistic level (E7). The range of the distribution is slightly higher than that reported by Westenberg and Gjerde (1999) in a longitudinal study exploring the transition from adolescence to adulthood. Subjects (age $=14$ ) at the beginning of their study, were distributed across four ego levels, ranging from the Self-protective (E3) through the Conscientious (E6) level. The current study findings are only slightly below the norms reported by Loevinger (1985) for a sample of men and women across a much wider age range. Also consistent with Loevinger's (1985) findings, the females in our sample displayed slightly higher $(M=5.51, S D=.853)$ ego scores than the males $(M=5.11, S D=.993)$. Numerous research studies (Bursik, 
1995; Cohn, 1991; Gfellner, 1986; Mabry, 1993) have reported on gender differences in ego development scores, thus our findings are in keeping with the literature.

The Self-protective level (E3) represented the smallest group (5.7\%), the Conformist level (E4) was represented at $8.6 \%$, the Self-aware level (E5) had the highest number of respondents (41.4\%), the Conscientious level (E6) also had a high number of respondents (37.1\%), and a small number of respondents $(7.1 \%)$ were found at the Individualistic level (E7).

While the current study sample had respondents scoring above the range of scores shown by the Westenberg and Gjerde (1999) sample, these scores were still normally distributed across this range. This distribution reinforces Silverman's (2005) description of internal asynchrony. While all of the students in our sample were presumed to have higher than normal levels of intelligence based upon their admittance to competitive Governor's School programs designed to meet the needs of gifted students, not all of our sample displayed higher than normal levels of ego development. Silverman (2005) asserts that intelligence alone is insufficient as a predictor of advanced development and that individuals must have within their personality the capacity to respond emotionally. Along with Piechowski (1992), Silverman (2005) stresses the need for potential to be cultivated and nurtured. Our study data suggests that while gifted individuals may be advanced intellectually, there is definite need to promote ego development for some students. In the adolescent transition longitudinal study, precocious students with higher levels of ego development at age 14, made significantly less progress in comparison with their less advanced peers. Westenberg and Gjerde 
(1999) suggest a developmental paradox and reinforce Silverman's (1997) contention that due to the asynchronous nature of their development, gifted individuals require support and guidance for optimal development to occur.

Dabrowskian Developmental Level - Research Question Two

As initial research exploring the constructs of developmental levels in relation to Dabrowski's theory of positive disintegration involved in-depth case studies, only a small amount of empirical support exists in the literature quantitatively describing the distribution of individuals relative to Dabrowskian developmental levels. Our study provides much to the research literature by providing a comparison sample for future research endeavors. The second research question sought to establish baseline data on the levels of development related to Dabrowski's theory of positive disintegration (TPD) for gifted adolescents as measured by the Definition Response Instrument (DRI).

The results of the DRI indicated that scores for the current study sample were distributed across four levels, from Level I (Primary Integration) through Level IV (Organized Multilevel Disintegration), with scores ranging from 1.0 to 3.83. A number of respondents (18.6\%) had developmental indices indicative of Level I (Primary Integration) while the vast majority of respondents (70\%) had indices indicative of Level II (Unilevel Disintegration). A small number of respondents (8.6\%) scored within Level III (Spontaneous Multilevel Disintegration) and two respondents (2.9\%) had scores indicative of Level IV (Organized Multilevel Disintegration).

While there are no known samples in the literature with which to compare this sample, the data provide a tremendous amount of information regarding the potential 
counseling needs of gifted adolescents. A number of our respondents are still within the Primary Integration (Level I) stage, which Piechowski (2003) describes as being marked by primary mental organizations aimed at gratifying biological needs and conforming to social norms. Individuals at this level will require an extremely different type of intervention to promote developmental growth than those in Dabrowski's Unilevel Disintegration (Level II) stage, the current level for the majority of our sample.

Level II is a critical transition phase in Dabrowski's theory as it is during this phase that the process of positive disintegration begins. Positive disintegration is the process during which the previously held personality structure must come apart in order to be replaced by higher-level personality structures. Dabrowski (1964) stated that "the disintegration process, through loosening and even fragmenting the internal psychic environment, through conflicts within the internal environment and with the external environment, is the ground for the birth and development of a higher psychic structure" (pp. 5-6). He felt that this process, while not always positive in its experience, was essential for the development of higher-level personality structures. He later clarified that not all disintegrative processes are developmental and that "chronic disintegration of mental functions is associated with negative disintegration" (Dabrowski \& Piechowski, 1996, p. 13), the results of which can be serious mental illness and suicide (Ackerman, 2009).

Autobiographical research (Mróz, 2009) has shown that while these disintegrative processes may originate earlier in life, it is often during adolescence when they surface as defenses against negative emotions or as attempts to compensate for 
frustrated emotional needs. Mróz (2009) stresses that in every case the experience of being understood was an essential component of successfully navigating the transition from Level II to Level III, and that without this support development often stalled and led to much deeper negative emotional experiences. Ackerman (2009) explains that in the process of development, an individual's personality structure is often characterized as bridging more than one level, and that in Dabrowski's theory there is the possibility of regressing to a lower level, even temporarily, given the arduous process of developmental growth. Piechowski (1975) emphasizes that personality development does not progress consistently over time, that there are "periods of great intensity and disequilibrium (psychoneuroses, depression, creative processes), and there are periods of equilibrium" (p. 259). Levels II - IV are characterized by internal and external conflicts, referred to as positive maladjustment by Dabrowski (1972), that are necessary in promoting further developmental growth. It is during this time that the unique vulnerabilities described by many in the field of gifted education (Cross, 2002; Delisle \& Galbraith, 2002; Dockery, 2005; Mendaglio, 2008; Moon \& Reis, 2004; Neihart et al., 2003; Piechowski, 1992; Silverman, 2005; Sword, 2001b; Winner, 1997) may be most evident. That $70 \%$ of our sample population falls within this critical transition period highlights a critical need for appropriate educational and counseling interventions to support these students through this difficult process.

Behavioral Characteristics - Research Question Three

Research question three sought to examine the impact of social and emotional traits of gifted adolescents as they are demonstrated by behavior within the school 
environment. As stated in chapter two, the current literature supports two contrasting views (Neihart, 1999). The first of these views proposes that giftedness enhances resiliency while the second view contends that giftedness increases vulnerabilities. The current study examined the experiences of gifted adolescents in the school environment according to behaviors observed and rated on the Clinical Assessment of Behavior Teacher Rating Scale (CAB-T). This rating scale provides measures of both clinical and adaptive behaviors across a number of subscales, of which the Internalizing (INT), Externalizing (EXT), Social Skills (SOC), Competence (COM), and Gifted and Talented (GAT) scales were chosen as relevant to the current study. The CAB-T also provides a total summation of all of the items that "represents the best estimate of the examinee's overall level of adjustment" (Bracken \& Keith, 2004, p. 19).

Behavioral Index (CBI) scores for our respondents indicated an overall healthy and adaptive level of functioning $(M=42.01, S D=6.57, M d n=41.00$, Mode $=40)$, with no $\mathrm{CBI}$ scores in the clinical risk range. On the CAB-T CBI, INT, and EXT scales, lower scores indicate more adaptive function. Internalizing (INT) scores ranged from $26-72$, thus a few respondents $(N=3)$ scored within the clinical risk range. However, the overall INT scores were within the normal range $(M=41.66, S D=8.23, M d n=40.00$, Mode $=35)$. Externalizing $(E X T)$ scores ranged from $29-56$ with all respondents falling within the normal range $(M=40.43, S D=6.76, M d n=40.00$, Mode $=33)$. For the $S O C$, COM, and GAT subscales, higher scores indicate more adaptive functioning. The participants in the current study averaged at the high end of the normal range for Social Skills (SOC), Competence (COM), and Gifted and Talented (GAT) behaviors, a finding in 
line with the specific population and sample focused upon in this inquiry. Social Skills $(S O C)$ scores $(M=56.97, S D=7.26, M d n=58.00$, Mode $=59)$ ranged from $42-72$, Competence $(C O M)$ scores $(M=56.97, S D=8.71, M d n=57.00$, Mode $=53)$ ranged from 36-80, and Gifted and Talented (GAT) scores $(M=57.03, S D=7.52, M d n=57.50$, Mode $=65)$ ranged from $39-74$

Thus, the data from the current study would seem to support the assertion that giftedness enhances resiliency. However, it is important to note that these scores represent the teachers' perceptions of the students as they view them in the classroom. Both of the schools represented in this study are highly competitive, gifted magnet schools, with rigorous admission criteria. Further, students at the participating schools can choose to attend these academically challenging programs and thus are more likely to fit the behavioral profile outlined above, particularly regarding the SOC, COM, and GAT scales as they are constructed by Bracken and Keith (2004). Bracken and Brown (2006) have proposed use of this instrument in indentifying students well suited for such programs. However, as proposed by Coleman and Cross (1988), some gifted students may be particularly adept at using social coping strategies to fit the expectations of their environment. Thus, while the students in this study do not appear to have significant emotional issues as perceived by their teachers, the data does not provide enough evidence to negate the possibility that the participants are experiencing psychological challenges. Further support for this interpretation are provided by a study of teacher perceptions of gifted adolescents (Greene, 2003) which found that teachers did not 
perceive most internal issues and expressed concerns about their limitations in addressing the social and emotional development of their students.

General Research Hypotheses

\section{Hypothesis One}

Hypothesis one proposed that the range and distribution of gifted adolescents' levels of ego development as measured by the Washington University Sentence Completion Test (WUSCT) would not differ significantly from established adolescent norms. Hypothesis one was not supported by the evidence as significant mean and distribution differences were found between the current study sample and established adolescent norms as reported by Westenberg et al. (1998), and Bursik and Martin (2006). The current sample scores $(M=5.31, S D=.941)$ were 1.5 levels higher than the Westenberg et al. (1998) sample scores were $(M=3.79)$. It is important to note that the Westenberg sample consisted of both typical adolescent students and psychiatric inpatient adolescent students. The current sample scores were also 1.0 level higher than the Bursik and Martin (2006) sample $(M=4.27, S D=.1 .17)$ which was taken from a public high school setting similar to that of our study in all demographics except for the percentage of gifted students, as this school was a typical high school and not a gifted magnet school.

This leads to the question that has been proposed by previous researchers in examining the link between intelligence and ego development. However, it has been concluded that ego development and intelligence are not interchangeable constructs (Cohn \& Westenberg, 2004). Results from the Bursik and Martin (2006) study 
demonstrated that ego level was a significant predictor of academic achievement, after controlling for the effects of intelligence and gender. Thus, it is not surprising that our sample, in which students all attend schools focused on high academic achievement, demonstrates higher ego levels. However, the evidence from our study is not sufficient to support a causal link.

An interesting additional finding in the current study was the significant difference in ego level scores between students at School $A(M=86.10, S D=6.56)$ and students at School $\mathrm{B}(M=91.46, S D=8.71)$. The research design does not provide specific information to determine the exact nature of these differences but there are a number of notable differences between the two schools including the degree of competitiveness for admission, the size of the program, the structure of the school day (half-day versus full-day program), the focus of the program (marine and environmental science versus government and international studies), and the setting of the program (rural versus urban).

Hypothesis Two

Hypothesis two proposed a moderate positive correlation between gifted adolescents' stage of ego development as measured by the Washington University Sentence Completion Test (WUSCT) and their Dabrowskian developmental level as measured by the Definition Response Instrument (DRI). While a slight positive correlation $(r=.221, p=.066)$ was found using the summed protocol scores on the WUSCT, significance was not established, thus hypothesis two was not supported. As analyses indicated significant differences for both gender and school, follow-up analyses 
were conducted while controlling for these variables, but the hypothesis was still not supported by the current study data. Lack of strong correlations indicates that while ego development and development as related to Dabrowski's theory of positive disintegration share similarities, they are two distinct constructs. Ackerman (2009) highlights some of the primary differences between Dabrowski's TPD and other cognitive developmental theories including that it is nonontogenetic, its focus on the role of emotion, its view of psychoneurosis and conflict, and its conception of values. Loevinger's theory of ego development is defined as the "evolution of meanings that the [individual] imposes upon inner experience and perceptions of people and events," and progresses in a "sequence of increasingly mature stages of functioning across the domains of personal relationship, impulse control, moral development, and cognitive style" (Hauser, Powers, \& Noam, 1991, p. 6). Dabrowski's theory of positive disintegration is a "developmental personality theory that describes the factors contributing to development, the process of development, and the characteristics of people at different levels of development" (Ackerman, 2009, p. 81). While ego development is conceptualized as a master trait that describes the way individuals make meaning of their personal life experiences and the world at large, TPD is more about the lived inner experiences and conflicts within an individual, and the impact of those on how an individual is present in the world. Dabrowski's TPD is not necessarily sequential, nor does development always take a positive direction. An understanding of both concepts is critical to understanding and supporting positive developmental growth across domains, as the underlying constructs appear intertwined. The current study 
begins to shed light on possible connections but much more research is needed to delineate the two theories and determine how to best utilize them in constructing appropriate developmental interventions.

Westenberg and Gjerde asked, "If there is a general pull towards the Self-aware level, how then are some individuals able to move beyond this level?" (p. 249). Perhaps components of Dabrowski's TPD, such as overexcitabilities, dynamisms, or the "third factor," are part of what is necessary to move individuals to higher ego levels. Loevinger (1976) saw the transition toward the Conscientious level as a major shift likely dependent upon internal pacers, such as intelligence or personality traits. Further exploration of ego development in conjunction with the traits inherent to Dabrowski's theory of positive disintegration may provide more insight into what is necessary for movement beyond the Self-aware stage.

Hypotheses Three and Four

Hypotheses three and four postulated significant correlations between gifted adolescents' ego development as measured by the Washington University Sentence Completion Test (WUSCT) and their degree of internalizing and externalizing behaviors as indicated by the Clinical Assessment of Behavior Teacher Rating Scale (CAB-T). Initial analyses for both internalizing and externalizing behaviors were not supported. However, as previous analyses had indicated significant gender and school differences for ego development these hypotheses were further explored while controlling for these variables. 
These follow-up analyses indicated a significant positive correlation $(r=.452$, $p=.011$ ) between ego development and Internalizing behaviors (INT) for students from School A. As previously outlined, a number of confounding variables exist in the differences between the two school populations, which hinders the ability to determine the precise nature of this relationship. Research (Hauser \& Safyer, 1994; Noam, 1992) finding higher levels of specific emotions, including anxiety, at more advanced ego stages often utilized self-report measures that may have provided greater access to these internalizing behaviors than the teacher rating scale used in the current study. Further, it is possible that the nature of the relationships between teachers and students differs between the schools, thus impacting the current study results.

Follow-up analyses, controlling for gender and school, also indicated a significant negative correlation $(r=-.342, p=.044)$ between ego development and Externalizing behaviors (EXT) for males, but not females, using the total protocol ratings (TPR SCT). Significant correlations were not found when using the summed protocol ratings (SUM SCT). As the TPR categorizes the sum scores into discrete stages, this may highlight slight differences that are not as pronounced when examining the SUM SCT $(r=-.264$, $p=.104)$. Our findings are consistent with that of Recklitis and Noam (1999) who did not find strong support for a connection between ego development and internalizing/externalizing behavioral distinctions, but did find that a relationship between coping strategies and ego development varied with gender. Our findings support their assertion that different intervention strategies may need to be developed for males in females in promoting ego development. 


\section{Hypothesis Five}

Hypothesis five proposes a normal distribution of behaviors exhibited by gifted adolescents as measured by the Clinical Assessment of Behavior Teacher Rating Scale (CAB-T). As fully illustrated in chapter four, hypothesis five is supported by the data for the current sample. Fully detailed in research question three, Behavioral Index (CBI) scores for our respondents indicated an overall healthy and adaptive level of functioning $(M=42.01, S D=6.57, M d n=41.00$, Mode $=40)$, with no $C B I$ scores in the clinical risk range. Analyses on the normalcy of the distribution of the current sample found that while our sample mean was below the normed mean $(M=50, S D=10)$, that the sample was normally distributed. Please refer back to research question three for discussion.

\section{Additional Findings}

Analyses of the distribution of the current sample on the related behavioral subscales revealed normal distribution of ratings on the Externalizing (EXT), Social Skills (SOC), Competence (COM), and Gifted and Talented (GAT) Scales, with mean ratings at slightly more adaptive levels than the norm. However, ratings on the Internalizing scale (INT) demonstrated a more positively skewed and peaked distribution than a normal distribution. A possible contributor to this finding may be the nature of the teacherstudent relationship at the sample schools. As reported by Greene (2003), teachers were not as aware of internal issues and had concerns related to addressing the social and emotional needs of their students. Data in our sample supported this assertion as the only item consistently left unmarked on the CAB-T response forms loaded on the 
Internalizing (INT) scale, indicating that teachers felt less able to accurately assess the internalizing behaviors of their students.

While not included in the original research hypotheses, analyses were conducted on the relationship between Dabrowskian developmental level as measured by the DRI and both Internalizing (INT) and Externalizing (EXT) behaviors. As gender and school variables were previously found to significantly impact ego development, these variables were controlled in the DRI - INT/EXT analyses as well. Significant relationships were found between Dabrowskian developmental level (DRI) and Internalizing behaviors (INT) for males $(r=.355, p=.036)$ but not females $(r=-.014, p=935)$, and for School A $(r=.385, p=.033)$, but not for School B $(r=.036, p=.828)$. As previously discussed, a number of variables potentially impact the significance of school attending in these relationships. Of interest to the current study are potential explanations and implications of a connection between Dabrowskian level of development and Internalizing behaviors for males but no apparent relationship between these variables for females. The current research literature does not provide sufficient information in attempting to interpret these findings.

An additional finding of particular interest for the current study is the significant negative correlation $(r=-.240, p=.045)$ between Dabrowskian developmental level (DRI) and Gifted and Talented (GAT) behaviors as measured by the CAB-T. Although this relationship did not hold true when gender and school variables were held constant, a contrasting significant positive correlation $(r=.252, p=.036)$, was found when examining the relationship between Dabrowskian developmental level (DRI) and the 
overall Behavioral Index (CBI). This presents a paradox as higher Dabrowskian developmental levels were related to lower scores of gifted and talented behaviors, the opposite of what one might expect in light of Dabrowski's theory and the components comprising developmental potential that are essential to positive developmental growth (Ackerman, 2009). However, individuals at higher Dabrowskian developmental levels, in our sample this consisted of individuals in the midst of the Level II, III, and IV which are stages involving positive disintegration and coinciding inner conflict, were rated as having more adaptive behavioral traits. While this is consistent with the cognitive development assertion that "higher is better" and that higher developmental levels are positively related to adjustment (White, 1985), it is in opposition with what might expect to find when taking into consideration the tremendous inner conflict purported to be necessary to move to these higher levels (Ackerman, 2009).

One potential explanation again involves the image management model proposed by Coleman and Cross (1988) that describes a process in which gifted adolescents utilize social coping strategies to meet the expectations of their environment. This interpretation may indicate that teachers are not adept at recognizing signs of inner distress in some of their students, and/or that some students are adept at concealing this inner distress from those around them. While much more examination is needed to fully understand these findings, it emphasizes the need for counseling interventions to be proactive in reaching out to gifted students and providing them an environment of understanding, acceptance, and validation so that they might feel able to address those troublesome issues they may feel the need to conceal. 


\section{Critique and Limitations}

This exploratory study adds to our understanding of the potential influences of ego development and development as related to Dabrowski's theory of positive disintegration on the unique social, emotional, and behavioral characteristics of gifted adolescents. However, the results must be viewed in light of the confines and potential threats to validity that surround its actual execution. These limitations will be discussed in terms of research design, sampling and instrumentation.

There are limitations inherent to correlational research, most clearly that no assumptions can be made regarding causation (Gall, Gall, \& Borg, 2005). While relationships may exist between one another, the precise nature of this relationship cannot be determined, nor can the influence of external variables be accurately assessed. As the purpose and nature of this study was exploratory, such limitations were anticipated and are not inconsistent with the goal of establishing future research directions.

An ever-present challenge inherent to studying gifted students is the lack of a consistent, unified definition of giftedness (Silverman, 1997). Participants included only those students who were qualified as gifted and talented in the state of Virginia, and only those who met the admissions requirements for, and chose to attend, two specific Governor's School programs. There was no comparison sample of typical adolescents, nor were students identified as gifted but not attending Governor's Schools included in the sample. While the researcher initially contacted five Governor's Schools across the 
state with more varied and diverse foci, only two schools chose to allow their students to be recruited as participants in the current study.

Sampling limitations are many, including the small sample size $(N=70)$, limited diversity of the sample, and potential selection bias. While students contacted to participate were randomly selected from the overall school population, a number of differences may exist between those students who chose to participate and those who did not. Students, and their parents, who were contacted as potential participants were informed of the general nature of the study in the informed consent process; those who chose to participate may have done so out of a particular interest in the study's topic and may differ from those who did not choose to participate. Of particular relevance to this study were the differences in timing and delivery of the measurement instruments. Although a standard procedure was followed in each measurement administration, at School A the researcher was given classroom time to describe the study and administer the instruments. Students could choose whether or not participate, but those students who chose to participate were not sacrificing limited free time or missing classroom instruction. This was not a feasible option at School B. Students who chose to participate at School B were given a much wider range of testing times but had to sacrifice either their study hall, lunch, or after school time, or request permission from a teacher to miss classroom instruction time. As both schools have highly academic foci this difference could have significantly impacted the characteristics of the students who were able to participate. 
Limitations in the measurement instruments may have influenced the study results. The short-form of the Washington University Sentence Completion Test (WUSCT) was chosen in an attempt to keep the overall length of the measurement sessions within a time frame that would work in the school setting. However, this form, especially when combined with the six item, free-response Definition Response Instrument (DRI) still took students a good amount of time to complete, thus a possibility of testing fatigue exists for both instruments. Use of the short-form of the WUSCT was well reasoned, but the short form does lose some reliability compared to the full 36-item protocol. While widely regarded as a valid and reliable instrument (D’Andrea \& Daniels, 1992; Gilmore \& Durkin, 2001), a potential reliability threat regarding the WUSCT involves the scoring of the instrument. Although the protocols were scored by two raters that prepared according to the training process outlined by Hy and Loevinger (1996), they were still novice raters and thus scores may have been affected. An attempt to compensate for this possibility was taken in consulting with an expert rater, but due to time constraints for the expert rater, only a small number of protocols were able to be included in this comparison. Further, as the raters were not blind to the population and hypotheses of the study, a potential threat to construct validity was introduced.

Little empirical evidence regarding the use of the Definition Response Instrument (DRI) exists in the current literature, thus it is difficult to ascertain the implications of the current study results as they pertain to the scores on this instrument. The Miller Assessment Coding System (MACS) was used in conjunction with the DRI as it 
provides more systematic, objective and reliable results than previous scoring methods (Miller, 1991). All instruments were scored by two trained raters and inter-rater reliability established, as reported in chapter three. However, no expert rater was available for establishing independent inter-rater reliability. Further, as both were novice raters and not blind to the study purpose and hypotheses, results were potentially affected.

The Clinical Assessment of Behavior (CAB) has been consistently found to be a valid, reliable instrument (Beran, 2006). As discussed in relation to research question three, the primary concern in the use of the CAB for the current study is if it accurately captured the internal experiences of the gifted adolescents in the current sample.

\section{Implications for Findings}

This study was intended to advance the understanding of developmental theories as they relate to the experience of gifted individuals during adolescence. Specifically examined in the current study were the domains of ego development and development as related to Dabrowski's theory of positive disintegration (TPD). Research has described gifted individuals as experiencing the world from a qualitatively different perspective due to the unique social and emotional characteristics of this population. The current study sought to empirically investigate this assertion through examining the intersections of developmental domains and exhibited behavioral characteristics in gifted adolescents.

The results of this study provide a starting point from which to examine how an understanding of the intersection of these developmental theories and expressed 
behaviors can shape counseling interventions aimed at promoting growth and development in gifted adolescents. The quantitative data presented provide a baseline against which future studies can build. Hence, one immediate direction for future research involves replication studies to verify the results among larger and more diverse samples. Critical to this line of research would be the inclusion of typical, "non-gifted" samples as comparison groups.

It is important to note that this research line does not only provide insight into the gifted population. While Dabrowski's theory of positive disintegration has been most widely discussed in the gifted literature, it is not confined to use with a gifted population. TPD is a complex and nuanced developmental theory that has many components, such as the overexcitabilities, that resonate with the gifted community and are extremely useful in understanding the social and emotional characteristics of gifted individuals. However, as concluded by Ackerman (2009), "the theory of positive disintegration provides a detailed and profound view of personality development and applies to a broad diversity of people and the environments from which they come... [TPD] is not only a theory for the gifted," (p. 93) but is relevant in a broad range of educational and clinical settings. Furthermore, the study of ego development has been extensively explored with typical adolescent populations, but research specific to gifted adolescents has been limited. Replication studies exploring the intersection of these two developmental theories using comparison samples will greatly strengthen the foundation for building intervention programs aimed at both gifted and typical adolescent populations. 
An immediate next step to be taken with the current study data is a thorough qualitative analysis of the wealth of information provided by the Washington University Sentence Completion Test (WUSCT) and the Definition Response Instrument (DRI). As both of these measures provide an opportunity for free-response answers, there is much to be gained from examining the descriptive data provided in the actual statements and perspectives shared by these gifted adolescents. While there is tremendous need for empirical support concerning the constructs examined in this study, adding a qualitative component enables researchers to better access the lived experiences and subjective realities of the study subjects (Lincoln \& Guba, 1985).

Finally, as the ultimate goal in understanding the social, emotional, and developmental issues of gifted adolescents is to develop appropriate and effective educational and counseling interventions to promote growth and psychological wellbeing, future research must embark upon empirically testing various interventions and counseling approaches. Researchers in the field of gifted education have proposed a number of counseling approaches based upon the ideas of Dabrowski's theory of positive disintegration. Ogburn-Colangelo (1979) first presented the theory in a counseling approach by highlighting the possibilities for support and reframing offered by Dabrowski's TPD. Nelson (1989) emphasized the power of the theory in validating the intense experiences of gifted individuals, "...to hear that psychoneurosis in not an illness can help the intensely sensitive make meaning of their experience of life" (p. 11). Mika (2002) has outlined specific strategies that counselors can employ in assisting students and clients cope with each of the Overexcitabilities described in Dabrowski's 
TPD. Finally, Dabrowski (in Mendaglio \& Tillier, 1992) himself advocated a long term, well planned program for individuals based upon their unique presentation of potentials, personality, and interests. He specified that such an approach should be multidimensional and developmentally focused; assisting the individual to cope with the often conflictual initial developmental experiences rather than treating them as symptoms to be ameliorated.

However, what each of these conceptual pieces lack are a clearly defined protocol and the empirical evidence necessary to support the efficacy and merits of such an approach. It is in this regard that the vast research base utilizing Loevinger's (1976) theory of ego development is most useful. As higher levels of cognitive complexity are associated with more adaptive behaviors (Brendel et al., 2002; Sprinthall \& Thies-Sprinthall, 1983) a primary goal of counseling interventions should be to promote development. Higher levels of both ego development and Dabrowskian development are associated with greater psychological maturity, increased adaptive functioning, and the ability to integrate conflicting information. Research exploring the deliberate psychological education (DPE) approach has supported that promoting psychological development of participants better equips individuals to deal with the stressors they may face throughout life (Sprinthall, 1991; Sprinthall \& Scott, 1989). Research with adolescents has specifically shown that growth can be enhanced though interaction with caring, skilled adults and peers in the context of well-planned and executed interventions that utilized a DPE model (Faubert et al., 1996). Further, DPE models have been shown to promote ego development in adolescents, resulting in an 
increase in interpersonal awareness, internalization of standards for moral judgment, greater understanding of the complexities and paradoxes of life, psychological causation, and individuality for participants (Sprinthall, Hall, \& Gerler, 1992).

Thus, examination of a well-planned and intentionally executed DPE intervention aimed at promoting ego development and Dabrowskian development in gifted adolescents is a critical area for future study. Such research would expand the initial connections established in the current study between these two highly relevant developmental theories and their significance for gifted adolescents. Such work would provide empirical support and additional scaffolding for the developmental frameworks already proven effective with various populations. The emphasis on Dabrowski's theory of positive disintegration in these approaches would enable them to be specifically tailored to the developmental needs and concerns of gifted adolescents. The current study has been instrumental in building a foundation for understanding these theories, from which future research and interventions can be based.

\section{Conclusion}

Uneven development, emotional and moral intensity, sensitivity to expectations and feelings, overexcitabilities, idealism, and complexity are but a few of the areas of difference for many gifted adolescents. While the research literature examining the unique social, emotional, and behavioral characteristics of gifted individuals has been growing, a tremendous need still exists for empirical studies exploring these traits as they intersect with the developmental paths of gifted students. Counselors are charged with the application of human development principles in addressing wellness and 
personal growth (ACA, 1997). School counselors are called upon to provide comprehensive, preventative, and developmental programs that address the needs of all students (ASCA, 2005). The National Association for Gifted Children (NAGC, 1995) highlights the need for counselors to have a deep understanding of the impact giftedness can have on a student's development. Hence, it is imperative that researchers continue exploring a wide range of developmental theories, across various developmental domains, to build a more comprehensive understanding of the unique experiences and challenges faced by gifted individuals across the lifespan. 


\section{References}

Ackerman, C. M. (2009). The essential elements of Dabrowski's theory of positive disintegration and how they are connected. Roeper Review, 31, 81-95.

Ackerman, C. M., \& Kane, M. (2002, November). Dabrowski: A man for all seasons. Paper presented at the $49^{\text {th }}$ Annual Convention of the National Association for Gifted Children, Albuquerque, NM.

Ackerman, C. M., \& Moyle, V. F. (2009). Introduction to special issue: Dabrowski's theory of positive disintegration. Roeper Review, 31, 79-80.

Amend, E. R. (2009). Dabrowski's theory: Possibilities and implication of misdiagnosis, missed diagnosis, and dual diagnosis in gifted individuals. In S. Daniels \& M. M. Piechowski (Eds.) Living with intensity (pp. 83-103). Scottsdale, AZ: Great Potential Press.

American Counseling Association. (1995). Code of ethics and standards of practice. Alexandria, VA: American Counseling Association.

American Counseling Association. (1997). Definition of Professional Counseling.

Retrieved April 5, 2009 from http://www.counseling.org/Counselors/

American Psychiatric Association. (1994). Diagnostic and statistical manual of mental disorders ( $4^{\text {th }}$ ed.). Washington, DC: Author.

American School Counselor Association. (2005). The ASCA national model: A framework for school counseling programs $\left(2^{\text {nd }}\right.$ ed. $)$. Alexandria, VA: Author.

Beach, L. (2004). Tall poppies: Personality characteristics of gifted high school students. Retrieved Jan 23, 2008, from PsycINFO database. 
Beran, T. N. (2006). Test review: Clinical Assessment of Behavior. Journal of Psychoeducational Assessment, 24, 399-403.

Borders, L. D. (1998). Ego development and counselor development. In P. M.

Westenberg, A. Blasi, \& L.D. Cohn (Eds.), Personality development: Theoretical, empirical, and clinical investigations of Loevinger's concept of ego development, (p. 331-346). Mahwah, NJ: Lawrence Erlbaum Associates.

Borders, L. D., \& Fong, M. L. (1989) Ego development and counseling ability during training. Counselor Education and Supervision, 29, 71-83.

Bracken, B. A., \& Brown, E. F. (2006). Behavioral identification and assessment of gifted and talented students. Journal of Psychoeducational Assessment, 24(2), 112-122.

Bracken, B. A., \& Keith, L. K. (2004). Clinical Assessment of Behavior. Lutz, FL: Psychological Assessment Resources.

Brendel, J., Kolbert, J., \& Foster, V. (2002). Promoting student cognitive development. Journal of Adult Development, 9, 217-227.

Brennan, T. P. (1987). Case studies of multilevel development. Unpublished doctoral dissertation, Northwestern University, Evanston, IL.

Bursik, K. (1995). Gender-related traits and ego development: Differential patterns for men and women. Sex Roles, 32, 601-615.

Bursik, K. (1999, August). Differential expression of "Big 5" personality traits with increasing ego development: Paper presented at the Meeting of the American Psychological Association, Boston, MA. 
Bursik, K., \& Martin, T. A. (2006). Ego development and adolescent academic achievement. Journal of Research on Adolescence, 16(1), 1-18.

Carlozzi, A., Gaa, J., \& Liberman, D. (1983). Empathy and ego development. Journal of Counseling Psychology, 30, 113-116.

Cash, A. B. (1999). A profile of gifted individuals with autism: The twice-exceptional learner. Roeper Review, 22, 22-27.

Cohn, L. D. (1991). Sex differences in the course of personality development: A metaanalysis. Psychological Bulletin, 109, 252-266.

Cohn, L. D., \& Westenberg, P. M. (2004). Intelligence and maturity: Meta-analytic evidence for the incremental and discriminant validity of Loevinger's measure of ego development. Journal of Personality and Social Psychology, 86, 760-772.

Colangelo, N. \& Assouline, S. G. (2000). Counseling gifted students. In K. A. Heller, F. J. Monks, R. J. Sternberg, \& R. F. Subotnik (Eds.), International handbook of giftedness and talent ( $2^{\text {nd }}$ ed., pp. 595-607). Amsterdam: Elsevier.

Coleman, L. J., \& Cross, T. L. (1988). Is being gifted a social handicap? Journal for the Education of the Gifted, 11, 41-56.

Coleman, L. J., \& Cross, T. L. (2001). Being gifted in school: An introduction to development, guidance, and teaching. Waco, TX, US: Prufrock Press.

Coleman, L. J., \& Cross, T. L. (2005). Being gifted in school: An introduction to development, guidance, and teaching (2nd ed.). Waco, TX, US: Prufrock Press. 
Columbus Group (1991, July). Unpublished transcript of the meeting of the Columbus

Group. Columbus, OH. Retrieved May 18, 2008, from

http://www.nagc.org/index.aspx?id=574

Cook-Greuter, S. R., \& Soulen, J. (2007). The developmental perspective in integral counseling. Counseling and Values, 51, 180-192.

Cramer, P. (1999). Ego functions and ego development: Defense mechanisms and intelligence as predictors of ego level. Journal of Personality, 67, 735-760.

Cross, T. L. (1997). Psychological and social aspects of educating gifted students. Peabody Journal of Education, 72(3\&4), 180-200.

Cross, T. L. (2001). On the social and emotional lives of gifted children. Waco, TX: Prufrock Press.

Cross, T. L. (2002). Competing myths about the social and emotional development of gifted students. Roeper Review, 25(3), 44-48.

Cross, T. L., Coleman, L., \& Terhaar-Yonkers, M. (1991). The social cognition of gifted adolescents in schools: Managing the stigma of giftedness. Journal for the Education of the Gifted, 15, 44-55.

D'Andrea, M. (1984). Primary prevention and high risk populations. Personnel \& Guidance Journal, 62(9), 554-559.

D'Andrea, M. \& Daniels, J. (1992). Measuring ego development for counseling practice: Implementing developmental eclecticism. Journal of Humanistic Education and Development, 31, 12-20.

Dabrowski, K. (1964). Positive disintegration. Boston: Little, Brown \& Company. 
Dabrowski, K. (1966). The theory of positive disintegration. International Journal of Psychiatry, 2(2), 229-244.

Dabrowski, K. (1967). Personality-shaping through positive disintegration. Boston: Little, Brown \& Company.

Dabrowski, K. (1970). Mental growth through positive disintegration. London: Gryf.

Dabrowski, K. (1972). Psychoneurosis is not an illness. London: Gryf.

Dabrowski, K. (1973). The dynamics of concepts. London: Gryf.

Dabrowski, K. \& Piechowski, M. M. (1977). Theory of levels of emotional development: From primary integration to self-actualization (Vol. 2). Oceanside, NY: Dabor Science.

Dabrowski, K. \& Piechowski, M. M. (1996). Multilevelness of emotional and instinctive functions. Lublin, Poland: Towarzystwo Naukowe Katolickiego Uniwersytetu Lubelskiego.

Daniels, S., \& Piechowski, M. M. (2009). Living with intensity. Scottsdale, AZ: Great Potential Press.

Delisle, J. (1995). Psyched out: Searching for the soul of gifted child education. Gifted Child Today, 18(4).

Delisle, J. R. (1990). The gifted adolescent at risk: Strategies and resources for suicide prevention among gifted youth. Journal for the Education of the Gifted, 13(3), 212-228.

Delisle, J., \& Galbraith, J. (2002). When gifted kids don't have all the answers: How to meet their social and emotional needs. Free Spirit Publishing: Minneapolis, MN. 
Hazell, C. G. (1982) An empirical study of the experience of emptiness. Unpublished doctoral dissertation, Northwestern University, Evanston, IL.

Hazell, C. G. (1999). The experience of emptiness and the use of Dabrowski's theory in counseling gifted clients: Clinical case examples. Advanced Development, 8, 3146.

Hunt, D. E. (1975). Person-environment interaction: A challenge found wanting before it was tried. Review of Educational Research, 45(2), 209-230.

Hunt, D. E. (1978). Inservice training as persons-in-relation. Theory into Practice, 17(3), 239-245.

Hy, L. X. \& Loevinger, J. (1996). Measuring ego development. Mahwah, NJ.: Lawrence Erlbaum.

John, O. P., Pals, J. L., \& Westenberg, P. M. (1998). Personality prototypes and ego development: Conceptual similarities and relations in adult women. Journal of Personality and Social Psychology, 74, 1093-1108.

Johnson, C. (1992). The emergence of the emotional self: A developmental theory. Symbolic Interaction, 15(2), 183-202.

Kane, M. (2009). Contemporary voices on Dabrowski's theory of positive disintegration. Roeper Review, 31, $72-76$.

Kerr, B. A. (1994). Smart girls: A new psychology of girls, women and giftedness. Dayton, OH: Ohio Psychology Press.

Kohlberg, L. (1975). Counseling and counselor education: A developmental approach. Counselor Education and Supervision, 14, 250-256. 
Kohlberg, L. (1984). Essays on moral development: The psychology of moral development (Vol. II). San Francisco: Harper \& Row.

Krettenauer, T., Ullrich, M., Hofmann, V., \& Edelstein, W. (2003). Behavioral problems in childhood and adolescence as predictors of ego-level attainment in early adulthood. Merrill-Palmer Quarterly, 49(2), 125-153.

Labouvie-Vief, G. (1993). Ego processes in adulthood: A comment on Jane Loevinger. Psychological Inquiry, 4, 1-16.

Labouvie-Vief, G., Hakim-Larson, J., \& Hobart, C.J. (1987). Age, ego level, and the life span development of coping and defense processes. Psychology and Aging, 2(3), 286-293.

Laycraft, K. (2009). Positive maladjustment as a transition from chaos to order. Roeper Review, 31, 113-122.

Lee, L., \& Snarey, J. (1988). The relationship between ego and moral development: A theoretical review and empirical analysis. In D. K. Lapsey, \& F. Clark Power (Eds.), Self, ego, and identity (pp. 151-208). New York: Springer-Verlag.

LeVine, E. S., \& Tucker, S. (1986). Emotional needs of gifted children: A preliminary, phenomenological view. Creative Child \& Adult Quarterly, 11(3), 156-165.

Lincoln, Y. S., \& Guba, E. G. (1985). Naturalistic Inquiry. Beverly Hills, CA: Sage.

Lind, S. (1998). A parent's guide to perfectionism. Communicator, CAG, 29(3).

Lind, S. (2001). Overexcitability and the gifted. SENG Newsletter, 1(1), 3-6. Retrieved March 24, 2009 from http://www.sengifted.org/articles_social/index.shtml 
Loevinger, J. (1976). Ego development: Conceptions and theories. San Francisco: Jossey-

Bass.

Loevinger, J. (1979). Construct validity of the sentence completion test of ego development. Applied Psychological Measurement, 3, 281-311.

Loevinger, J. (1985). Revision of the Sentence Completion Test for ego development. Journal of Personality and Social Psychology, 48, 420-427.

Loevinger, J. (1994). Has psychology lost its conscience? Journal of Personality Assessment, 62, 2-8.

Loevinger, J. (1998). Technical foundations for measuring ego development. Mahwah, NJ: Lawrence Erlbaum.

Loevinger, J. \& Wessler, R. (1970). Measuring ego development: Construction and use of a Sentence Completion Test (Vol. 1). San Francisco: Jossey-Bass.

Lovecky, D. V. (1992). Exploring social and emotional aspects of giftedness in children. Roeper Review, 15(1), 18.

Lysy, K. Z. (1979). Personal growth in counselors and noncounselors: A Jungian and Dabrowskian approach. Unpublished doctoral dissertation, University of Illinois, Champaign-Urbana, IL.

Mabry, C. (1993). Gender differences in ego level. Psychological Reports, 72, 752-754.

McDonald, V. (2006). The relationship between racial attitudes, ego developmental level and multicultural counseling knowledge and awareness in school psychologists. Unpublished doctoral dissertation, The College of William and Mary, Williamsburg, VA. 
Mendaglio, S. (1998). Counseling gifted students: Issues and recommendations for teachers and counselors. AGATE, 12, 18-25.

Mendaglio, S. (2002). Dabrowski's theory of positive disintegration: Some implications for teachers of gifted students. AGATE, 15(2), 14-22.

Mendaglio, S. (2008). Dabrowski's theory of positive disintegration. Scottsdale, AZ: Great Potential Press.

Mendaglio, S., \& Tillier, W. (1992, September 24-26). Feeling bad can be good: Using Dabrowski's theory to reframe gifted children's adjustment difficulties. Paper presented at the 3rd Annual Society for the Advancement of Gifted Education Conference, Calgary, AB.

Mendaglio, S., \& Tillier, W. (2006). Dabrowski's theory of positive disintegration and giftedness: Overexcitability research findings. Journal for the Education of the Gifted, $30(1 ; 1), 68-87$.

Mika, E. (2002). Gifted children and overexcitabilities and a preliminary clinical study. In N. Duda, (Ed.), Positive Disintegration: The Theory of the future. 100th Dabrowski anniversary program on the man, the theory, the application and the future (pp. 323-336). Ft. Lauderdale, FL: Fidlar Doubleday.

Miller, N. B. (2008). Emotion management and emotional development: A sociological perspective. In S. Mendaglio (Ed.) Dabrowski's theory of positive disintegration (pp. 227-248). Scottsdale, AZ: Great Potential Press. 
Miller, N. B. (1991). Miller Assessment Coding System: Manual for Rating Levels of Emotional Development. Department of Sociology, University of Akron, Akron, $\mathrm{OH}$.

Miller, N. B. (1985). A content analysis coding system for assessing adult emotional development. Unpublished doctoral dissertation, University of Denver, Denver, CO.

Miller, N. B., \& Silverman, L. K. (1987). Levels of personality development. Roeper Review, 9(4), 221.

Moon, S., Reis, S., \& National Association for Gifted Children. (2004, March 23). Social/Emotional Issues, Underachievement, and Counseling of Gifted and Talented Students. Essential Readings in Gifted Education Series. Corwin Press.

Moyle, V. F. (2002). Metaphor in the therapeutic setting: Putting Dabrowski to work. In N. Duda (Ed.), Positive disintegration: The theory of the future (pp. 337-348). Fort Lauderdale, FL: The Institute for Positive Disintegration in Human Development.

Mróz, A. (2009). Theory of positive disintegration as a basis for research on assisting development. Roeper Review, 31, 96-102.

Naglieri, J. A., LeBuffe, P. A., \& Pfeiffer, S. I. (1994). Devereux scales of mental disorder. San Antonio, TX: Psychological Corporation.

National Association for Gifted Children. (1995). Addressing affective needs of gifted children. Retrieved April 5, 2009 from http://www.nagc.org/index.aspx?id=384

Neihart, M. (1999). The impact of giftedness on psychological well-being: What does the empirical literature say? Roeper Review, 22(1), 10. 
Neihart, M., Reis, S. M., Robinson, N. M., Moon, S. M. (2002). The social and emotional development of gifted children: What do we know? Waco, TX: Prufrock Press.

Nelson, K. C. (1989). Dabrowski's Theory of Positive Disintegration. Advanced Development, 1, 1-14.

Noam, G. (1992). Development as the aim of clinical intervention. Development and Psychopathology, 4, 679-696.

Noam, G. (1998). Solving the ego development - mental health riddle. In P. M. Westenberg, A. Blasi, \& L. D. Cohn (Eds.), Personality development: Theoretical, empirical, and clinical investigations of Loevinger's conception of ego development. Hillsdale, NJ: Erlbaum.

Novy, D. M., \& Francis, D. J. (1992). Psychometric properties of the Washington University Sentence Completion Test. Educational and Psychological Measurement, 52(4), 1029.

O'Connor, K. J. (2002). The application of Dabrowski's theory to the gifted. In M. Neihart, S. M. Reis, N. M. Robinson \& S. M. Moon (Eds.), The social and emotional development of gifted children: What do we know? (pp. 51-60). Waco, TX, US: Prufrock Press.

Ogburn-Colangelo, M. K. (1979). Giftedness as multilevel potential: A clinical example. In N. Colangelo \& R. Zaffrann (Eds.), New Voices in Counseling the Gifted (pp. 165187). Dubuque, lowa: Kendall Hunt Pub. Co..

Ogburn-Colangelo, M. K. (1989). Giftedness as multilevel potential: A clinical example. Advanced Development, 1, 187-200. 
Parker, W. D., \& Mills, C. J. (1996). The incidence of perfectionism in gifted students. Gifted Child Quarterly, 40(4), 194-199.

Perry, W. (1971). Forms of Intellectual and Ethical Development in the College Years. New York:

Holt, Reinhart and Winston.

Piaget, J. (1961). The genetic approach to the psychology of thought. Journal of Educational Psychology, 52(6), 275-281.

Piechowski, M. M. (1975). A theoretical and empirical approach to the study of development. Genetic Psychology Monographs, 92, 231-297.

Piechowski, M. M. (1978). Self-actualization as a developmental structure: A profile of Antoine de Saint-Exupéry. Genetic Psychology Monographs, 97(2), 181-242.

Piechowski, M. M. (1979). Developmental potential. In N. Colangelo \& R. Zaffrann (Eds.), New voices in counseling the gifted. lowa: Kendal/Hunt Publishing.

Piechowski, M. M. (1990). Inner growth and transformation in the life of Eleanor Roosevelt. Advanced Development, 2, 35-53.

Piechowski, M. M. (1992). Etty Hillesum: "The thinking heart of the barracks." Advanced Development, 4, 105-118.

Piechowski, M. M. (2003). From William James to Maslow and Dabrowski: Excitability of character and self-actualization. In D. Ambrose, L. M. Cohen \& A. J. Tannenbaum (Eds.), Creative intelligence: Toward theoretic integration. (pp. 283-322). Cresskill, NJ, US: Hampton Press. 
Piechowski, M. M. (2008). Discovering Dabrowski's theory. In S. Mendaglio (Ed.) Dabrowski's theory of positive disintegration (pp. 41-78). Scottsdale, AZ: Great Potential Press.

Piechowski, M. M. (2009). Peace Pilgrim: Exemplar of level V. Roeper Review, 31, 103113.

Recklitis, C. J., \& Noam, G. G. (1999). Clinical and developmental perspectives on adolescent coping. Child Psychiatry and Human Development, 30(2), 87-101.

Redmore, C. (1983). Ego development in the college years: Two longitudinal studies. Journal of Youth and Adolescence, 12, 301-306.

Reis, S. M., \& McCoach, D. B. (2000). The underachievement of gifted students: What do we know and where do we go? Gifted Child Quarterly, 44(3), 152-170.

Reynolds, C. R., \& Kamphaus, R. W. (2004). BASC-2 Behavior Assessment System for Children, second edition manual. Circle Pines, MN: American Guidance Service.

Rimm, S. (2003). Underachievement: A national epidemic. In N. Colangelo \& G. A. Davis (Eds.), Handbook of gifted education ( $3^{\text {rd }}$ ed.)(pp. 424-443). Needham Heights, MA: Allyn \& Bacon.

Robinson, N. M. (2002). Individual differences in gifted students' attributions for academic performances. In M. Neihart, S. M. Reis, N. M. Robinson \& S. M. Moon (Eds.), The social and emotional development of gifted children: What do we know? (pp. 61-69). Waco, TX: Prufrock Press.

Roedell, W. (1984). Vulnerabilities of highly gifted children. Roeper Review, 6(3), 127130. 
Sanborn, M. P. (1979). Counseling and guidance needs of gifted and talented students. In A. H. Passow (Ed.), The gifted and talented: Their education and development (pp. 424-428). Chicago: University of Chicago Press.

Santmire, T. E. (1990). Understanding gifted adolescents: Another legacy of Leta Stetter Hollingworth. Roeper Review, 12(3), 188.

Schiever, S. W. (1985). Creative personality characteristics and dimensions of mental functioning in gifted adolescents. Roeper Review, 7(4), 223-226.

Schmidt, M. L. (1977). The pebble in song and legends: Primary integration in studies of personality and development. Unpublished master's thesis, University of Illinois, Urbana-Champaign, IL.

Seeley, K. (1993). Facilitators for talented students. In J. Van Tassel-Baska (Ed.). Excellence in educating gifted and talented learners. (pp. 473-487). Denver, CO: Love Publishing Co.

Silverman, L. K. (1990). Issues in affective development of the gifted. In J. VanTasselBaska (Ed.), A practical guide to counseling the gifted in school setting $\left(2^{\text {nd }}\right.$ ed., pp. 15-30). Reston, VA: Council for Exceptional Children.

Silverman, L. K. (1993). Counseling the gifted and talented. Denver, CO: Love Publishing Co.

Silverman, L. K. (1997). The construct of asynchronous development. Peabody Journal of Education, $72(3 \& 4), 36-58$. 
Silverman, L. K. (2002). Asynchronous development. In M. Neihart, S. M. Reis, N. M. Robinson \& S. M. Moon (Eds.), The social and emotional development of gifted children: What do we know? (pp. 31-37). Waco, TX, US: Prufrock Press.

Silverman, L. K. (2005). Intensitive! Intensities and sensitivities of the gifted. Social and emotional needs of gifted children. Hobart, Tasmania: Tasmanian Association for the Gifted, Inc., 2006.

Silverman, L. K. (2007). What we have learned about gifted children: 1979 - 2007. Denver, CO: Gifted Development Center.

Sprinthall, N. A. (1991). Social Role-Taking Revisited: A Neglected Way to Promote Ego, Moral and Conceptual Development of Adolescents. Paper presented at the Association of Moral Education Conference, Athens, GA.

Sprinthall, N. A. (1994). Counseling and social role taking: Promoting moral and ego development. In J. R. Rest, \& D. Narváez (Eds.), Moral development in the professions: Psychology and applied ethics. (pp. 85-99). Hillsdale, NJ, England: Lawrence Erlbaum Associates, Inc.

Sprinthall, N. A. \& Mosher, R. L. (1978). Value Development as the Aim of Education. New York, NY: Character Research Press.

Sprinthall, N. A. \& Scott, J. R. (1989). Promoting psychological development, math achievement, and success attribution of female students through deliberate psychological education. Journal of Counseling Psychology, 36, 440-446.

Sprinthall, N. A., \& Thies-Sprinthall, L. (1983). The need for theoretical frameworks in educating teachers: A cognitive developmental process. In K. Howey and W. 
Garner (Eds.), Education of teachers: A look ahead, (pp. 74-97). New York: Longman.

Sprinthall, N. A., Hall, J. S., \& Gerler, E. R. (1992). Peer counseling for middle school students experiencing family divorce: A deliberate psychological education model. Elementary School Guidance \& Counseling, 26(4), 279-294.

Sword, L. (2001a). Emotional intensity in gifted children. Victoria, Australia: Gifted and Creative Services.

Sword, L. (2001b). Psycho-social needs: Understanding the emotional, intellectual and social uniqueness of growing up gifted. Victoria, Australia: Gifted and Creative Services.

Sword, L. (2003). Gifted children: Emotionally immature or emotionally intense? Victoria, Australia: Gifted and Creative Services.

Terrasier, J. C. (1985). Dyssynchrony--uneven development. In J. Freeman (Ed.), The psychology of gifted children. New York: John Wiley \& Sons.

Thomas, V., \& Ray, K. E. (2006). Counseling exceptional individuals and their families: A systems perspective. Professional School Counseling, 10(1), 58-65.

Tieso, C. L. (1999). Meeting the socio-emotional needs of talented teens. Gifted Child Today, 22, 38-43.

Tieso, C. L. (2007). Overexcitabilities: A new way to think about talent? Roeper Review, $29,232-239$. 
Tyska, C. A. (1980). A comparative case study of self-actualization in Eleanor Roosevelt and Antoine de Saint-Exupery. Unpublished master's thesis, University of Illinois, Urbana-Champaign, IL.

Virginia Department of Education (1996). The Virginia Plan for the Gifted. Retrieved August 19, 2008 from http://www.doe.virginia.gov/VDOE/Instruction/Gifted/ VAPlanforGifted1996.pdf

Virginia Department of Education (2005). Virginia Administrative Code, Chapter Eight. Retrieved August 19, 2008 from http://www.doe.virginia.gov/VDOE/Instruction/ Gifted/gftregs.pdf

Virginia Department of Education (2008). Virginia Governor's School Program. Retrieved August 19, 2008 from http://www.doe.virginia.gov/VDOE/Instruction/ Govschools/

Webb, J. T. (1998) Existential depression in gifted individuals, Communicator, CAG, 29(3).

Webb, J. T. (2005). Mis-Diagnosis and Dual Diagnosis of Gifted Children: Gifted and LD, ADHD, OCD, Oppositional-Defiant Disorder. Scottsdale, AZ: Great Potential Press. Westenberg, P. M., \& Block, J. (1993). Ego development and individual differences in personality. Journal of Personality and Social Psychology, 65, 792-800.

Westenberg, P. M., \& Gjerde, P. F. (1999). Ego development during the transition form adolescence to young adulthood: A 9-year longitudinal study. Journal of Research in Personality, 33, 233-252. 
Westenberg, P. M., Blasi, A., \& Cohn, L. D. (1998). Personality development: Theoretical, empirical, and clinical investigations of Loevinger's conception of ego development. Mahwah, NJ: Lawrence Erlbaum.

Westenberg, P. M., Jonckheer, J., Treffers, P. D. A., \& Drewes, M. J. (1998). Ego development in children and adolescents: Another side of the impulsive, selfprotective, and conformist ego levels. In P. M. Westenberg, A. Blasi, \& L. D. Cohn (Eds.), Personality development: Theoretical, empirical, and clinical investigations of Loevinger's conception of ego development, (pp. 89-112). Mahwah, NJ: Lawrence Erlbaum Associates.

White, M. S. (1985). Ego development in adult women. Journal of Personality, 53, 561574.

Winner, E. (1997). Exceptionally high intelligence and schooling. American Psychologist, 52(10), 1070-1081. 


\section{Appendix A}

\section{Virginia Administrative Code \\ Database updated through 21:24 V.A.R. August 8, 2005}

8VAC20-40-10. Applicability.

This chapter shall apply to all local school divisions in the Commonwealth.

Statutory Authority

$\S \S 22.1-16$ and 22.1-253.13:1 of the Code of Virginia.

Historical Notes

Derived from VR270-01-0002 §1.1, eff. June 25, 1986; amended, Virginia Register Volume 11, Issue 9, eff. February 22, 1995.

8VAC20-40-20. Definitions.

The words and terms, when used in this chapter, shall have the following meanings, unless the content clearly indicates otherwise:

"Appropriately differentiated curricula" for gifted students refer to curricula designed in response to their cognitive and effective needs. Such curricula provide emphasis on both accelerative and

enrichment opportunities for (i) advanced content and pacing of instruction, (ii) original research or production, (iii) problem finding and solving, (iv) higher level thinking that leads to the generation of products, and (v) a focus on issues, themes, and ideas within and across areas of study.

"Gifted students" means those students in public elementary and secondary schools beginning with kindergarten through graduation whose abilities and potential for accomplishment are so outstanding that they require special programs to meet their educational needs. These students will be identified by professionally qualified persons through the use of multiple criteria as having potential or demonstrated abilities and who 
have evidence of high performance capabilities, which may include leadership, in one or more of the following areas:

1. Intellectual aptitude or aptitudes. Students with advanced aptitude or conceptualization whose development is accelerated beyond their age peers as demonstrated by advanced skills, concepts, and creative expression in multiple general intellectual ability or in specific intellectual abilities.

2. Specific academic aptitude. Students with specific aptitudes in selected academic areas: mathematics; the sciences; or the humanities as demonstrated by advanced skills, concepts, and creative expression in those areas.

3. Technical and practical arts aptitude. Students with specific aptitudes in selected technical or practical arts as demonstrated by advanced skills and creative expression in those areas to the extent they need and can benefit from specifically planned educational services differentiated from those provided by the general program experience.

4. Visual or performing arts aptitude. Students with specific aptitudes in selected visual or performing arts as demonstrated by advanced skills and creative expression who excel consistently in the development of a product or performance in any of the visual and performing arts to the extent that they need and can benefit from specifically planned educational services differentiated from those generally provided by the general program experience.

"Identification" is the process of reviewing student data collected at the screening level and conducting further evaluation of student potential to determine the most qualified students for the specific gifted program available.

"Identification/Placement Committee" means a standing committee which is composed of a professional who knows the child, classroom teacher or teachers, others representing assessment specialists, gifted program staff and school administration, and others deemed 
appropriate. This committee may operate at the school or division level. In either case, consistent criteria must be established for the division.

"Placement" means the determination of the appropriate educational option for each eligible student.

"Screening" is the process of creating the pool of potential candidates using multiple criteria through the referral process, review of test data, or from other sources. Screening is the active search for students who should be evaluated for identification.

"Service options" include the instructional approach or approaches, setting or settings, and staffing selected for the delivery of appropriate service or services that are based on student needs.

"Student outcomes" are specified expectations based on the assessment of student cognitive and affective needs. Such outcomes should articulate expectations for advanced levels of performance for gifted learners.

Statutory Authority

$\S \S 22.1-16$ and 22.1-253.13:1 of the Code of Virginia.

Historical Notes

Derived from VR270-01-0002 §1.2, eff. June 25, 1986; amended, Virginia Register Volume 11, Issue 9, eff. February 22, 1995. 


\section{Part II}

Responsibilities of the Local School Divisions

8VAC20-40-30. Applicability.

The requirements set forth in this part are applicable to local school divisions providing educational services for gifted students in elementary and secondary schools from kindergarten through graduation.

Statutory Authority

$\S \S 22.1-16$ and 22.1-253.13:1 of the Code of Virginia.

Historical Notes

Derived from VR270-01-0002 \$2.1, eff. June 25, 1986; amended, Virginia Register Volume 11, Issue 9, eff. February 22, 1995.

8VAC20-40-40. Identification.

A. Each school division shall establish a uniform procedure with common criteria for screening and identification of gifted students. If the school division elects to identify students with specific academic aptitudes, they shall include procedures for identification and service in mathematics, science, and humanities. These procedures will permit referrals from school personnel, parents or legal guardians, other persons of related expertise, peer referral and self-referral of those students believed to be gifted. Pertinent information, records, and other performance evidence of referred students will be examined by a building level or division level identification committee. Further, the committee or committees will determine the eligibility of the referred students for differentiated programs. Students who are found to be eligible by the Identification/Placement Committee shall be offered a differentiated program by the school division. 
B. Each school division shall maintain a division review procedure for students whose cases are appealed. This procedure shall involve individuals, the majority of whom did not serve on the Identification/Placement Committee.

Statutory Authority

$\S \S 22.1-16$ and 22.1-253.13:1 of the Code of Virginia.

Historical Notes

Derived from VR270-01-0002 §2.2, eff. June 25, 1986; amended, Virginia Register Volume 11, Issue 9, eff. February 22, 1995.

8VAC20-40-50. Criteria for screening and identification.

Eligibility of students for programs for the gifted shall be based on multiple criteria for screening and identification established by the school division, and designed to seek out high aptitude in all populations. Multiple criteria shall include four or more of the following categories:

1. Assessment of appropriate student products, performance, or portfolio;

2. Record of observation of in-classroom behavior;

3. Appropriate rating scales, checklists, or questionnaires;

4. Individual interview;

5. Individual or group aptitude tests;

6. Individual or group achievement tests;

7. Record of previous accomplishments (such as awards, honors, grades, etc.);

8. Additional valid and reliable measures or procedures.

If a program is designed to address general intellectual aptitude, aptitude measures must be included as one of the categories in the division identification plan. If a program is designed to address specific academic aptitude, an achievement or an aptitude measure in the specific academic area must be included as one of the categories in the division identification plan. If a program is designed to address either the visual/performing arts or 
technical/practical arts aptitude, a performance measure in the specific aptitude area must be used. Inclusion of a test score in a division identification plan does not indicate that an individual student must score at a prescribed level on the test or tests to be admitted to the program. No single criterion shall be used in determining students who qualify for, or are denied access to, programs for the gifted.

Statutory Authority

$\S \S 22.1-16$ and 22.1-253.13:1 of the Code of Virginia.

Historical Notes

Derived from VR270-01-0002 §2.3, eff. June 25, 1986; amended, Virginia Register Volume 11, Issue 9, eff. February 22, 1995.

8VAC20-40-60. Local plan.

A. Each school division shall submit to the Department of Education for approval a plan for the education of gifted students. Modifications to the plan shall be reported to the Department of Education on dates specified by the department. The plan shall include the components as follow:

1. A statement of philosophy;

2. A statement of program goals and objectives;

3. Procedures for the early and on-going identification and placement of gifted students; beginning with kindergarten through secondary graduation in at least one of the four defined areas of giftedness;

4. A procedure for notifying parents or legal guardians when additional testing or additional information is required during the identification process and for obtaining permission prior to placement of students in the appropriate program; 
5. A policy for notifying gifted students' change of placement within, and exit from the program, which includes an opportunity for parents who disagree with the committee or committees decision to meet and discuss their concern or concerns with an appropriate administrator;

6. Assurances that records are maintained according to 8VAC20-150-10 et seq., Management of

Student's Scholastic Record in the Public Schools of Virginia;

7. Assurances that (i) testing and evaluation materials selected and administered are sensitive to cultural, racial, and linguistic differences, (ii) identification procedures are constructed so that they identify high potential/ability in all underserved culturally diverse, low socio-economic, and disabled populations, (iii) standardized tests have been validated for the specific purpose for which they are used, (iv) instruments are administered and interpreted by a trained personnel in conformity with the instructions of their producer;

8. A procedure to identify and evaluate student outcomes based on the initial and ongoing assessment of their cognitive and affective needs;

9. A procedure to match service options, including instructional approaches, settings, and staffing, to designated student needs;

10. A framework for appropriately differentiated curricula indicating accelerative and enrichment opportunities in content, process, and product;

11. Procedures for the selection/evaluation of teachers and for the training of personnel to include administrators/supervisors, teachers, and support staff;

12. Procedures for the appropriate evaluation of the effectiveness of the school division's program for gifted students; and 
13. Other information as required by the Department of Education.

B. Each school division shall establish a local advisory committee composed of parents, school personnel, and other community members. This committee shall reflect the ethnic and geographical composition of the school division. The purpose of this committee shall be to advise the school board through the division superintendent of the educational needs of all gifted students in the division. As a part of this goal, the committee shall review annually the local plan for the education of gifted students, including revisions, and determine the extent to which the plan for the previous year was implemented. The recommendations of the advisory committee shall be submitted in writing through the division superintendent to the school board.

Statutory Authority

$\S \S 22.1-16$ and 22.1-253.13:1 of the Code of Virginia.

Historical Notes

Derived from VR270-01-0002 §2.4, eff. June 25, 1986; amended, Virginia Register Volume 11, Issue 9, eff. February 22, 1995.

8VAC20-40-70. Funding.

State funds administered by the Department of Education for the education of gifted students shall be used to support only those activities identified in the school division's plan as approved by the Board of Education.

Statutory Authority

$\S \S 22.1-16$ and 22.1-253.13:1 of the Code of Virginia.

Historical Notes

Derived from VR270-01-0002 §2.5, eff. June 25, 1986; amended, Virginia Register Volume 11, Issue 9, eff. February 22, 1995. 


\section{Appendix B}

\section{Virginia Governor's School Program}

\section{(Virginia Department of Education, online 2008)}

\section{Introduction}

The Virginia Governor's School Program began in 1973 when Governor Linwood Holton established the first summer residential programs for 400 gifted students from across the commonwealth. From its beginnings, with three summer schools in 1973, the program has expanded to more than 40 sites throughout the commonwealth.

Virginia Governor's Schools provide some of the state's most able students academically and artistically challenging programs beyond those offered in their home schools. With the support of the Virginia Board of Education and the General Assembly, the Governor's Schools presently include summer residential, summer regional, and academic-year programs serving more than 7,500 gifted students from all parts of the commonwealth.

The years since 1973 have brought refinement and change to the programs, yet one aspect, the student, has remained constant. Each year, hundreds of outstanding young people come to one of the different Governor's Schools in search of knowledge and eager to accept the challenge of acquiring advanced skills. Each group makes the Virginia Governor's School Program a special experience by creating a community of learners who demonstrate their remarkable talents in diverse and meaningful ways.

\section{What types of Governor's Schools are available?}

Three types of Governor's Schools provide appropriate learning endeavors for gifted students throughout the commonwealth: Academic-Year Governor's Schools (AYGS), Summer Residential Governor's Schools (SRsGS), and the Summer Regional Governor's Schools (SRgGS). 


\section{Academic-Year Governor's Schools}

The Virginia Department of Education, in conjunction with localities, sponsors regional Academic-Year Governor's Schools that serve gifted high school students during the academic year. Currently, 18 Academic-Year Governor's Schools provide students with acceleration and exploration in areas ranging from the arts, to government and international studies, and to mathematics, science, and technology.

The Virginia Board of Education must approve proposals for new or expanding Governor's Schools. The board passed, in 1998, Procedures for Initiating AcademicYear Governor's Schools to direct the actions of regional planning groups. Each school creates a program tailored to the needs of its students. Academic-Year Governor's Schools vary in format. While three are full-day programs, fulfilling all requirements students need to graduate, most are part-time programs. Students in these schools spend a portion of their day at the Governor's Schools but rely on their high schools to provide other programming required for graduation. Students use computers, robotics, and other current technology in laboratory activities; they conduct in-depth research, work with other students to develop special projects and performances, and alongside mentors in business, industry, government, and universities gaining experiences that enhance their understanding of the content as well as contemporary career options.

The Academic-Year Governor's Schools have developed innovative ways to serve their students. Appomattox Regional Governor's School for the Arts and Technology, Central Virginia Governor's School, Maggie L. Walker Governor's School, Roanoke Valley Governor's School, and Thomas Jefferson High School for Science and Technology are housed in their own facilities. Other Academic-Year Governor's Schools share campuses with high schools, community colleges/universities, or professional organizations. The Governor's School for the Arts in Norfolk shares facilities at the Wells Theatre and with the Virginia Ballet. Several new schools are using interactive television to link multiple high school sites. A. Linwood Holton Governor's School is the commonwealth's first completely virtual Governor's School. Daily, students in more than 24 high schools in 13 counties in Southwest Virginia are taught through an Internet 
connection using a variety of software. Commonwealth Governor's School uses compressed video technology and coordinated large group activities to produce a community of learners at multiple sites across three counties.

Faculties for the Academic-Year Governor's Schools are selected based on advanced degrees, professional experience, and training and/or experience with gifted high school students. Most teachers have the gifted add-on endorsement that represents postgraduate training in gifted education, and several are certified through the National Board of Professional Teaching Standards. Each school is responsible for providing staff development to extend its teachers' knowledge and use of innovative teaching strategies, technology, and contemporary subject matter.

The Academic-Year Governor's Schools are established as "joint schools" by Virginia school law. As such, they are typically managed by a regional governing board of representatives from the school boards of each participating division. The regional governing board is charged with developing policies for the school including the school's admissions process. While these processes differ from school to school, all applicants are assessed using multiple criteria by trained evaluators who have experience in gifted education and the focus area of the specific Academic-Year Governor's School.

The Virginia Department of Education oversees and evaluates the Academic-Year Governor's Schools. Each school is evaluated through the use of evaluation rubrics designed to determine the effectiveness in curriculum, professional development, program design, guidance and counseling, identification and selection process, and facilities. A full-site evaluation team visits each school every six years.

\section{Summer Residential Governor's Schools}

Summer Residential Governor's Schools provide gifted high school juniors and seniors with intensive educational experiences in visual and performing arts; humanities; mathematics, science, and technology; life science and medicine; or through mentorships in marine science or engineering. 
Each Summer Residential Governor's School focuses on one special area of interest. Students live on a college or university campus for up to five weeks each summer. During this time, students are involved in classroom and laboratory work, field studies, research, individual and group projects and performances, and seminars with noted scholars, visiting artists, and other professionals. In the two mentorships, students are selected to work side-by-side with research scientists, physicians, and a variety of other professionals. A director and a student-life staff provide supervision of students 24 hours a day, throughout the program.

One of the most important aspects of the Summer Residential Governor's Schools is the opportunity participants have to live, study, and get to know other students with similar interests and abilities from across Virginia. Both co-curricular and extracurricular activities are designed to encourage students' interests and abilities. Recreation and free time are provided outside of the academic environment that enable these students to enjoy, what for many is, their first summer living away from home.

Any Virginia gifted tenth- or eleventh-grade student may apply for the Summer Residential Governor's Schools. Applications are made available in October through a Superintendent's Memo. Prospective students may click here to have access to the information and applications. Additional copies are sent to high school guidance departments of public and private schools, as well as each school division's gifted education coordinator. Each school division has a specific number of nominations it may send to the Virginia Department of Education.

Nominations may be made by teachers, guidance counselors, peers, or by the students themselves. A school or division selection committee chooses the nominees from each school or division and forwards the nominees to a state committee. Consideration is given to students' academic records, test scores, extra-curricular activities, honors, and awards, creativity, original essays, and teacher recommendations. Students applying for the Visual and Performing Arts Summer Residential Governor's School participate in a statewide adjudication where they audition or present portfolios for review before a pair of professionals in the specific arts field. Because of the limited number of residential 
placements available, not all students who are nominated by their schools can be accepted for participation.

The Virginia Department of Education evaluates the Summer Residential Governor's Schools once every four years. Rubrics similar to those developed by the Academic-Year Governor's School directors are used to evaluate the Summer Residential programs. Visiting teams include specialists or university faculty with expertise in the content or focus area, Academic-Year Governor's Schools directors and teachers, local gifted education coordinators, and other professionals directly involved in the specific fields.

\section{Summer Regional Governor's Schools}

Twenty Summer Regional Governor's Schools are available throughout the state. The Summer Regional Governor's Schools exist in a variety of formats. Most often, groups of school divisions design these programs to meet the needs of their local gifted elementary and middle school students. These schools provide exciting opportunities in the arts, sciences, and humanities. The Department of Education approves each Summer Regional Governor's School and evaluates each school once every six years.

Summer Regional Governor's Schools typically are housed at a public school or on the campus of a college, community college, or university. The lengths of programs vary, with some lasting a week or less while others may last four or more weeks. Most students return to their homes at the end of each day's activities; however, the University of Virginia's College at Wise, Southside, and Valley/Ridge Summer Regional Governor's Schools are residential.

Gifted students may apply for the regional summer school in their area. The Summer Regional Governor's School director and the planning committee with representatives from the participating school divisions at each regional site establish nomination and selection procedures. Program topics and grade levels vary among the sites and change from year to year in response to annual local evaluations and changing concerns in the localities sponsoring the Summer Regional Governor's Schools. 


\section{What is the purpose of the Governor's Schools?}

Governor's Schools give gifted students academic and visual and performing arts opportunities beyond those normally available in the students' home schools. Students are able to focus on a specific area of intellectual or artistic strength and interest and to study in a way that best suits the gifted learner's needs. Each program stresses nontraditional teaching and learning techniques. For example, small-group instruction, hands-on-experiences, research, field studies, or realistic or artistic productions are major elements in the instructional design at all schools. Students become scientists, writers, artists, and performers as they work with professional mentors and instructors. Every effort is made to tailor learning to needs of the community of learners that compose the program.

The Virginia Governor's School Program has been designed to assist divisions as they meet the needs of a small population of students whose learning levels are remarkably different from their age-level peers. The foundation of the Virginia Governor's School Program centers on best practices in the field of gifted education and the presentation of advanced content to able learners.

\section{Who administers the Governor's Schools?}

The Virginia Governor's School program is administered by the Virginia Department of Education, Office of Secondary Instructional Services, in cooperation with local school divisions, colleges, and universities. A local director at each Governor's School site has direct responsibility for the logistics of the program. Academic-Year Governor's Schools have directors and regional governing boards that provide policy and administration of these schools. Program and site directors at the Summer Residential Governor's Schools along with the principal specialist in the Virginia Department of Education work together to manage and maintain these programs. 


\section{How are the Governor's Schools funded?}

A variety of revenue finances the operation of the Virginia Governor's School Program. The Department of Education and the participating school divisions fund the Virginia Governor's Schools. The Virginia General Assembly has provided AcademicYear Governor's Schools with additional funding through the "Governor's School addon." This funding along with an appropriate share of participating divisions' basic student allocation for these students are considered appropriate funding sources for the Academic-Year Governor's Schools.

The Department of Education through an appropriation from the General Assembly funds the Summer Residential Governor's Schools. In addition to these general funds sources, school divisions from which selected students come are charged a portion of the tuition charges. Host colleges and universities make in-kind contributions with additional support often provided by foundations and the host communities.

The Summer Regional Governor's Schools are provided a fixed amount of funding based on the needs of the program. Additional funding is expected to be provided by the participating localities. Most localities assume responsibility for transporting students to and from the Summer Regional Governor's School sites. Local colleges and universities make in-kind contributions with additional support provided by foundations and the host communities.

\section{How are sites for the Summer Residential Governor's Schools selected?}

Based on a request for proposals (RFP) offered by the Virginia Department of Education, universities and colleges throughout the commonwealth develop proposals to host these programs. A committee of in-state and out-of-state educators, members of the Virginia Advisory Committee for the Education of the Gifted, and others who are knowledgeable in the area of specialization evaluates these proposals for the Department of Education. Evaluation expectations are outlined in the RFP. The selected institution receives a one-year contract that may be renewed for four more years, based on successful evaluations. Current contracts expire in the summer of 2003. 
The local program directors, in conjunction with the Department of Education, choose locations for the Summer Regional Governor's School sites. The selections are based on availability of trained instructional personnel, facilities, and ancillary support. Localities work with the Department of Education to reformat and modify programs as needed.

\section{Who establishes policies for the Governor's Schools?}

The Department of Education, regional governing boards, local superintendents, site or program directors, school boards, and advisory committees establish policies for the Governor's Schools. These policies are described in an administrative procedures document for each school. All Virginia Governor's Schools submit a copy of the current administrative procedures document to the Department of Education annually in the fall.

\section{How are Governor's Schools high standards maintained?}

Each Governor's School maintains its standards through a system of internal evaluations. Summaries of findings are submitted to the Department of Education as part of the administrative procedures document. Internal evaluation methods may include collecting information from students and staff, interviews and written surveys with administrators, instructors, students, and parents, and analysis of other documents related to the programs.

Teams of external evaluators visit each Governor's School on a regular basis. Evaluation rubrics have been developed based on the National Association for Gifted Children's standards. The Governor's School directors receive commendations and recommendations from the team sponsored by the Department of Education. The final report, sent to the director and the chairperson of the regional governing board, summarizes the findings and conclusions of the team. This information is part of the annual report prepared for the Virginia Board of Education. 
What is the relationship of the Governor's Schools to state and local plans for gifted education?

The "Regulations Governing the Educational Program for Gifted Students" mandate differentiated instructional opportunities for gifted students in grades K-12 in Virginia, and the Virginia Governor's School Program is an important component of the comprehensive program. School divisions incorporate the different Governor's Schools as options for their students; however, each locality is expected to provide additional options for students who choose not to attend or are unable to attend Governor's Schools. Local administrators of gifted programs are actively involved in the Virginia Governor's School Programs. Their support typically includes serving on advisory committees, nominating students, identifying potential instructors, participating in school evaluations, and communicating information about the program to the appropriate local audiences.

\section{What is the effect of Governor's Schools on local school divisions?}

Local schools benefit from Governor's Schools in several ways. Students who participate in Summer Residential Governor's Schools return in the fall with new experiences to share with their teachers and classmates. Teachers who serve as instructors for Summer Residential Governor's Schools acquire new skills for working with gifted students. These teachers' knowledge of content, instruction, and community resources is expanded through participation in these programs. Also, individuals from colleges, universities, business, industry, government, and other community volunteers interact with students and instructors in a Governor's School and often increase their involvement with local schools.

The Academic-Year Governor's Schools have an important influence on students and educators in the local school divisions. These Governor's Schools help localities by providing additional educational challenges for the small number of exceptionally gifted students needing more specifically designed instruction. The staffs of Academic-Year Governor's Schools provide in-service training for other local teachers, conduct special performances and demonstrations for students, and share equipment, facilities, and expertise. 
Many Academic-Year Governor's Schools' teachers serve as leaders or active members in their professional associations providing colleagues at the state and national level with valuable examples of differentiated instruction and curriculum design. Several Academic-Year Governor's Schools were charter members and founders of the National Consortium of Specialized Secondary Schools of Mathematics, Science, and Technology (NCSSSMST). The Governor's School for Government and International Studies served as the 2000 State Elections Headquarters for the Virginia Student/Parent Mock Elections program.

\section{What is the relationship between Governor's Schools and business and industry?}

Because Academic-Year Governor's Schools stress the creation of a learning community, local businesses and industries play an important role in these programs. They provide mentors who work with Governor's School students to give them realworld experience in careers and to assist them with research projects. Local businesses and industries provide guest lecturers during Governor's School classes. Business and industry also contribute equipment and supplies, facilities, and expert advice to help support the Governor's Schools. Visiting artists, authors, and lecturers provide insights for students who attend the Governor's Schools, offering students an opportunity to make valuable contacts in their areas of interest. The directors of each Governor's School actively seek ways to incorporate mentors and experiences from the community and business into their programs. Numerous partnerships have been formed between Academic-Year Governor's Schools and community businesses; several schools are supported through the efforts of foundations developed by parents and community leaders to provide additional financial and technological support.

For more information, contact:

Donna L. Poland, Ph.D. Specialist, Governor's Schools \& Gifted Education Office of Middle and High School Instruction

Virginia Department of Education P.O. Box 2120

Richmond, VA 23218-2120

Voice: (804) 225-2884

Fax: (804) 786-5466

e-mail: Donna.Poland@doe.virginia.gov 


\title{
Appendix C
}

\section{Sample Informed Consent Forms}

\author{
Informed Consent [Parents]
}

I, (print name here) am willing for my child (print name here)

to participate in a study being conducted at Chesapeake Bay Governor's School for Marine and Environmental Science to help gain a better understanding of the developmental issues faced by gifted individuals during adolescence. I understand that this study is being conducted by Carrie Lynn Bailey, a doctoral candidate in counseling at the College of William and Mary.

As a participant in this study, I am aware that my child I will be asked to complete two research instruments at a conveniently scheduled time during the course of the school day. The research instruments are: the Washington University Sentence Completion Test (WUSCT), the Definition Response Instrument (DRI), and a brief demographic questionnaire. In addition, my child's homeroom teacher will be requested to complete the Clinical Assessment of Behavior (CAB).

I am aware that my child's participation is voluntary and that I may withdraw from this study at any time without penalty. The assessments and demographic questionnaire will be confidential and identified by a student code. No identifying information will be reported in the study results.

I also understand that a copy of the results of the study will be provided to me upon request. I am aware that I may report dissatisfactions with any aspect of this research project to the Chair of the Protection of Human Subjects Committee.

By allowing my child's participation in this study, I understand that there are no obvious risks to my child's physical or mental health.

Confidentiality Statement

As a participant in this study, I am aware that all records will be kept confidential and neither my name, nor my child's name, will be associated with any of the results of this study. If I have any questions that arise in connection with my participation in this study, I should contact Dr. Victoria Foster, the chair of Mrs. Bailey's Doctoral Committee at (757) 221-2321 or vafost@wm.edu. I understand that I may report any problems or dissatisfaction to Dr. Thomas Ward, chair of the School of Education Internal Review Committee at (757) 221-2358 or tiward@wm.edu or Dr. Michael Deschenes, chair of the Protection of Human Subjects Committee at the College of William and Mary at (757) 221-2778 or mrdesc@wm.edu. The investigator in this study may be reached by contacting Carrie Bailey, (804) 627-2547, clbail@wm.edu.

Date

Parent's Signature

THIS PROJECT WAS FOUND TO COMPLY WITH APPROPRIATE ETHICAL STANDARDS AND WAS EXEMPTED FROM THE NEED FOR FORMAL REVIEW BY THE COLLEGE OF WILLIAM AND MARY PROTECTION OF HUMAN SUBJECTS COMMITTEE (Phone 757-221-3966) ON 2008-10-23 AND EXPIRES ON 2009-10-23. 


\section{Informed Consent [Students]}

I, (print name here) am willing to participate in a study being conducted at Chesapeake Bay Governor's School for Marine and Environmental Science to help gain a better understanding of the developmental issues faced by gifted individuals during adolescence. I understand that this study is being conducted by Carrie Lynn Bailey, a doctoral candidate in counseling at the College of William and Mary.

As a participant in this study, I am aware that I will be asked to complete two research instruments at a conveniently scheduled time during the course of the school day. The research instruments are: the Washington University Sentence Completion Test (WUSCT), the Definition Response Instrument (DRI), and a brief demographic questionnaire. In addition, my homeroom teacher will be requested to complete the Clinical Assessment of Behavior (CAB).

I am aware that my participation is voluntary and that I may withdraw from this study at any time without penalty. The assessments and demographic questionnaire will be confidential and identified by a student code. No identifying information will be reported in the study results.

I also understand that a copy of the results of the study will be provided to me upon request. I am aware that I may report dissatisfactions with any aspect of this research project to the Chair of the Protection of Human Subjects Committee.

By participating in this study, I understand that there are no obvious risks to my physical or mental health.

\section{Confidentiality Statement}

As a participant in this study, I am aware that all records will be kept confidential and my name will not be associated with any of the results of this study. If I have any questions that arise in connection with my participation in this study, I should contact Dr. Victoria Foster, the chair of Mrs. Bailey's Doctoral Committee at (757) 221-2321 or vafost@wm.edu. I understand that I may report any problems or dissatisfaction to Dr. Thomas Ward, chair of the School of Education Internal Review Committee at (757) 221-2358 or tjward@wm.edu or Dr. Michael Deschenes, chair of the Protection of Human Subjects Committee at the College of William and Mary at (757) 221-2778 or mrdesc@wm.edu.

The investigator in this study may be reached by contacting Carrie Bailey, (804) 627-2547, clbail@wm.edu. 
Informed Consent [Teacher]

I, (print name here) am willing to participate in a study being conducted at Chesapeake Bay Governor's School for Marine and Environmental Science to help gain a better understanding of the developmental issues faced by gifted individuals during adolescence. I understand that this study is being conducted by Carrie Lynn Bailey, a doctoral candidate in counseling at the College of William and Mary.

As a participant in this study, I am aware that I will be asked to one research instrument for selected students at a conveniently scheduled time during the course of the school day. The research instrument is the Clinical Assessment of Behavior (CAB).

I am aware that my participation is voluntary and that I may withdraw from this study at any time without penalty. The assessment will be confidential and identified by a student code. No identifying information will be reported in the study results.

I also understand that a copy of the results of the study will be provided to me upon request. I am aware that I may report dissatisfactions with any aspect of this research project to the Chair of the Protection of Human Subjects Committee.

By participating in this study, I understand that there are no obvious risks to my physical or mental health.

\section{Confidentiality Statement}

As a participant in this study, I am aware that all records will be kept confidential and my name will not be associated with any of the results of this study. If I have any questions that arise in connection with my participation in this study, I should contact Dr. Victoria Foster, the chair of Mrs. Bailey's Doctoral Committee at (757) 221-2321 or vafost@wm.edu. I understand that I may report any problems or dissatisfaction to Dr. Thomas Ward, chair of the School of Education Internal Review Committee at (757) 221-2358 or tjward@wm.edu or Dr. Michael Deschenes, chair of the Protection of Human Subjects Committee at the College of William and Mary at (757) 221-2778 or mrdesc@wm.edu.

The investigator in this study may be reached by contacting Carrie Bailey, (804) 627-2547, clbail@wm.edu.

Date

Participant's Signature

THIS PROJECT WAS FOUND TO COMPLY WITH APPROPRIATE ETHICAL STANDARDS AND WAS EXEMPTED FROM THE NEED FOR FORMAL REVIEW BY THE COLLEGE OF WILLIAM AND MARY PROTECTION OF HUMAN SUBJECTS COMMITTEE (Phone 757-221-3966) ON 2008-10-23 AND EXPIRES ON 2009-10-23. 


\section{Appendix D}

\section{Demographic Information Form}

Directions: Please respond to each of the following items. No one involved in this study will be able to match names with background information. Thank you!

Student ID Code:

(Please fill in your first, middle, and last initial \& your grade level)

1. Age:

2. Gender (Please circle one): Female Male

3. Ethnicity (Please circle one):

Hispanic-American

African-American

Native-American

Caucasian

Asian-American/Pacific Islander

Other

4. Grade Level in School (Please circle one):

Freshman

Sophomore

Junior

Senior

5. School Name: 


\section{Appendix E}

WASHINGTON UNIVERSITY SENTENCE COMPLETION TEST FOR WOMEN (Form 81) Abbreviated Form

Date:

Instructions: Complete the following sentences.

1. Raising a family

2. A man's job

3. The thing I like about myself is

4. What gets me into trouble is

5. When people are helpless

6. A good father

7. When they talked about sex, I

8. I feel sorry

9. Rules are

10. Men are lucky because

11. At times she worried about

12. A woman feels good when

13. A husband has a right to

14. A good mother

15. Sometimes she wished that

16. If I can't get what I want

17. For a woman a career is

18. A woman should always 


\section{WASHINGTON UNIVERSITY SENTENCE COMPLETION TEST FOR MEN (Form 81)}

Abbreviated form

Date:

Instructions: Complete the following sentences.

1. Raising a family

2. A man's job

3. The thing I like about myself is

4. What gets me into trouble is

5. When people are helpless

6. A good father

7. When they talked about sex, I

8. I feel sorry

9. Rules are

10. Men are lucky because

11. At times he worried about

12. A woman feels good when

13. A husband has a right to

14. A good mother

15. Sometimes he wished that

16. If I can't get what I want

17. For a woman a career is

18. A man should always 


\section{Appendix F}

\section{DEFINITION RESPONSE INSTRUMENT}

(Each question in presented at the top of a separate sheet of paper. Respondents are asked to spend as much time as needed to complete the question and use the back of the paper if necessary.)

1. Please describe times when you are strongly affected by what others think of you or times when you have compared yourself in some way to others.

2. Please describe those questions which cause strong doubts within you, that frustrate you and perhaps result in anxiety or depression. The problems should involve struggles which are internal (for example, philosophical, sexual, emotional), not struggles which are primarily external (for example, a purely economic problem).

3. Describe times when you feel inadequate, unworthy, not good enough or frustrated with what may be lacking in yourself (abilities, skills, talents, personal qualities, etc.).

4. Describe those situations which cause you to feel frustration or anger towards yourself. Such feelings may stem from something you did and later regretted, as well as something you feel you should have done, but did not do. Likewise, you may be angry with yourself for having felt a certain way or having believed something you no longer feel is true.

5. Think of times when you try to stand back and look at yourself objectively. Upon what specific things do you reflect? Please elaborate.

6. Think of your "ideal self" and those qualities that you think are best for an ideal life. What attributes do you most dream of having?

adapted from Gage, Morse, and Piechowski 1981

(Miller, 1991) 


\title{
VITA
}

\author{
Carrie Lynn Bailey \\ 251 Providence Road, Deltaville, VA 23043 \\ 804.776.7627 \\ clbail@wm.edu
}

\section{EDUCATION:}

2009 Doctor of Philosophy in Counselor Education

The College of William \& Mary, Williamsburg, VA

(CACREP accredited)

Cognate: Developmental Issues in School and Family Counseling

Dissertation Title: An Examination of the Relationships between Ego Development, Dabrowski's Theory of Positive Disintegration and the Behavioral Characteristics of Gifted Adolescents

2000 Masters of Education in School and Community Counseling Old Dominion University, Norfolk, VA

1994 Bachelor of Science in Psychology

The College of William \& Mary, Williamsburg, VA

\section{CERTIFICATIONS:}

2009 Licensed Professional Counselor (LPC)

Virginia Board of Counseling

2001 Licensed Professional School Counselor (LPSC)

Virginia Department of Education

$2000 \quad$ National Certified Counselor (NCC)

National Board of Certified Counselors 